

\section{DISCLAIMER}

This report was prepared as an account of work sponsored by an agency of the United States Government. Neither the United States Government nor any agency Thereof, nor any of their employees, makes any warranty, express or implied, or assumes any legal liability or responsibility for the accuracy, completeness, or usefulness of any information, apparatus, product, or process disclosed, or represents that its use would not infringe privately owned rights. Reference herein to any specific commercial product, process, or service by trade name, trademark, manufacturer, or otherwise does not necessarily constitute or imply its endorsement, recommendation, or favoring by the United States Government or any agency thereof. The views and opinions of authors expressed herein do not necessarily state or reflect those of the United States Government or any agency thereof. 


\section{DISCLAIMER}

Portions of this document may be illegible in electronic image products. Images are produced from the best available original document. 


\title{
CASE STUDY OF THE \\ BROWNELL LOW ENERGY REQUIREMENT HOUSE
}

\author{
Ralph F. Jones, Richard F. Krajewski, and Gerald Dennehy
}

May 1979

This report was prepared as an account of work sponsored by the United States Government. Neither the

United States nor the United States Department of

Energy, nor any of their employees, nor any of their

contractors, subcontroctors, or theis, employees, the

any wheranty, express or implied, or aseyes, makes

liability or responsibility for the or assumes any legal

or usefulness of any informe aceuracy, completeness

process disclosed, or represents, apparatus, product or

infringe privately owned resents that its use would not

ASSOCIATED UNIVERSITIES, INC.

UNDER CONTRACT NO. EY-76-C-02-0016 WITH THE

UNITED STATES DEPARTMENT OF ENERGY

OFFICE OF BUILDINGS AND COMMUNITY SYSTEMS 
The work described in this report was conducted as part of a program of RD\&D for Energy Conservation in Buildings managed by Brookhaven National Laboratory for the U.S. Department of Energy, Officc of Buildings and Community Systems.

Brookhaven National Lahoratory is operated by Associated IIni= versities, Inc. (AUI), under a contract with the U.S. Department of Energy. AUI is a non-profit, research management organization sponsorcd by ninc Universities: Ciolumbia, Cornell, Harvard, Johns Hopkins, Massachusetts Institute of Technology, Princeton, Pennsylvania, Rochester, and Yale.

We are indebted to John P. Millhone, Office of Buildings and Community Systems and John H. Cable, Architectural and Engineering Systems Branch, of the Department of Energy, for their support in the preparation of this report.

We would also like to express our appreciation to Bruce Brownell and his associates in Brownell Lumber Company for their contributions to the preparation of the report.

NOTIGE

\footnotetext{
This report was prepared as an account of work sponsored by the U/niter States Government. Neither the United States nor the United States Deparment of Energy (DDE), nor any of their emplnyees, nor any of their rnntractors, subcontractors. or their employees, makes any warranty, express or implied, or assumes any legal liability or responsibility for the accuracy, completeness or usefuliness of any information, apparatus, product or process disclosed, or represents that its use would not infringe privately owned rights.
}

Printed in the United States of America Available from National Technical Information Service

U.S. Department of Commerce 5285 Port Royal Road Springfield, VA 22161

Price: Printed Copy $\$ 6.00$; Microfiche $\$ 3.00$ 
An evaluation is made of the design and thermal performance of an innovative house built in 1977 in the Adirondacks area of New York State. The house has a very tight and well-insulated envelope, with the rigid insulation board applied to the outside of the frame. Passive solar gain through south-facing glass, along with internal "free" sources of heat, are shown to provide a substantial part of the building's heating requirements. Effective integral thermal storage, provided by the exposed interior structure, serves to keep interior temperature excursions within acceptable limits. Additional remote storage is provided in the form of a large thermal storage sand bed, with air ducts, located below the basement floor. Calculations and measured performance data show that the house's space heating needs are only about 40 percent of those of a similar size house built to HUD minimum property standards, and less than 25 percent of those of a typical inventory house in the Northeast United States. 
THIS PAGE

\section{WAS INTENTIONALLY LEFT BLANK}


I. Introduction ...................... . 1

II. Historical Background. . . . . . . . . . . . . . . . I 1

A. Introduction ..................... 1

B. Experience with Fiber Glass Insulation. . $. \because . \therefore .2$

C. New Insulation Concepts and Vapor Barriers . . . ... . . 3

D. Passive Solar Gain and Thermal Storage . . . . . . . . 4

E. Design Evolution and Market Acceptance . . . . . . . . . 5

F. $560 \mathrm{ft}^{2}$ Low Energy, Requirement (LER) House . .. . . . . 6

G. 2,300 $\mathrm{ft}^{2}$ LER House. . . . . . . . . . . . . . . 11

1. Introduction . . . . . . . . . ......... 11

2. Design Features. . . . . . . . . . . . . . . Il

3. Design Philosophy. ................ . 24

4. Building Performance . . . . . . . . . . . . 25

III. Technical Aralysis ................ . . . . . 26

A. Thermal Performance. . . . . . . . . . . . 26

1. Introduction . . . . . . . . ........ . 26

2. Calculated Envelope Performance. . . . . . . . 28

3. Internal Heat Sources and Solar Gain $: \because . . \div \quad \because . .29$

4. Measured Building Performance. ............. 33

5. Performance of Thermal Storage Bed ........ 44

B.: Architectural Features . ................. . . 57

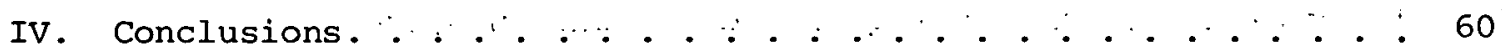

A. Introduction ................. . . 60

B. Construction Adaptation for Mass Market. . . . . . $\because . .61$

C. Retrofit Possibilities. . . . . . . . . . . . . 63

D. Other, Brownell Projects. . . . ........... 65

References...................... . . . . 65

Appendix . . . . . . . . . . . . . . . . . . . . . . . 67 
1. $560 \mathrm{ft}^{2}$ prototype house . . . . . . . . . . . . . 7

2. Thermal performance of prototype house. . . . . . . . . . 10

3. $2,300 \mathrm{ft}^{2} \mathrm{LER}$ house . . . . . . . . . . . . . . . . 12

4. Diagrammatic section of LER house ................ . . 13

5. Lower level plan. . . . . . . . . . . . . ...... . 14

6. First floor pian. . . . . .............. . . . 15

7. Upper level plan. . . . . . . . . . . . . . . . . . 16

8. Cross sestion view. . . . . . . . . . . . . . . . 1.6

9. South elevation . . . . . . . . . . . . . . . 17

10. North elevation ......................... 17

11. East elevation. . . . . . . . . .......... . . 18

12. West elevation. . . . . . . . . . . . . . . . . 19

13. Roof system detail. . . . . . . . . . . . . . . 20

14. Wall section detail .................... . . 21

15. Details of thermal storage bed... . . . . . . . . . . . 22

16. Structural details. : . . . . . . . . ....... . . 23

17. Comparative steady state thermal performance. . . . . . . . . 31

18. Detail of Figure 17 at break-even temperature . . . . . . . 31

19. Measured house thermal performance, week of: $1 / 27 / 78$ to $2 / 2 / 78 \quad 34$

20. Plan view of thermal storage air distribution system. . . . . 45

21. Recorded sand bed temperatures, $3 / 6 / 78$ to $3 / 31 / 78$. . . . . 47

22. Measured thermal storage system performance data, $3 / 6 / 78$. to $3 / 31 / 78$. . . . . . . . ......... 48

23. Measured house thermal performance data, week of $3 / 6 / 78$ to $3 / 13 / 78$. . . . . . . . . . . . . . . . 19

24. Air distribtuion system performance . . . . . . . . . . 51

25." Branch duct air film coefficient. . . . . . . . . . . . 51

26. Sand bed and duct air temperature variation . . . . . . . . . 51

27. Diagrammatic view of existing and modified thermal storage systems... . . . . . . . . . . . . . . . . . . 54 
28. Comparative performance curves for existing and modified thermal storage systems. . . . . . . . . . . . .

29. Thermal capacity vs. storage volume for various storage bed designs.

Table

1. Construction Cost Estimate. . . . . . . . . . . . . 27

2. Calculated Building Envelope Performance-- $0^{\circ} \mathrm{F}$. . . . . 28

3. Estimated Annual Fuel Usage for Space Heating . . . . . . . 32

4. Comparative Heating Requirements of Brownell LER House. . . . 32

5. Daily Normalized Heating Requirement (NHR), January 17 through March 31, 1978 . . . . . . . . . . . . .

6. Diurnal Storage Capacity Summary. . . . . . . . . . . . 40

7. Calculated Building Envelope Performance in As-Tested Condition. . . . . . . . . . . . . . . . . 41

8. Solar Gain in As-Tested Condition . . . . . . . . . . . . . . 42

9. Thermocouple Locations. . . . . . . . . . . . . . . . . 44

10. Interior Temperature Rise on Sunny Days . . . . . . . . . . . . 49

11. Diurnal Storage Capacity summary. . . . . . . . . . . . 57

A-1. Steady State Heat Loss Calculation. . . . . . . . . . . 70

A-2. Heat Loss Caloulation as Tested Condition . . . . . . . . 71 


\section{INTRODUCTION}

Studies conducted at Brookhaven National Laboratory (BNL) since 1975 have shown that substantial benefits can be derived from introduction of thermal storage systems in residential buildings.1,2 In 1977, BNL staff became aware of efforts by individual builders to construct commercial and residential buildings that combine thermal storage with a building envelope of very high thermal efficiency. This combination makes it possible for the buildings to satisfy a substantial fraction of their heating energy requirements by passive solar energy gain through windows, without overheating the occupied space during the day.

One builder, Bruce Brownell, of Edinburg, New York, built a 2,300-ft ${ }^{2}$ house with these design features on speculation in 1977. He refers to his design as a Low. Energy Requirement (LER) House. It is the purpose of this report to provide a case study of this innovative residential structure. The study includes information on the design and construction of the building, and its calculated and measured thermal performance. It is believed that the information will be of interest and useful to architects, builders, and others having concern for energy-conserving residential building design.

The report is organized in four sections, as follows.

Section I. Introduction.

Section II. Historical Background. This section provides a description of Brownell's work in connection with LER houses. The section was prepared partly by Bruce Brownell and partly by BNL staff from information provided by Brownell. Assistance was provided by the following members of Brownell's staff: Jim Sager, Tom Doherty, Sue Aulisi, and Joe Eichenberger.

Section III. Technical Evaluation. This section contains a detailed analysis, prepared by BNL staff, of the technical and architectural features of the LER house and its thermal performance.

Section, IV. Conclusions. This section, also prepared by BNL staff, provides a discussion of the applicability of Brownell's design philosophy and design features to other residential. construction.

\section{HISTORICAL BACKGROUND}

A. Introduction

Bruce Brownell has been associated since the early nineteen-sixties with Brownell Lumber Company, a family lumber business located in Edinburg, New York. Edinburg is in the Adirondack Mountains area of New York State, where the winter climale is such that careful allention must be given to the requirements for space heating in the design and construction of homes. 
Brownell is a 1964 graduate of the New York State College of Forestry, with a degree in wood Products Engineering. He worked for General Electric Company in Schenectady, New York under the G.E. College Apprentice Program. He also worked for a short time after graduation at weyerhaeuser Company in Coos Bay, Oregon, before rejoining the family business on a full time basis in 1965. He had developed a strong interest in low energy requirement (LER) houses and formed a new division of Brownell Lumber Company, Adirondack Alternate Energy, to pursue the design and construction of LER houses.

Brownell's work culminated in 1977 with construction of a 2,300-ft ${ }^{2}$ house incorporating in one structure most of the key design elements he had worked with over the previous 15 years. These include (1) superior insulation (urethane board stock) combined with infiltration and vapor barriers not only on the exterior walls and roof but below the house as well, (2) application of the insulation on the outside rather than the inside of the building envelope, (3) provision of a significant area of south-facing glass for passive solar gain, (4) incorporation of substantial comfort range thermal storage, principally in the form of a large sand mass containing air ducts located below the cellar floor (but.within the insulation envelope), and (5) low-speed fans for continuous circulation of air through the occupied space and the thermal storage mass. It was intended that the heating requirements of this LER house, in the 8,300 degree-day Adirondack environment, would be met almost entirely by heat from three sources: (1) waste heat from appliances, (2) passive solar gain, and (3) metabolic heat from occupants. Only a small amount of supplemental electric resistance baseboard heating or heat from a wood stove was expected to be required in the most severe winter weather.

B. Experience with Fiber Glass Insulation

Brownell first became involved in construction of conventional houses in the late nineteen-fifties. He soon developed an interest in thermal performance. By applying simple heat load analysis to quality houses of known construction he found that they generally required a larger Btu input for heating than that indicated by desiqn calculations. Investiqation of this discrepancy over several seasons and in many homes led to the conclusion that it was due largely to the insulation. The fibex glass insulation employed was not performing according to its nominal $\mathrm{R}$ value rating.

Preliminary evaluation, based on estimation of Btu input to the house and degree days experienced, showed that the thermal performance of the house degraded during the winter. The performance was poorer in January than in November and December, and deteriorated more in February and March.

The following winter Brownell began monitoring installed fiber glass insulation using thermometers in the walls and attic areas. He observed frost and ice crystals within the wall region of the fiber glass where the dew point and freezing point converge. As the outside air temperature dropped, this frost line moved into the middle of the insulation space. Under some conditions, the frost and ice formations actually pulled the fiber glass blanket down inside the stud cavity. 
The heat loss through the attic insulation prevented frost from forming there. There was considerable beading of moisture and frost formation, however, associated with the roofing nails. As the attic air temperature cycled, balls of frost were found to form on the points of the roofing nails which penetrate slightly through the roof plywood. The frost melts and moisture drops into the insulation, causing it to be wet for the greater part of the heating season.

As a result of his observation of the apparent installed performance of fiber glass in cold Adirondack-type climates, Brownell feels that typical fiber glass installations employed there perform at less than half their rated $\mathrm{R}$ value.

In 1961-1962 Brownell attempted to deal with the moisture problems he had observed. He began by writing letters to the fiber glass manufacturers requesting their help. He received standard replies with advertising handouts. His second series of letters to the manufacturers specifically stated the moisture problem. He asked for performance testing results showing the effects of moisture buildup on $\mathrm{R}$ value. These letters were generally unanswered or produced copies of reports on standard tests using the guarded hot box method. A third series of letters pointed out that these tests did not relate to the climate and environment in which fiber glass was typically performing from October through April. These letters also produced no results. The last time he attempted to reach the fiber glass industry was in 1975 and again, as in the past, he received no satisfactory response.

\section{New Insulation Concepts and Vapor Barriers}

During this time, Brownell independently began experimenting with different building techniques, including continuous venting of walls and ceilings and improved vapor barriers. He found that improved vapor barriers, such as polyethylene sheeting applied to the studs before applying the sheetrock, improved the insulating capabilities of fiber glass, but that it still fell short of stated $R$ values.

In 1963, Brownell constructed a house using continuous Type-C foil-faced paper as a vapor barrier. He installed one 3/8-in. sheetrock layer on the walls and ceilings, glued the. Iuil to the shcctrook, then glued nn a second layer of 3/8-in. sheetrock. The only penetrations of this wall barrier were the nails in the wood trim at the top and bottom. He also took care in applying the foil. layer between the subfloor plywood and the underlayment. Some nails in the underlayment did penetrate the foil, however. Great pains were taken to caulk the wall penetrations, such as electrical outlets, pipes, and vents. This house seemed to perform better, and was draft free, but data on actual moisture content in the fiber glass are not available.

On other houses, he tried to ventilate the stud box by drilling two or three holes at the top and bottom. The electrician did this while drilling for wiring. The air flowed from the cellar, through the stud box, out through the top plate, and into the room. The top molding was spaced to allow the air 
to.flow freely, keeping the fiber glass much drier but probably increasing air infiltration and thus losing the potential savings.

In the mid-nineteen-sixties local electric utility companies began to promote electric heat by underwriting the first year's heat bill if the house was constructed to their recommended specifications. These specifications demanded greater attention to detail and encouraged the use of polyethlyene vapor barriers on the walls and ceiling in conjunction with fiber glass insulation. The utility companies' encouragement of tight construction inadvertently caused some problems that were not foreseen. The specifications did not require installation of a vapor barrier under the house to prevent ground moisture penetration. With effective vapor barriers on the ceiling and walls but none protecting the sixth side of the house, moisture condensed on the windows and inner walls. Brownell believed that the condensation was caused by intrusion of moisture through the cellar floor or slab. He states that many builders did not underotand this, and that there was a considerable amount of confusion surrounding polyethylene vapor barriers. He tried placing polyethylene below the concrete foundation, but found that it degraded within two years. This may have been due to the quality of the material available at that time. He was later able to provide an effective below-floor barrier that would not degrade.

In the middle sixties, Brownell started to use rigid board insulations, integrating them with new building techniques. In 1966 rigid board insulations came on the market which were readily adaptable to the Brownell method of building cathedral ceilings. Brownell constructed several houses using four inches of beadboard stock ( $R$ 20) covered with a 20-year hot tar built-up roof. These houses performed much better than conventional fiber-glass-insulated houses. He noted a marked reduction in snow melting but still had the common ice damming at eaves which resulted in water leakage.

Urethane board insulation became commercially available in $1 \times 8 \mathrm{ft}$ sheets in 1968 with an $k$ val he of 6 per inch. Brownell found lhis to be the most effective riqid board availahis. He exporimented with vasiuus methuas of post and beam construction and modifications of conventional stud-built houses, with the insulation on the outside of the structure. He tried several variations of foam board stock attachment, joining and in-field applications, always working within the limits of the flammability of the product, which was of some concern. The early urcthanes were prone to warp with exposure to water and sun, but improved urethanes became available. The improved urethanes made it possible for the first time to construct a relatively moistureproof house. The design he was evolving could be characterized as a house completely encapsulated on the outside with rigid foam insulation, including the surface below the house.

\section{Passive Solar Gain and Thermal Storage}

Earlier in the sixties Brownell had begun experiments with solar orientation of houses. He advocated then, as he does now, glass on approximately one-third of the total south wall. By 1966, with an improved insulation 
envelope, his houses, particularly the south rooms, would overheat on sunny days in the winter, even with outside temperatures at $-10^{\circ} \mathrm{F}$. Occupants were forced to open windows and vent most of this excess energy and later in the day use conventional heating systems to balance the heat losses.

One early approach to solving this problem was to use a differential thermostat-actuated fan to move air from the ceilings of warm south rooms into the cooler cellar. The cellar's concrete blocks were insulated with zonolite masonry cavity insulation. The mass in the walls was expected to store the excess energy. Brownell viewed this cellar heat storage arrangement as a "heat energy battery," which could be used to balance the solar temperature swings and save fossil fuels.

E. Design Evolution and Market Acceptance

By combining the new externally applied board insulations with his earlier approach to optimum orientation and siting, Brownell was able in 1966-1968 to design 1,800 to 2,000-ft ${ }^{2}$ houses with heating loads of only 50,000 to $60,000 \mathrm{Btu} / \mathrm{hour}$. At that time he switched to electric resistance heating because the capacity of the smallest available oil-fired heating equipment greatly exceeded his requirements.

Brownell's greatest problem at this time was to convince his clients to adopt the urethane envelope theory. Most felt it to be unnecessary and, in light of the cheapness of fuel, not cost effective. He was able to convince one family to use urethane board stock under part of the cellar area because they wanted to utilize this space for an apartment. The insulated part of the cellar has been noticeably warmer in the winter than the uninsulated part. In another case he was able to convince a client to use four inches of styrofoam over a post and beam frame, but not under the house. However, he did provide an effective poly barrier under the sixth side of the house, which he installed below 12 inches of fill under the concrete floor.

By this time Brownell's homes were mainly constructed using the traditional post and beam method. He regarded their attractive appearance and rugged simplicity as most compatible with and desirable to the individual who wishes the life style afforded by a low energy requirement dwelling. Other reasons he gives for the use of post and beam construction are (1) the placement of vertical posts on four-foot centers facilitates external application of the structure's interior finishes and insulation, which are available in $4 \times 8$ sizes; (2) the elimination of the outer stud wall cavities found in conventional construction usually provides over 5\% more usable floor space; (3) there is greater freedom in the design of a floor plan as inner structural walls are eliminated within 24-foot spans; (4) large wooden beams are attractive and psychologically create a feeling of security by their very size. Outside noises are virtually eliminated by the insulating technique created for post and beam construction.

It should be noted, however, that the LER concept does not require post and beam construction. The post and beam method is not feasible in most parts 
of the country, principally because of unavailability of beams and lack of experience in their use. The LER concept may be applied to a stud wall building with equal effectiveness, isolating the structure of the house from the outside environment. Total encapsulation of the living space is the fundamental reason for the LER energy efficiency. The failure of the conventional construction method to achieve this thermal isolation is the major reason for its energy inefficiency.

F. 560-Ft ${ }^{2}$ Low Energy Requirement (LER) House

After years of failure to impress upon people the importance of energyefficient design, Brownell decided to build a small test house himself. He had incorporated individual design innovations in other houses, but wanted to test all of them in combination. In 1973 and 1974 he designed a small 560- $\mathrm{ft}^{2}$ house which would be built next to his retail store to test the urethane envelope, south orientation, and large internal mass approach. He planned carefully to lay out a building which would try many of the conceprs he had developed. He wanted to construct a urethane envelope of R30-R40 around a post and beam building. Calculations showed that the energy available from the daily living cycle (i.e., waste heat from hot water, cooking, refrigerator, TV, and lights) would supply a major part of the heat required by the building. A small area of glass on the south side would augment the heat from appliances. Finally, heat would be given off by the occupants themselves. It was expected that these three sources would supply all the heat required by the building except during periods of severe winter weather.

Brownell was exchanging information on energy-efficient buildings at this time with Edward O'Hanlon. O'Hanlon is president of Advance Cooler Manufacturing Corp., a maker of commercial walk-in freezers and modular insulated wall systems using urethane foam. In 1973 and 1974 Advance built a 15,000-ft ${ }^{2}$ combination factory and office building which incorporates large panels of four-inch-thick rigid casting-type polyurethane foam, sandwiched between aluminum sheets. ${ }^{3}$ The panels are linked by a patented "foam lock" process to create a continuous building envelope. The building receives solar energy through south-facing windows, and stores heat in a four-fout bed of sand below the concrete floor. O'Hanlon estimated that the factory would use less than one-tenth of the purchased energy required for a comparable conventionally built structure.

Brownell also was involved, in 1974 and 1975, with a milmum energy building constructed at the Atmospheric Sciences Research Center, State University of New York at Albany. ${ }^{4}$ This project was initiated by 0 'Hanlon and Donald $L$. McClenehan. The building combined active and passive solar heating with structural storage, massive insulation, and a virtually airtight structure. Brownell Lumber Co: contributed materials for use in this building.

The 560- $\mathrm{ft}^{2}$ LER house was built by Brownell in 1975 and 1976. A photograph of the house appears in Figure 1 . It is of post and beam construction with four inches of urethane insulation totally encapsulating the structure, and four feet of sand as mass ("heat energy battery") under the floor. The 


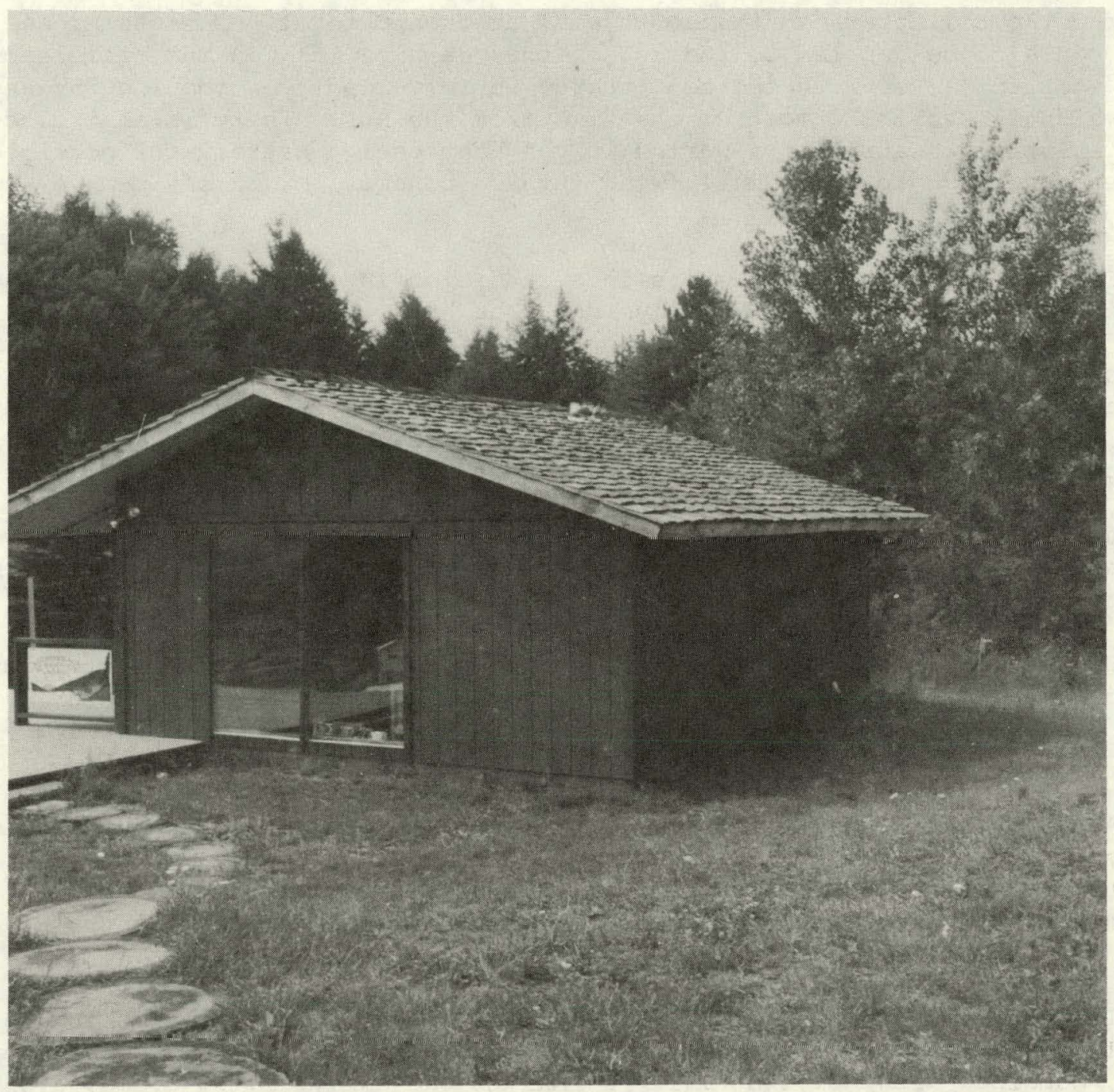

Figure 1. $560 \mathrm{ft}^{2}$ prototype house. 
urethane on the exterior walls is sandwiched between the interior and exterior finishes of the house and is separated from the living area by $1 / 2-i n$. fireproof sheetrock for fire resistance. The four feet of sand ( 120 tons) has an air duct system buried in it which is fed by a fan taking air from the cathedral ceiling and blowing it down through the mass and out registers around the inner perimeter of the buildings. Provision was made for solarassisted domestic hot water with a 120-gallon tempering tank buried in the sand and the collectors on the south wall at ground level. This solar energy input can also be coupled to the mass after reaching its maximum efficiency as a water collector with the heat energy battery readily accepting $75^{\circ}$ energy which is available most of the time from the sun. There is also electric resistance heating wire buried in the heat energy battery for possible future connection to a windmill (wind furnace concept) or to off-peak electric power.

The LER house concept result.s in a condition in which tcmpcrature and humidity are the same everywhere inside. The house receives its majnr energy input from the daily living rycle (anpliances). The sccond encrgy inpul is from south-facing glass as passive solar, and the third is from people. The constant circulation of air (at low velocity) serves to connect these inputs lo be "averaged" by the heat energy battery. The battery should be large enough that one day's input or output does not change it by more than a degree or so. Cooling is accomplished by manually opening the house windows and doors when it is cooler outside or by letting a thermostatically controlled damper couple the air system and heat energy battery to a pipe buried in the ground, which discharges or cools the mass.

Brownell's calculations show the envelope heat loss for the small house, including an allowance for infiltration, to be about $104 \mathrm{Btu} / \mathrm{hour}-\mathrm{OF}$ or 2,500 Btu/DD. At a $0^{\circ} \mathrm{F}$ average outside air temperature, he calculates an envelope loss of $5,783 \mathrm{Btu} /$ hour or $138,800 \mathrm{Btu} / \mathrm{day}$.

As an offset to this heat loss, Brownell calculates that the normal living cycle of a family of two would provide about $77,000 \mathrm{R}+11 /$ / $a y$, and solar gain through south, east, and west glass provides another 37,000 Btu/day. Together, these sources provide about 114,000 Btu/day, or 82 percent of the total heat loss of $138,800 \mathrm{Btu} /$ day at $0^{\circ} \mathrm{F}$ outside air temperature.

The house experienced about 60 "live-ins" by various people during the 1976-1977 winter. Their use of appliances (stove, refrigerator, dishwasher, etc.), combined with human activity normal to the daily living cycle, along with the passive solar input, supplied most of the enerqy required to heat the house. 'I'he house was occupied a little over $50 \%$ of the time. Electric resistance heating $(2,250$ Watts $)$ supplied energy to supplement that provided by the daily living cycle. It was found necessary to raise the temperature after returning from an absence of more than several days to make up for the loss of daily living cycle heat input.

The LER house went through the most severe six-week portion of the winter of 1976-1977 with an electric resistance heating energy use of only $818 \mathrm{kWh}$ 
over 2,110 degree days (DD), or $0.39 \mathrm{kWh} / \mathrm{DD}$. The total energy used was less than $1 \mathrm{kWh}$ per degree day.

There is also a wood stove installed in the small LER house which was not used during 1976-1977, but which would normally replace the electric heat. The stove is supplied with outside combustion air. Its output, if left free standing, would be excessive. Therefore, it was enclosed by lowering a fireproof countertop over it. A differential thermostat-controlled fan circulates air from the living space around the stove to deposit most of the stove's heat directly in the heat energy battery.

Brownell feels, on the basis of his experience with the $560-\mathrm{ft}^{2}$ test house, that one of the most important single features of the LER house is that for the first time it is possible to control humidity in a residence other than by use of mechanical systems. Most people in areas where space heating is required live in interiors that are excessively dry. In contrast, the LER house performs at 45 to $55 \%$ relative humidity as a byproduct of the daily living cycle; i.e., cooking, washing, drying, body perspiration, and the low ventilation rate. Humidity could be easily introduced or removed with conventional equipment of the smallest size, but experience has proved this unnecessary: Humidity can also be reduced during the heating season by opening a window or door. It is not uncommon for the relative humidity to fall 1\% per minute in the dry winter climate if a window is open.

Figure 2 provides daily performance data for the small LER house for the month of January 1978. This figure was prepared by Bruce Brownell from data collected in his monitoring of the house. The average occupancy during this period was one person. It shows that the average interior humidity was in the 45 to 55\% range while outside air temperatures were in the range of $0^{\circ}$ to $25^{\circ} \mathrm{F}$. ASHRAE references indicate that the typical relative humidity in winter months in houses of average construction is below 25 percent.

General data for the month of January 1978, provided by Brownell, are noted at the bottom of Figure 2. With an average interior temperature of about $68^{\circ} \mathrm{F}$ and an average outside temperature of about $15^{\circ} \mathrm{F}$, he reports an electric heat input of only $0.37 \mathrm{kWh} / \mathrm{DD}$. This is slightly less than the $0.39 \mathrm{kWh} / \mathrm{DD}$ input reported earlier for the six-week period in the winter of 1976-1977.

Brownell believes that there are other sociological and psychological benefits as well. Peace of mind is created when one realizes that with loss of utility power the house will only lose several degrees temperature a day. Humidity control seems to eliminate stuffy, dry noses, sore throats, colds, breaking hair, and static shocks. House plants grow very well with little watering. This is not to be confused with a greenhouse atmosphere which is more humid and generally not acceptable in dwellinys.

As a result of having built and demonstrated the small LER house, Brownell attracted more interest in his design concepts. Approximately ten LER houses of various sizes designed by Brownell were built by individuals 
under Brownell's direction in 1976-1977. (Brownell designs and markets precut post and beam home package systems.) More than 20 other homes were built which are insulated halfway to his standards, i.e., with two inches of board insulation on the outside of the frame.

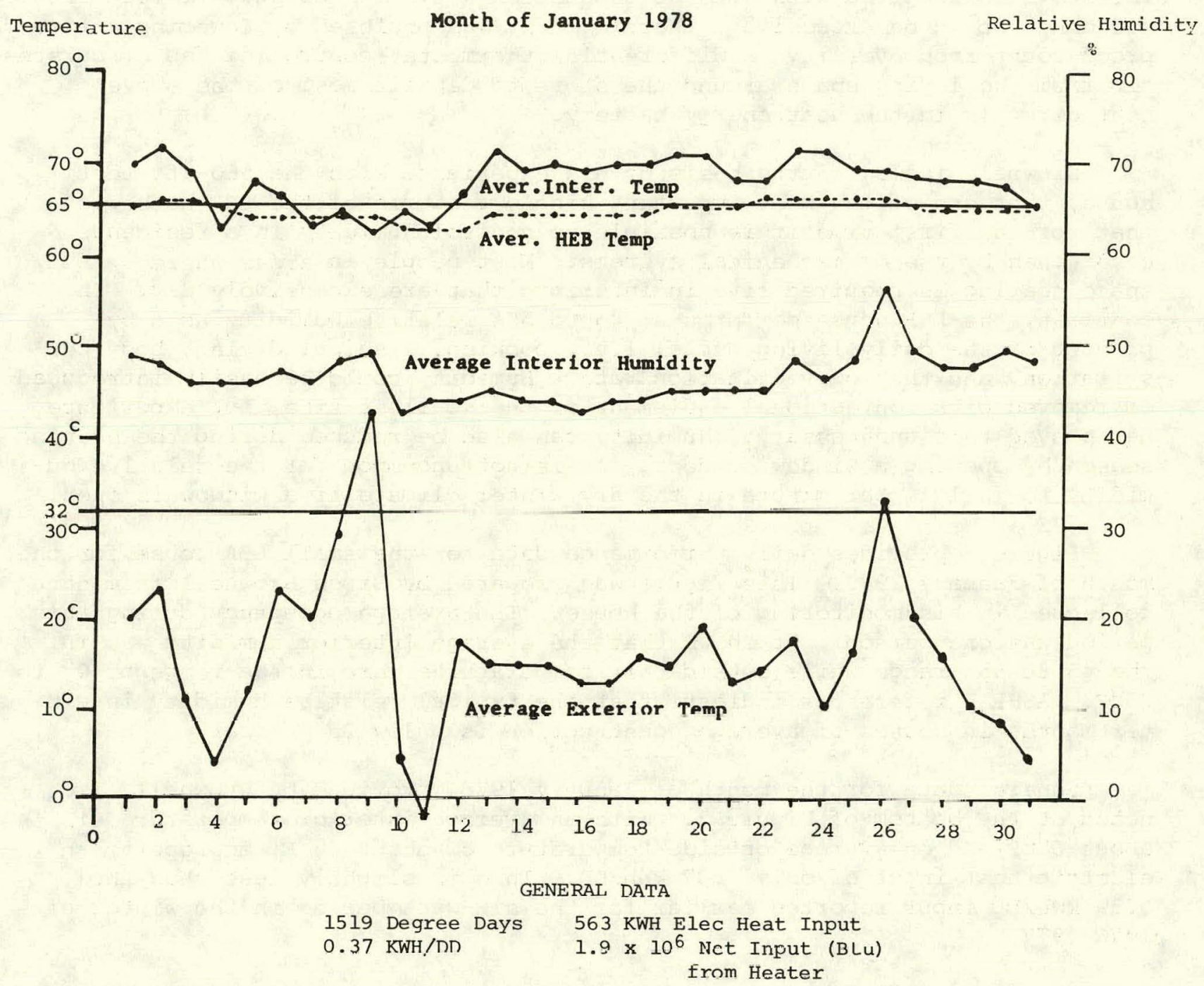

Figure 2. Thermal performance of prototype house. 
1. Introduction. In 1977 Brownell designed and initiated construction of a larger more conventional LER house which he decided to build on speculation. A photograph of the completed house appears in Figure 3. The house is a 2,300 $\mathrm{ft}^{2}$ traditional New England saltbox design with three bedrooms and two baths. It also employs the post and beam construction common in the Adirondack area and incorporates all the energy features of the small LER house but has considerably more passive solar input. It has 387 square feet of glass of which 250 square feet ( 65 percent) is south facing, 57 square feet ( 15 percent) is east facing, 72 square feet ( 18 percent) faces west, and only 8 square feet ( 2 percent) faces north. The north glazing is located in the kitchen. The house has 150 tons of storage consisting of two feet of sand (115 tons) below a concrete floor, concrete cellar walls, and a large 20-ton chimneylike thermal mass rising in the building's center. The central mass contains downflow circulation air ducts on either side of the smoke flue connecting to the thermal storage mass below the floor.

The 2,300 $\mathrm{ft}^{2}$ house has provision for later addition of a solar greenhouse on the south wall which would be connected to the thermal mass by a separate ducting system. Thus, heat could be exchanged between the greenhouse and the house itself without exchanging humidity.

2. Design Features. The 2,300 $\mathrm{ft}^{2}$ house was intended by Brownell to incorporate the design features of previous LER houses into a production design model which would meet the price and other demands of the Adirondack vacation home without compromising thermal efficiency. The basic arrangement of the house is shown in Figure 4. The plans, sections, and elevation are shown in Figures 5 through 14. Photographs of the thermal storage bed and the house itself during contruction appear in Figures 15 and 16. The basic roof lines are stylistically New England saltbox, although the 250 square feet of south-facing glass is not typical of the style, nor is the north elevation with its single window. The house is situated on a south slope $\left(43^{\circ} \mathrm{N}\right.$ latitude) with two-thirds of the southern elevation lower level accessible to grade. The grade was leveled to the south to provide a reflective (snow-covered) surface for additional solar gain. Brownell has plans to provide optional movable insulated shutters which could provide 1,000 Btu/hour savings at night, but these have not yet been installed. The house plan, which also is not in character with the typical center hall saltbox plan, is a more contemporary open plan with a two-story living room and high central 3- by 5-foot thermal mass and chimney which houses the air recirculation system. Also included are an active solar collector mounted at ground level to take advantage of snow-cover reflection and facilitate maintenance. This will provide domestic hot water to a storage tank. A summer mode option is provided by an air pipe below ground from which air can be drawn to discharge heat from the mass.

The building and the sand mass are encapsulated in four inches of polyisocyanurate insulation. The total thermal mass, as noted, is 150 tons. At some point in the future, resistance wire buried in the sand mass may be connected to a wind-driven generator or to off-peak electric power. An airtight 


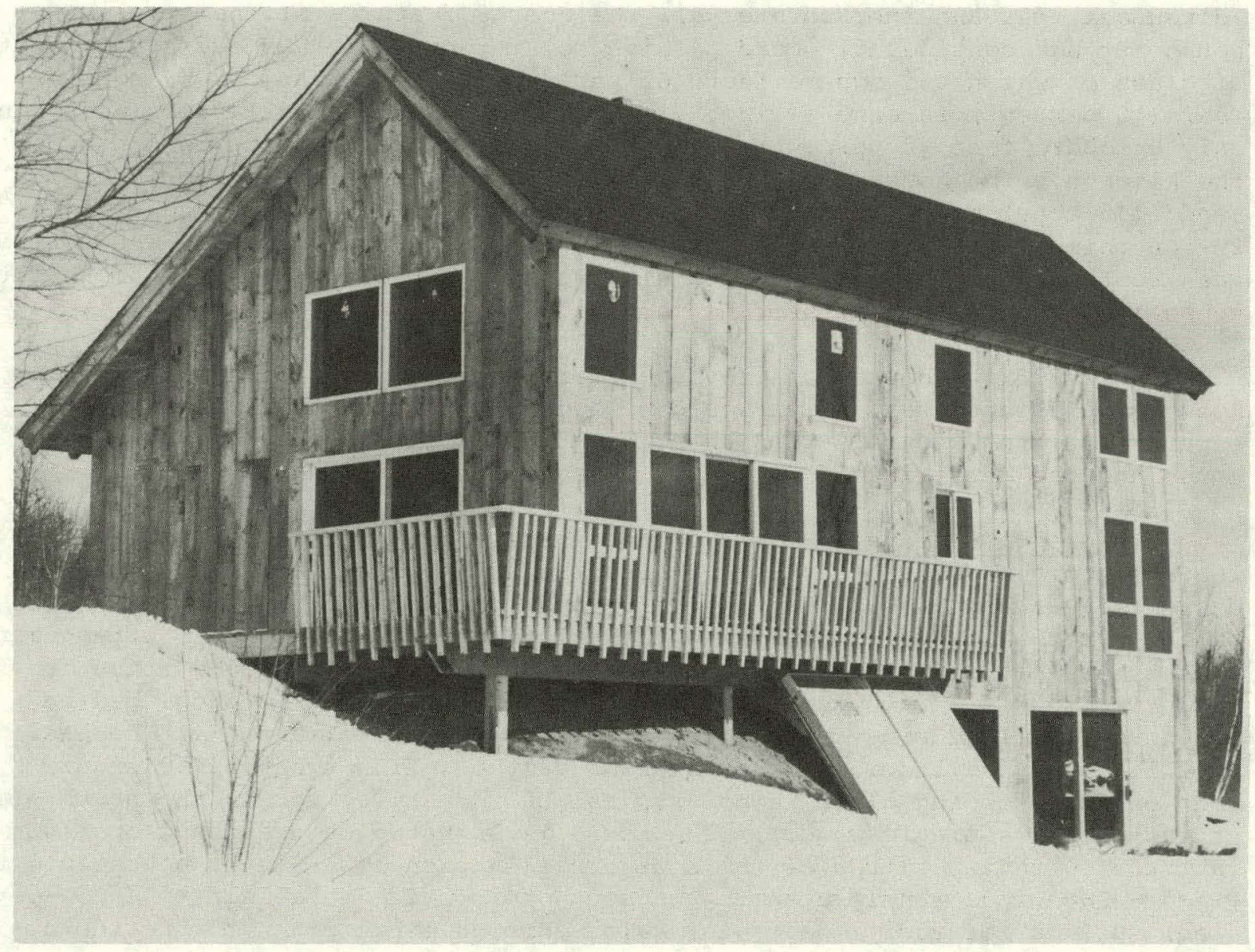

Figure 3. 2,300 $\mathrm{ft}^{2}$ LER house. 


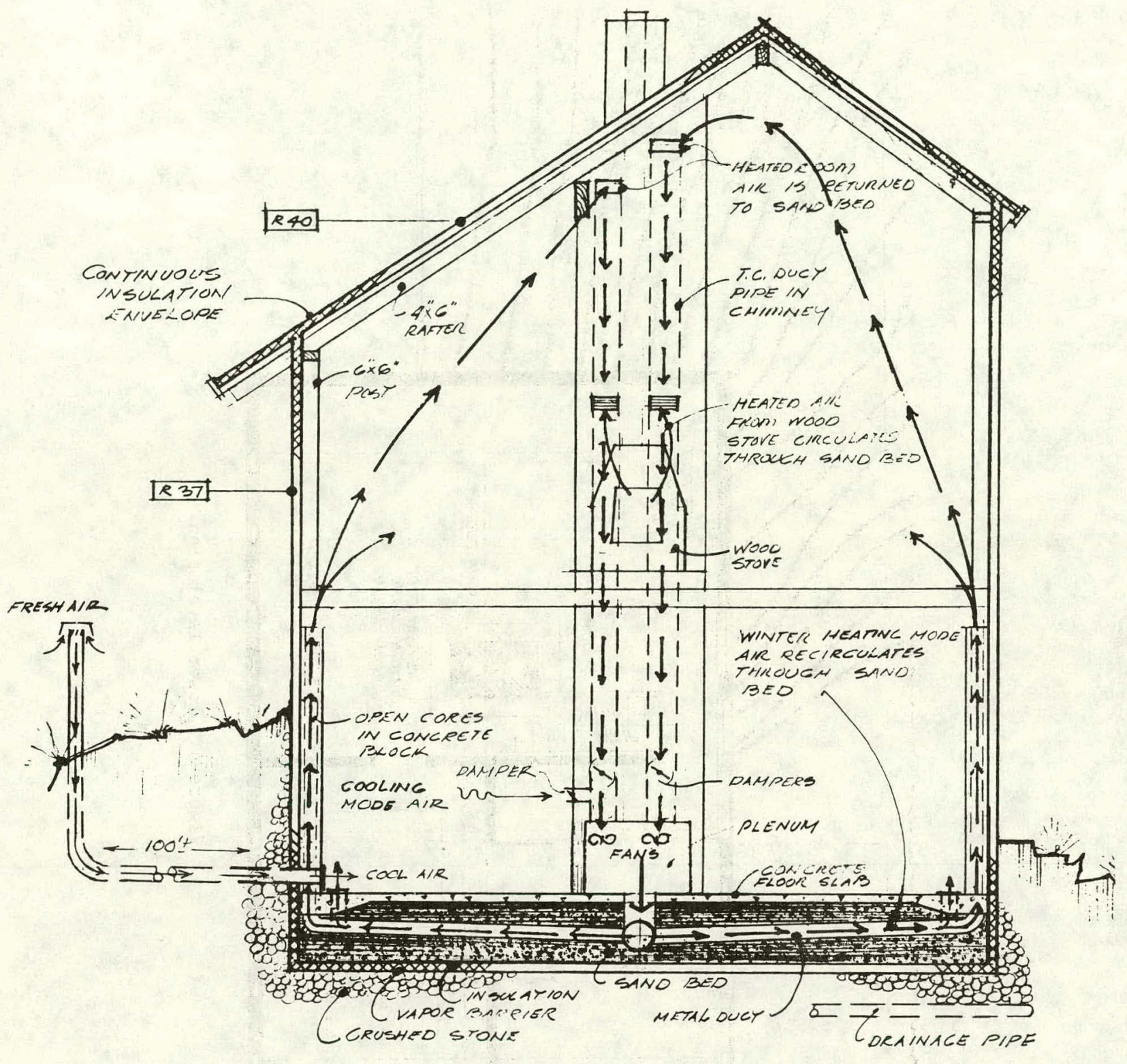

Figure 4. Diagrammatic section of LER house. 


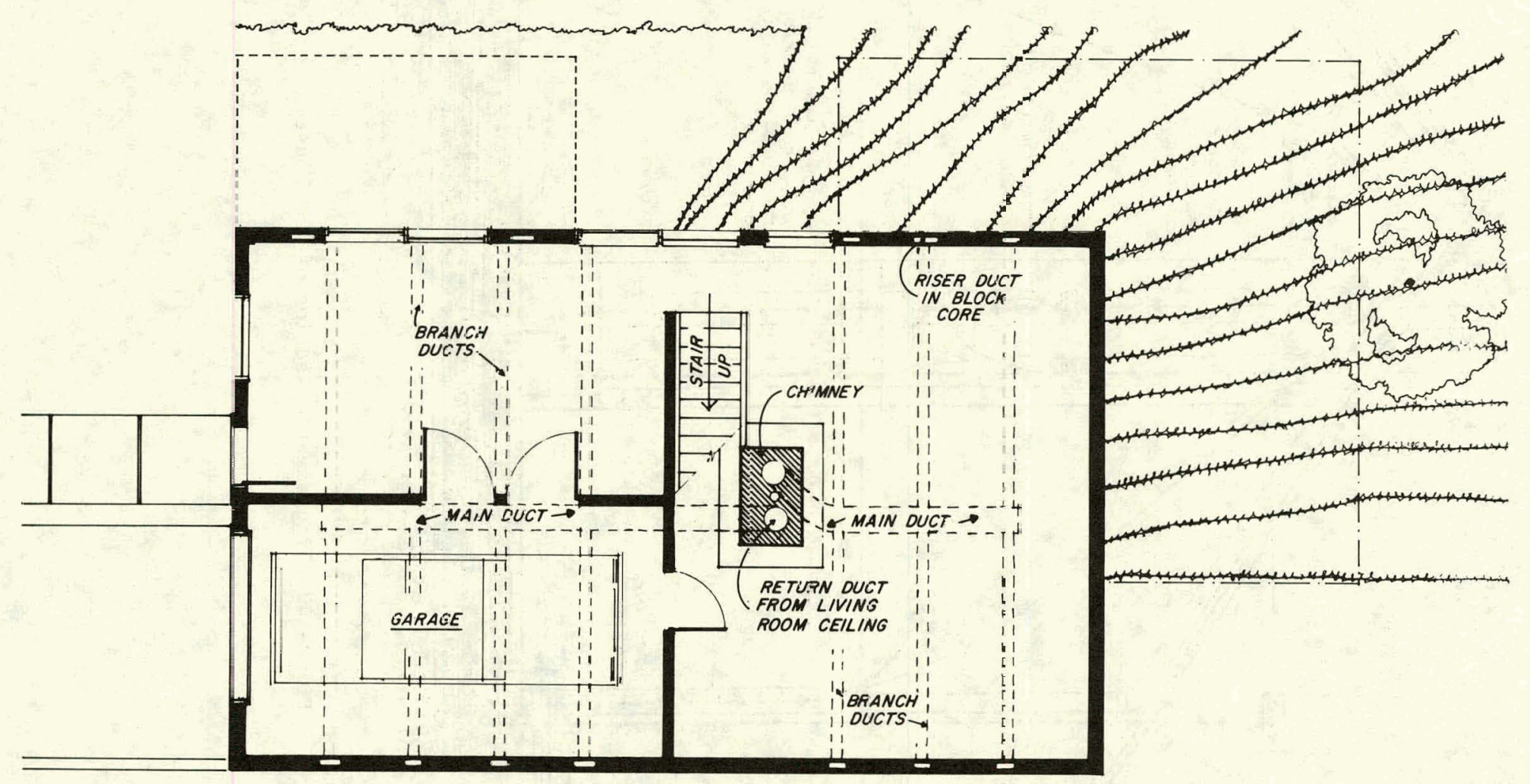

Figure 5. Lower -evel plan. 


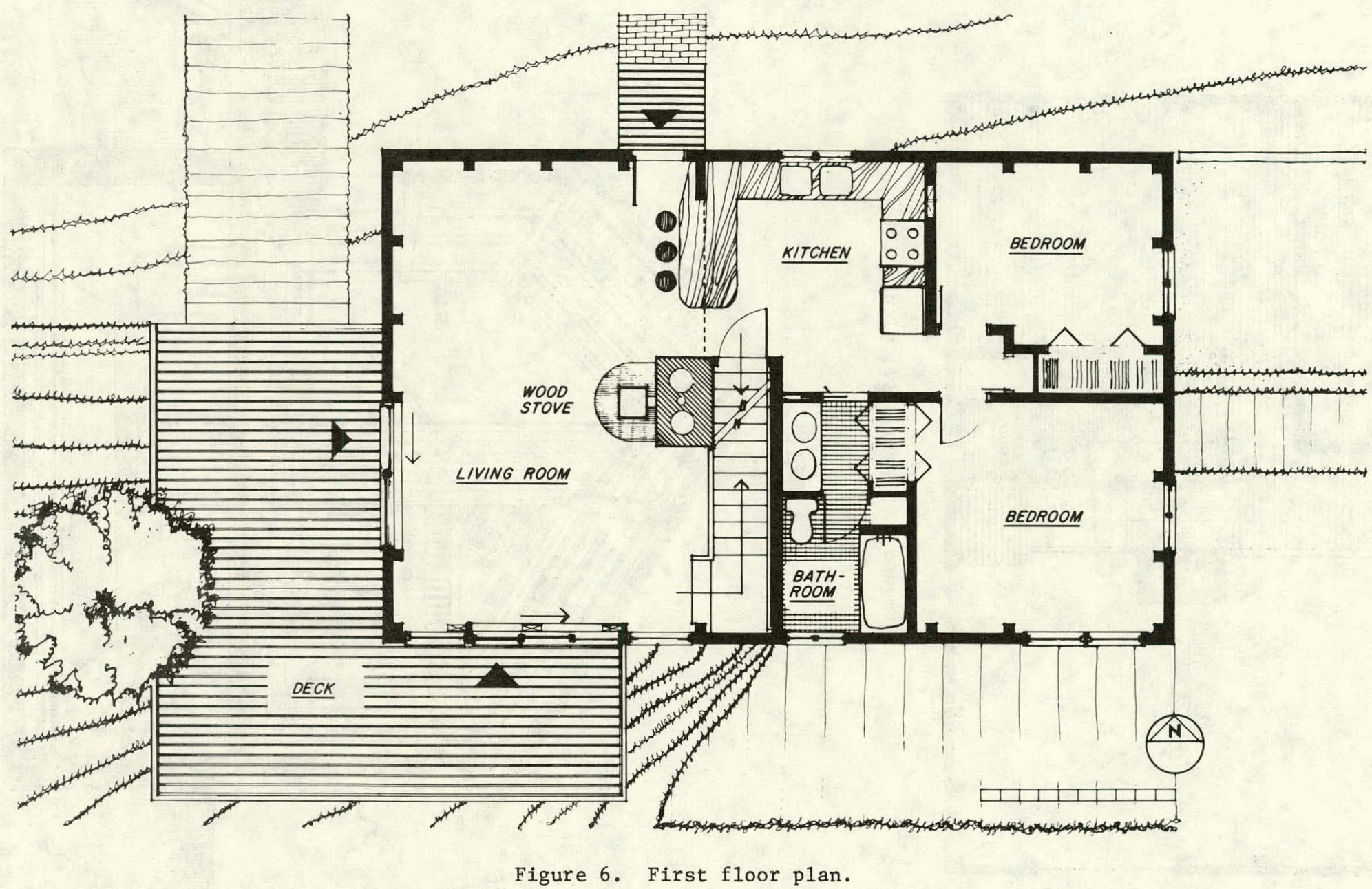




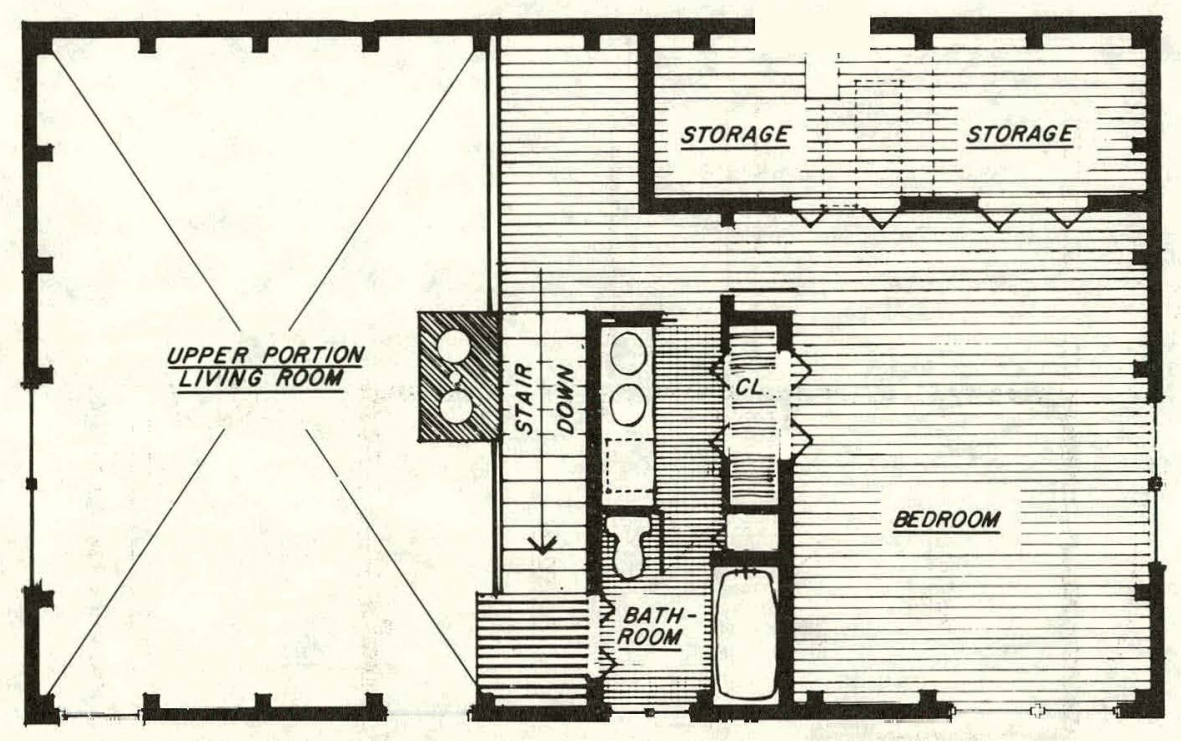

Figure 7. Upper level plan.

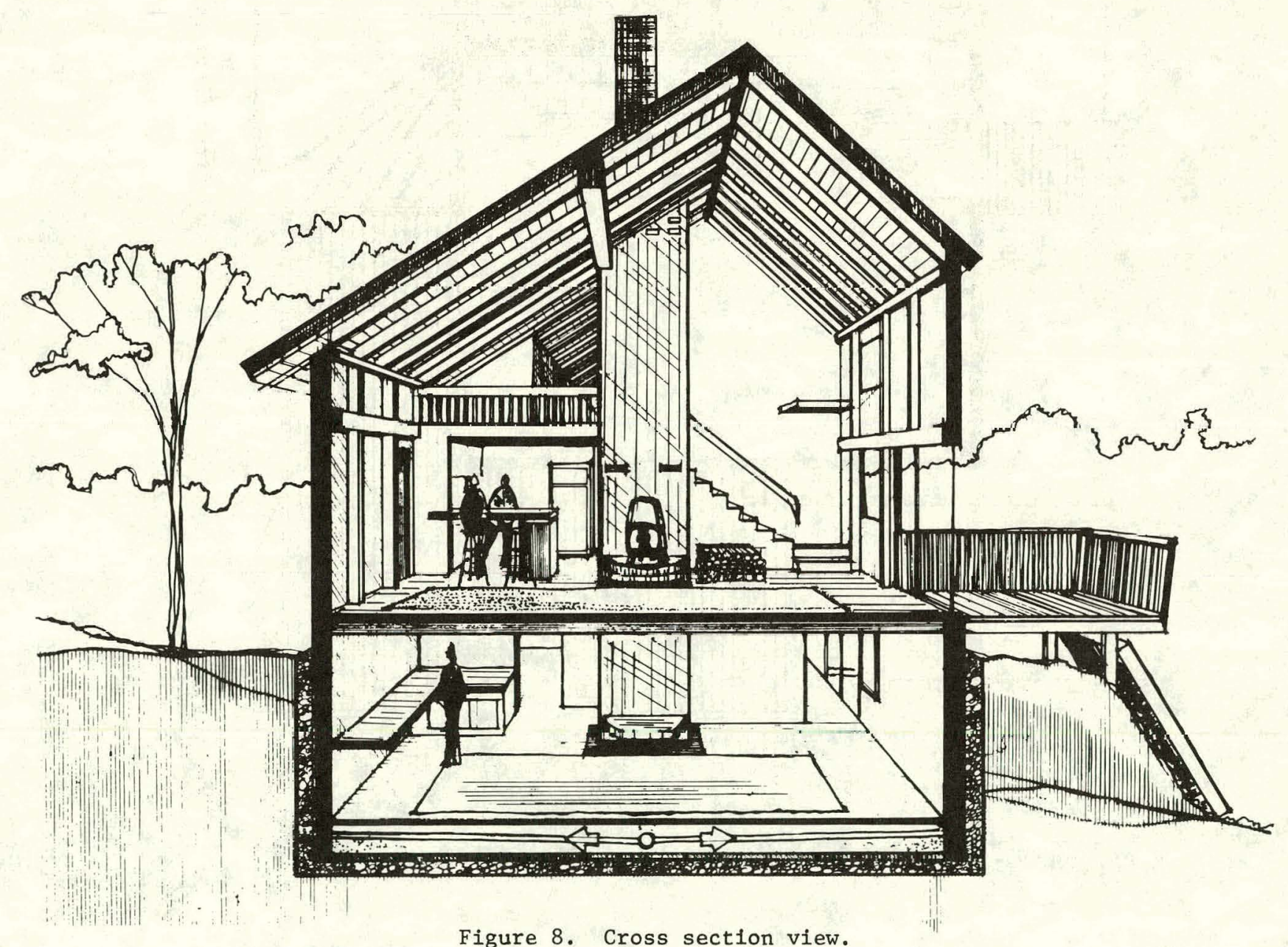

Figure 8. Cross section view. 


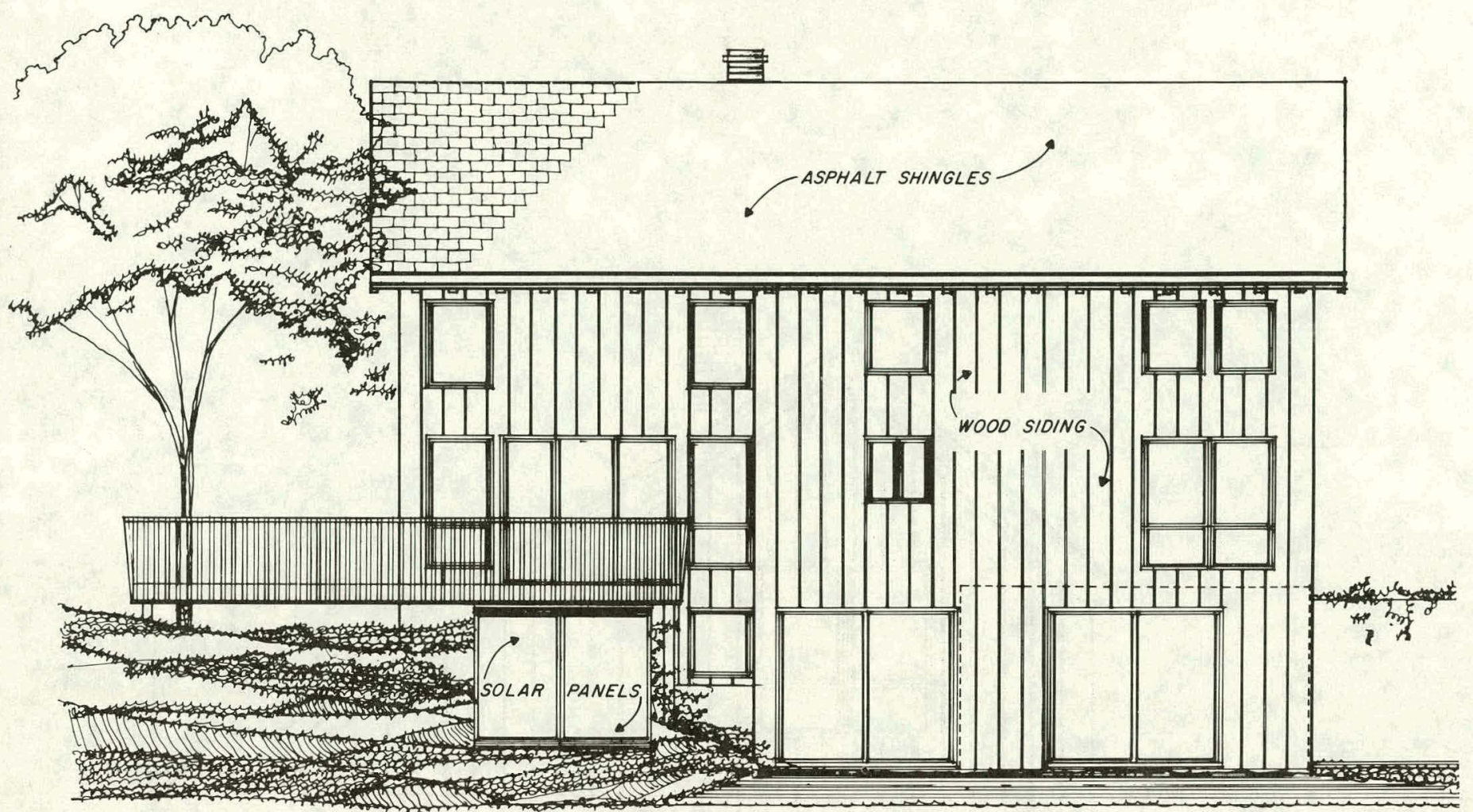

Figure 9. South elevation.

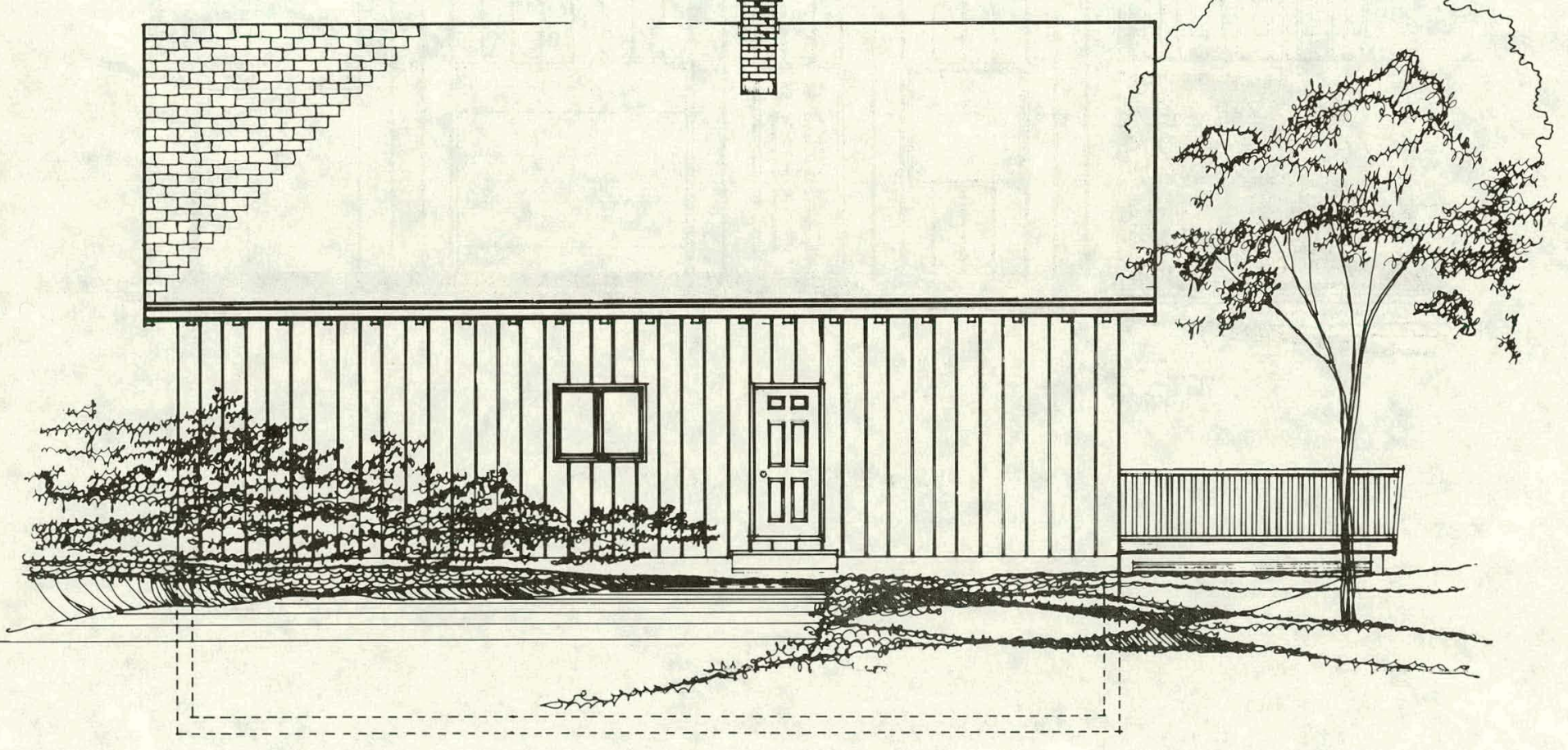

Figure 10. North elevation. 


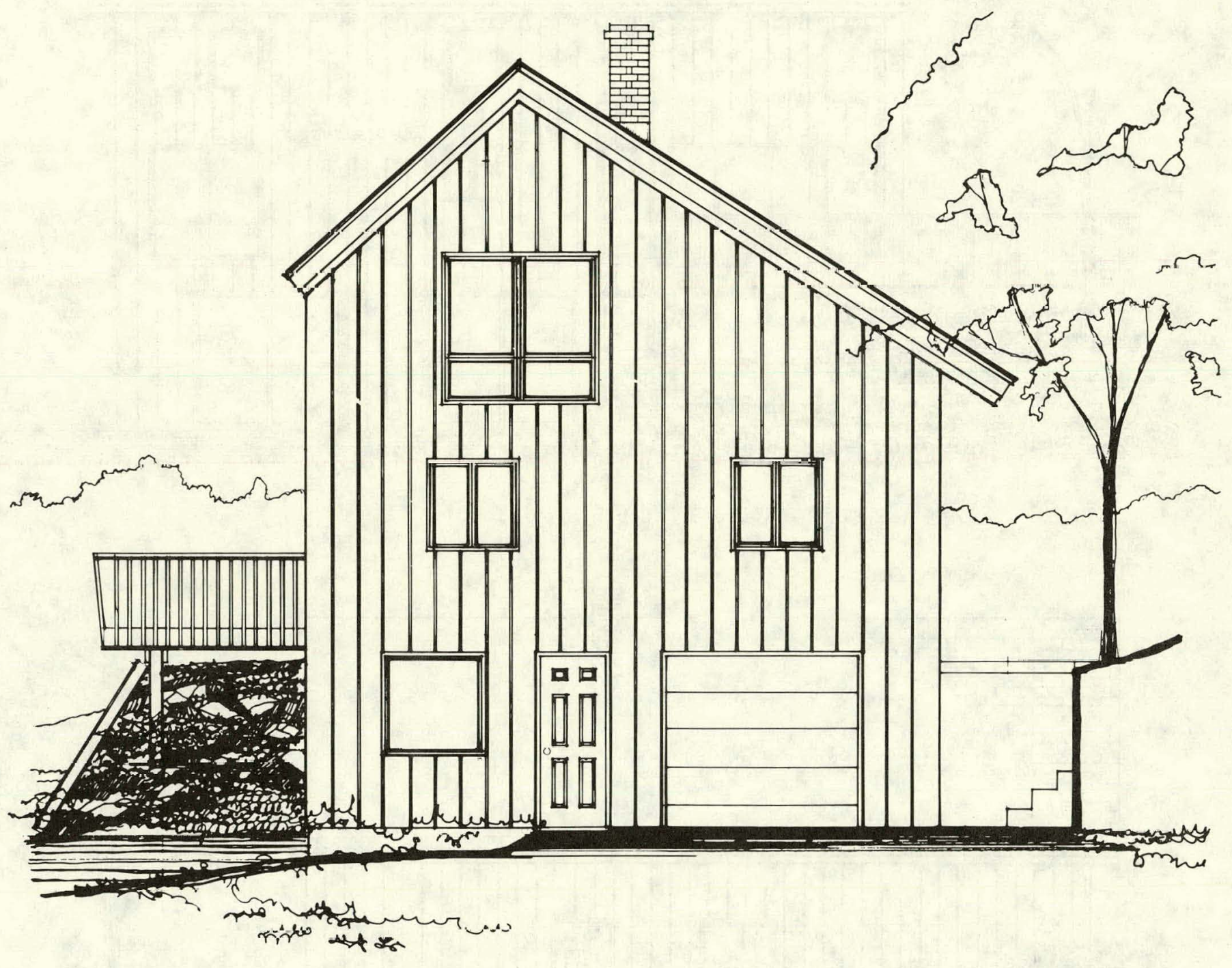

Figure 11. East elevation. 


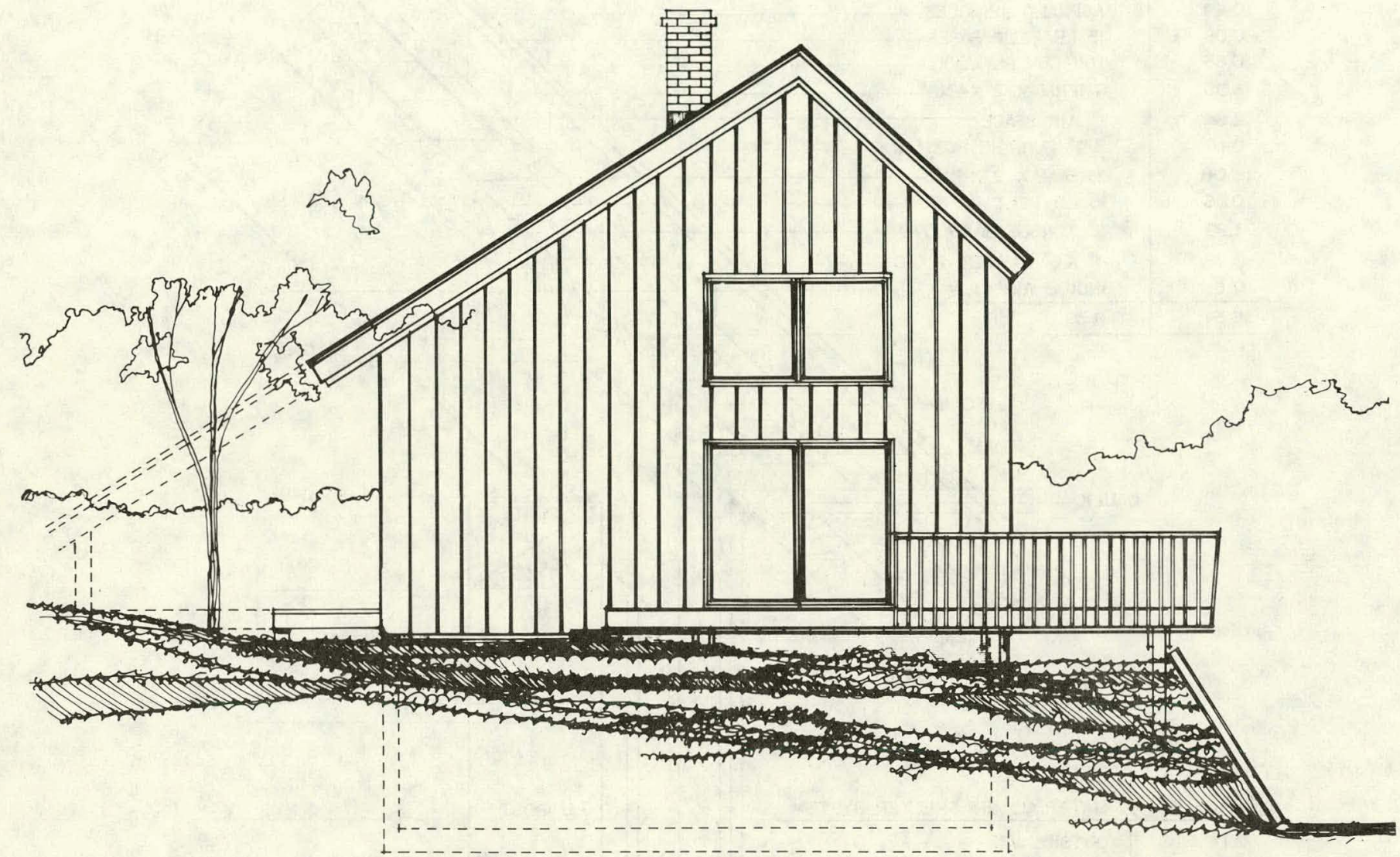

Figure 12. West elevation. 


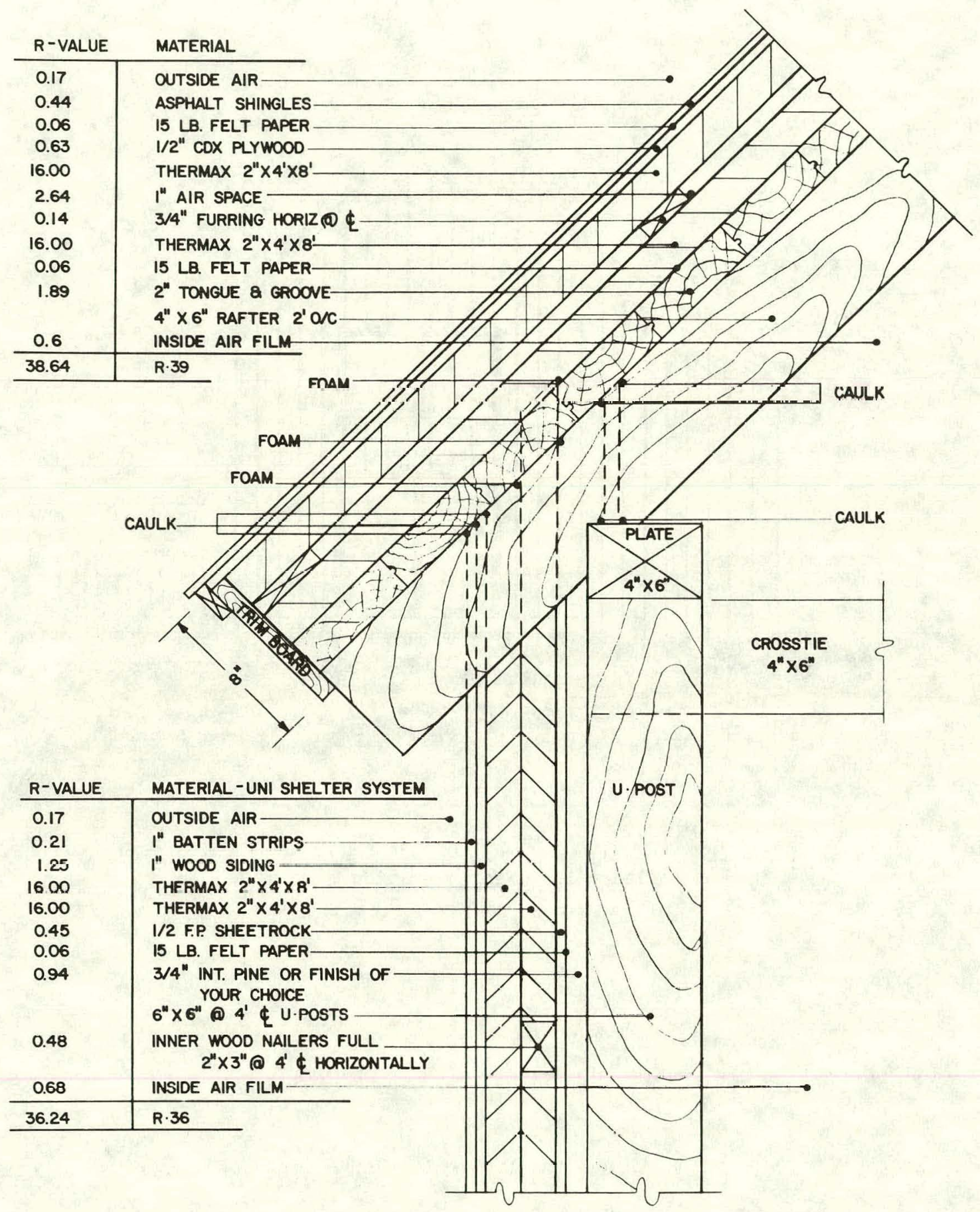

Figure 13. Roof system detail. 


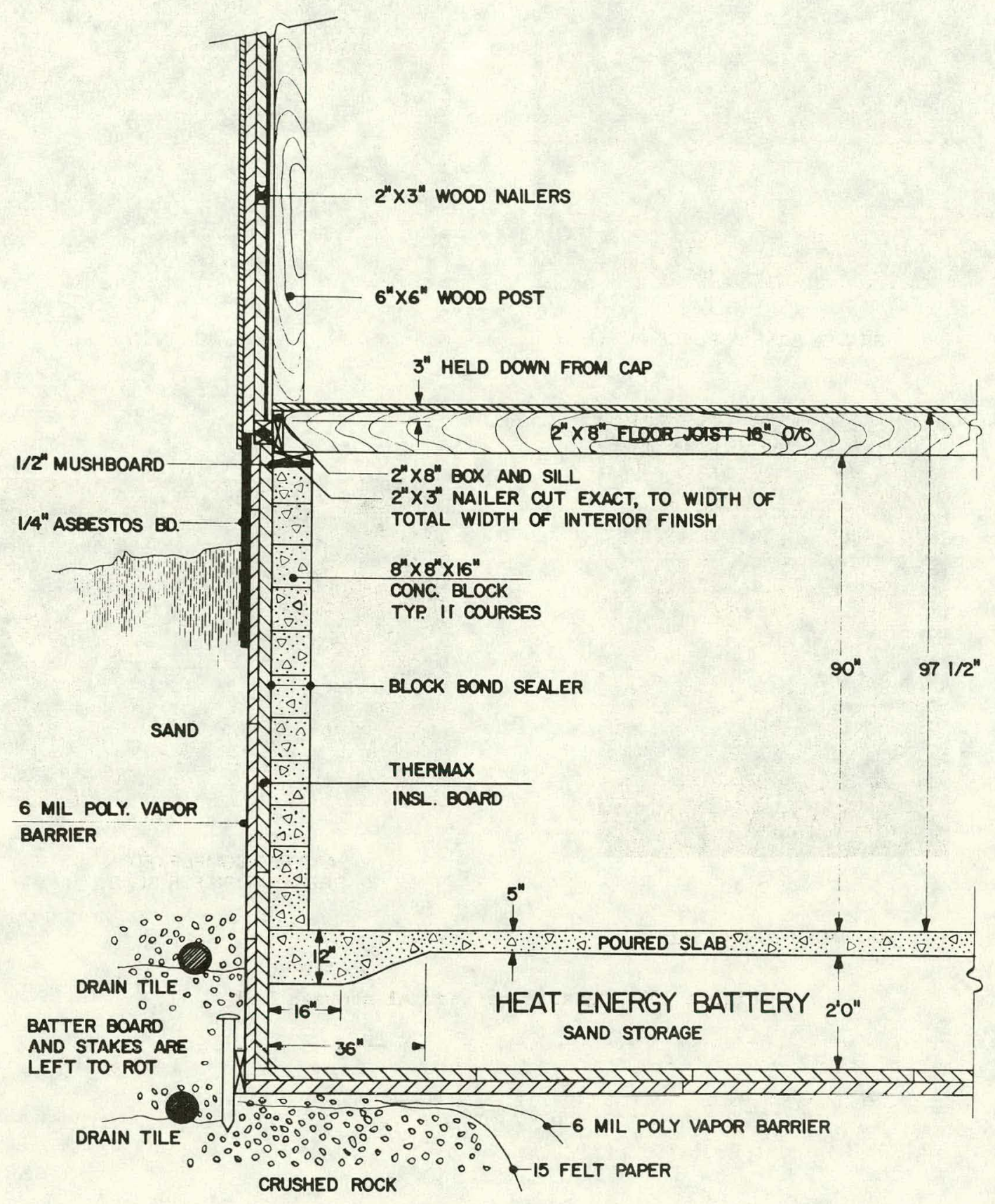

Figure 14. Wall section detail. 


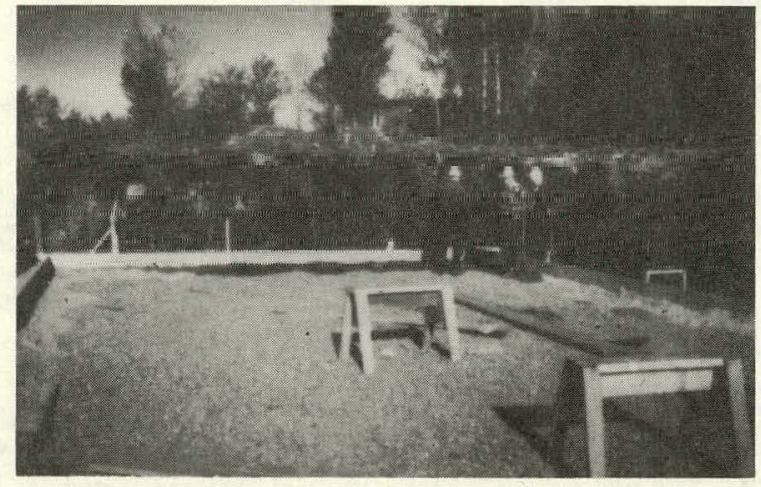

GRAVEL BASE IN PLACE

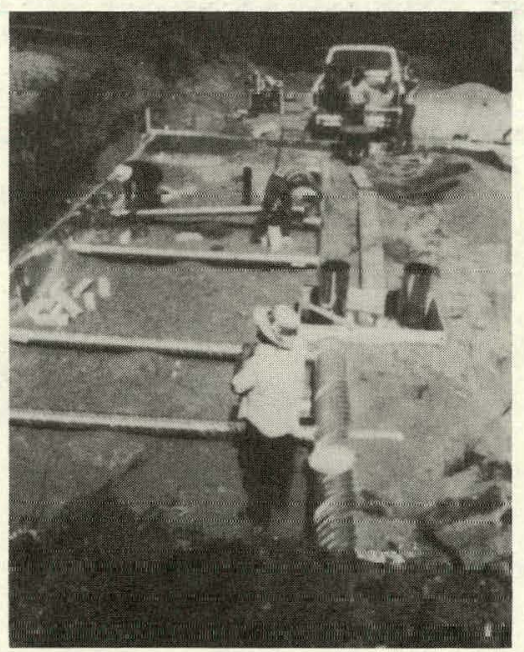

DUCTWORK COMPLETED

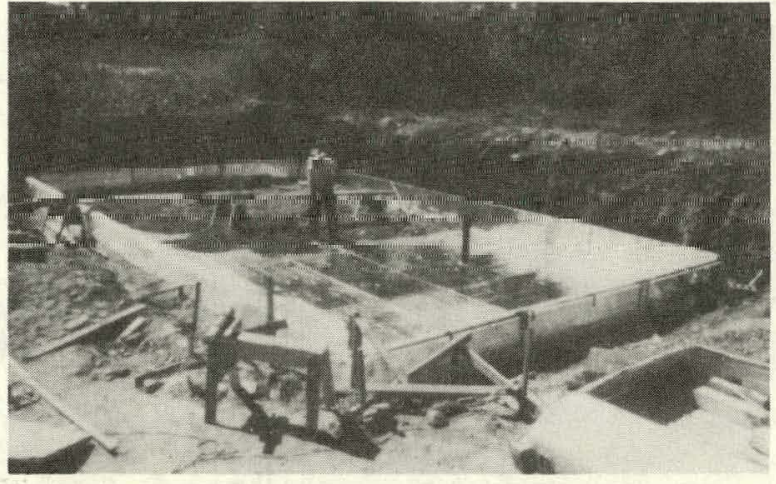

INSULATION INSTALLED

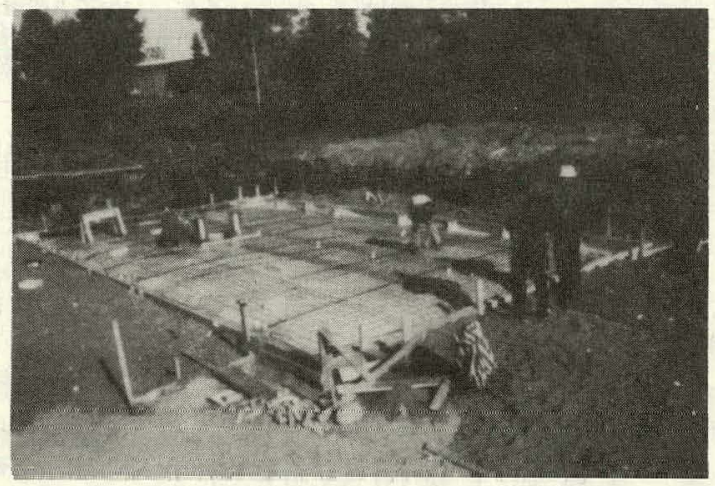

SAND BED COMPLETED IN

PREPARATION FOR SLAB

Figure 15. Details of thermal storage bed. 


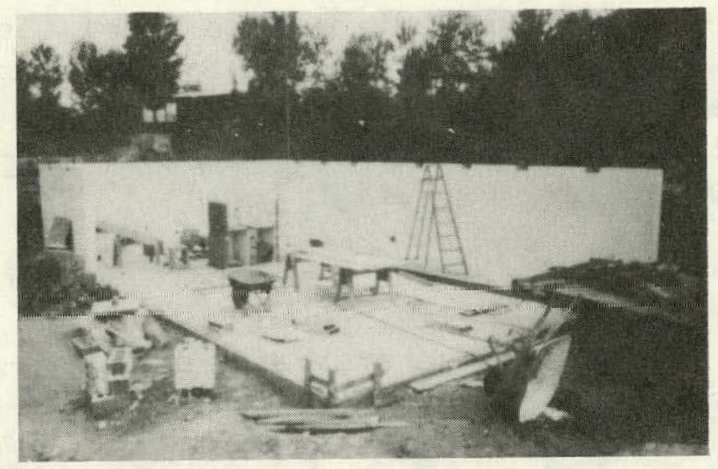

DUCTED MASONRY FOUNDATION WALL

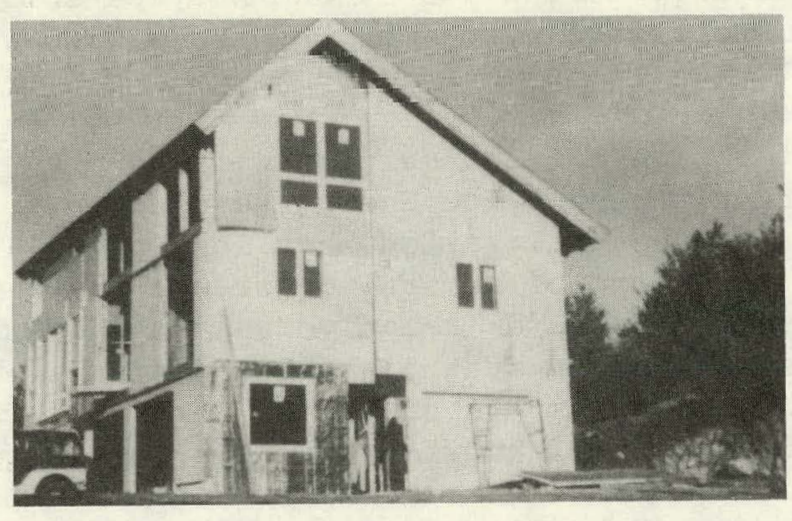

SIDING APPLIED OVER INSULATION

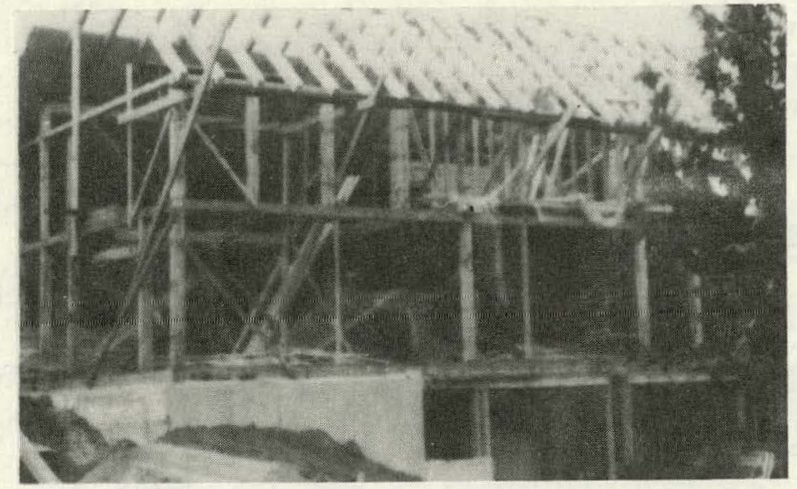

POST AND BEAM FRAME

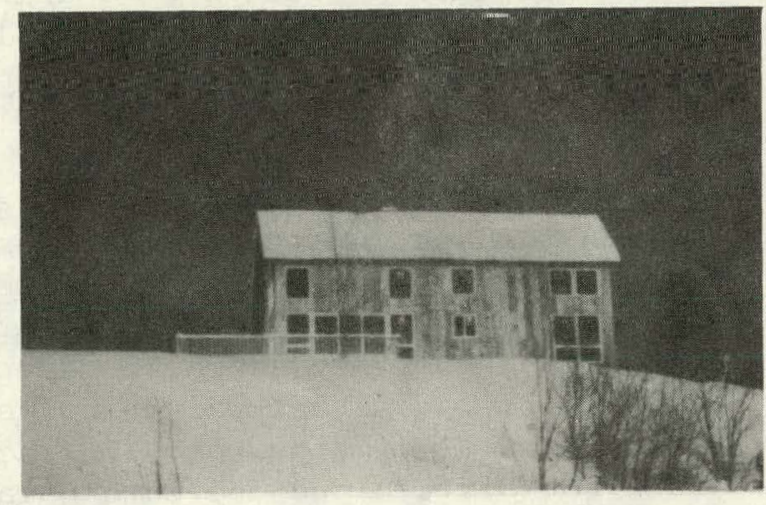

SOUTH ELEVATION

Figure 16. Structural details. 
wood-burning stove, with dampered return grills located immediately above the stove, allows heated air to flow into the room space or to be transferred directly into the heat energy battery.

The sectional drawings indicate the careful construction details of the below-grade structure designed to eliminate moisture intrusion into the storage mass. There is a crushed rock substrate with imbedded drain piping and multiple vapor barriers consisting of 6-mil polyethelene film, 15-pound tarred felt, and the integral vapor barrier of the insulation facing.

The exterior vertical wood siding is attached with wood sleepers let into the inner layer of insulation. A continuous one-half-inch plywood roof sheathing provides the nail base for roof shingles. The architectural styling and plan layout of the house are a development of Brownell's client contact and seem quite appropriate for his markel.

As discussed earlier, Brownell feels that one of the most important design features of his house is its ability to control humidity. 'The 2,300 $\mathrm{ft}^{2}$ house should perform at 45 to 55 percent $\mathrm{RH}$ as a result of the normal living cycle moisture release from cooking, washing, toilet usage, and body perspiration. This humidity can be easily controlled in winter by opening a window or door.

3. Design Philosophy. Brownell feels there are sociological and psychological benefits which accrue as a result of the Low Energy Requirement design concept. He describes these as (1) the realization that loss of utility power will mean only a slow temperature drop of several degrees a day, (2) the comfort of living in a structure that affords relatively even temperatures and humidity, where house plants thrive and static shock and dry respiratory passages, which increase susceptibility to colds and viral infections, are eliminated, and (3) the satisfaction of knowing that the building does not disturb the delicate balance of nature in the environment.

The design concept offers a simple energy system that can bc casily understood and requires a minimum of maintenance. It is Brownell's hope that these two features will lead to a general acceptance over more complicated energy systems with unknown service and performance lives. The LER house does not require space age technology; it is simply constructed of readily available materials with known life and performance.

The heat cnergy battery, in Brownell's view, can also accept additional energy sources as they might occur, e.g., from wind generators. Diverse mechanical systems, such as the heat pump and electronic air cleaners, can be inteqrated into the air-handling system if desired.

On the basis of the people he is presently dealing with, Brownell sees changes in the housing marketplace. These people, in his judgment, are pioneers in a new way of life and are creating a small but influential market with concern for enerqy awareness and environmental consciousness. Their low energy life style is reflected in such things as natural foods, organic 
gardening, and good physical condition, which reflect personal commitment to soft technology. He feels that builders should gear themselves to the growth of this influence as well as bottom line life cycle costs. The builders of the next generation of mass housing, while perhaps not adopting post and beam construction, should attempt to utilize more efficient insulation, thermal mass integration, and careful solar orientation together with other appropriate soft technology for both philosophical and economic reasons. As he puts it, the LER concept is "getting it all together," taking advantage of all the free heat available, and balancing the structure's heat losses to achieve a near equilibrium from the free heat sources alone.

Brownell was brought up in one of the last areas of Eastern wilderness, where a simple approach to life and sense of self-reliance are essential; his work reflects this philosophy. One of his ideas for the future is to provide a diesel-powered generator (total energy system) which would produce electrical energy at a cost comparable to utility prices. The exhaust heat would be recovered by dumping into the heat energy battery. The overall efficiency of fuel utilization would be very high. A significant feature of Brownell's design philosophy is that each housing unit should be made as independent as poșsible from outside energy sources.

A choice exists between the capital-intensive approach of increasing energy supplies and the more labor-intensive approach of emphasizing lowtechnology conservation initiatives as typified by Brownell's work. The approach taken by Brownell to house construction provides a good example of what is possible in the residential sector in effecting such a shift toward more labor-intensive systems with reduced demand for new energy supplies.

4. Building Performance. There are varying figures as to the percentages of heat loss through uninsulated walls and ceilings in a residential structure. The insulation industry's estimates vary from 35 to $60 \%$. Other studies indicate a combined average loss of $28 \%$ through uninsulated walls and ceilings. Still other studies show that infiltration alone commonly causes between 30 and $40 \%$ of the total heat loss in residential buildings in winter months. There is evidence that infiltration acts not only to introduce air which must be heated, but also adversely affects the thermal performance of the installed insulation through which the air passes. 5

The amount of fuel savings possible through efficient thermal envelope design alone is therefore impressive. With the addition of thermal storage concepts, the utilization of "free heat" becomes feasible, and the energy conservation potential of a total concept like Brownell's can be realized. The construction on a large scale of low thermal-loss houses with a reasonable capacity for thermal storage would not only save a great deal of energy but would, in effect, give utilities serving electric heat customers a remote storage network which could mitigate the utilities' peak loads.

Brownell calculates the possible "free heat" gain in his saltbox house (family of four) as follows: $682 \mathrm{Btu} /$ hour for metabolic load, 4,677 Btu/hour living cycle heat, and $6,726 \mathrm{Btu} /$ hour solar gain for a total of 12,805 Btu/ hour. (An additional 1,000 Btu/hour would be available if insulating shutters 
were provided.) This free heat together with the energy conserved through the improved thermal integrity of the building envelope results in a substantial reduction of heat required from the house's auxiliary heating system on a winter day. The optional wood stove used by Brownell delivers about 30,000 Btu/hour. He calculates that it would provide the balance of the required heat under winter conditions if operated as little as 12 to 15 hours per week. Thus, the Brownell house has the potential; in areas where wood is readily available, to require very little or no fossil or electric energy for its space heating.

According to Brownell's estimates, the cost to build the LER house is about $\$ 9,250$ or $\$ 4.02$ per square foot higher than the cost of conventionally constructed houses of similar size. His detailed estimate of the cost differences is provided in Table 1 . He estimates that the purchased energy needed to heat the house is about $\$ 750$ to $\$ 850$ less than that required for a conventional 2,300- $\mathrm{ft} \mathrm{t}^{2}$ house in his area of the country. On that basis, he suggests that the energy conserving features of the house have a simple payback period of about 11 to 12 years. He feels that the period is shortened to 8 to 10 years if probable future eneryy price increases are taken into. account.

As stated earlier, the foregoing section of this report is based largely on information provided by Bruce Brownell. The statements regarding the character of the house and its performance are based on his views. The following section of the report, in contrast, provides a technical analysis of the house prepared entirely by BNL staff, based on observations and measurement of the thermal performance of the building.

\section{1. 'I'E'CHNLL'AL ANALYSIS '}

A. Thermal Performance

1. Introduction. Evaluation of the thermal. performance of the Brownell LER House was found to be a considerably more complex task than had been anticipated at the outset of this study. The approach taken was one of analytical assessment followed by measurement of the actual thermal performance of the building. The measured performance data ralsed questions which suyges= ted a need for further theoretical analysis. The process eventually led to what is believed to be a reasonably accurate understanding of the thermal pertormance of this innovative structure.

The somewhat iterative process of evaluation described above, which was found necessary in analyzing the Brownell house, may be the required approach in evaluating high thermal performance buildings which utilize thermal storage and solar and internal thermal gains. Therefore, in preparing the following section, the sequential process of evaluation that was utilized is described in more detail than would otherwise be considered necessary. 
Table 1
Construction Cost Estimate

Materials Labor Total

Cost increases

Thermal storage bed

Excavate extra $3 \mathrm{ft}$ deep and level stone 57.75 tons crushed stone

4-in. drainage pipe through stone

Load sand in concrete blocks

88 pcs $2-i n$. $x 4$ ft $\times 8$ ft Thermax

10 rolls duct tape--alum foil

Chimney base--air distribution bọ .

Sand, 50.89 yards

Aluminum air duct system

Second set batten boards

1600-W electric resistant wiring (option)

Sand resistance wire placement

Duct work in house and fans

Wall and roof insulation

Taping and caulking

4-in. Thermax on first level

4-in. Thermax on rest walls/spacers

4-in. Thermax on roof/spacers

Solar hot water heating

Daystar panels

Total increases

$\$ 233.00$

248.00

12.62

$1,774.00$

67.80

110.00

72.00

737.00

38.38

88.00

$$
\frac{632.62}{\$ 4,004.42}
$$

$\$ 297.70$

$1,290.94$

$1,713.60$

$\frac{2,067.84}{\$ 5,370.08}$

$\$ 1,490.00$
$\$ \quad 190.00$

106.00

36.00

193.00

288.00

224.00

36.00

116.00

.288 .00

$\$ 1,477.00$

$\$ 5,481.42$

$\$ \quad 128.00$

160.00

360.00

280.00
$\$ 928.00$

$\$ 6,298.08$

$\$ \quad 600.00 \quad \cdot \$ 2,090.00$

$\$ 13,869.50$

Cost decreases

Eliminate $160,000 \mathrm{Btu}$ oil furnace

Conventional, fiber glass insulation.

Total decreases

. . $\$ 2,852.00$

$\therefore \quad 1.761 .32$

$\$ 4,613.32$

Net cost increase
, $\quad 9,256.18^{2}$

or $\$ 4.02 / \mathrm{sq}$. ft.

${ }^{1}$ Cost differences as compared with conventional post and beam house for Edinburg, $N$. $Y .$, summer 1978 .

2 Brownell did not include the cost of a wood stove or other auxiliary heating in this calculation. A wood stove would add roughly $\$ 500$ to the net cost increase. This omission is offset in part, however, by inclusion of $\$ 204$ for the optional $1600 \mathrm{w}$ electric resistance wiring in the sand bed. 
2. Calculated Envelope Performance. As discussed earlier in this report, a key feature of the Brownell LER house is an envelope designed for superior thermal performance. As a first step in the thermal analysis, a steady state heat loss calculation was performed for the house. For purposes of comparison, similar calculations were performed for three other house envelope designs with the same amount of floor space and exterior appearance. These calculations were based on a $68^{\circ} \mathrm{F}$ inside temperature and a $0^{\circ} \mathrm{F}$ outside temperature. An air change rate of 0.5 per hour was assumed for the Brownell house (occupied mode). Higher rates of 0.75 were assumed for the Arkansas and HUD designs and 1.0 was used for the inventory house. The results are shown in Table 2. The comparison houses were assumed to have fiber glass batt insulation and the manufacturer specified $R$ values were used in the calculations.

\begin{tabular}{|c|c|c|c|}
\hline \multicolumn{4}{|c|}{$\begin{array}{c}\text { Table } 2 \\
\text { Calculated Building Envelope Performancc-- } 0^{\circ} \mathrm{F}\end{array}$} \\
\hline Design & $\begin{array}{l}\text { Heat loss, } \\
\text { Btu/hour }\end{array}$ & $\begin{array}{l}\text { Heat loss, } \\
\text { Btu/day }\end{array}$ & $\begin{array}{l}\text { Normalized heating } \\
\text { requi rement (NHR), } \\
\text { Btu/ }{ }^{\circ} \text { F-hour }\end{array}$ \\
\hline Brownell LER House & 38,171 & 916,100 & 561 \\
\hline $\begin{array}{l}\text { House of Arkansas-type } \\
\text { construction }\end{array}$ & 53,533 & $1,284,800$ & 787 \\
\hline $\begin{array}{l}\text { House designed to HUD } \\
\text { minimum property } \\
\text { standards }\end{array}$ & 62,623 & $1,503,000$ & 921 \\
\hline Typical inventory house* & 93,419 & $2,242,000$ & 1,374 \\
\hline
\end{tabular}

${ }^{*}$ A representative 15 to 20 year old house in the Northeast U. S.

The 38,171-Btu/hour calculated heat loss of the Brownell house is 29 percent less than that for the Arkansas-type house, 639 percent less than that for a HUD minimum property standards house, and 59 percent less than that for a typical house in the Northeast U. S. inventory.

Because of the high thermal performance of Brownell's wall and roof construction, the heat loss through glazing represents a large fraction, approximately 39 percent, of the total envelope heat loss. A substantial further improvement could be provided if the windows could be shuttered somehow at night. Application of a material with an $R$ value of 5 would reduce the heat loss by 30 percent to about 26,600 Btu/hour on a $0^{\circ} \mathrm{F}$ day.

A more complete description of the comparison houses in Table 2, along with the detailed calculation of heat losses, will be found in the Appendix. 
3. Internal Heat Sources and Solar Gain. In the heat loss calculations described above, account was not taken of the effects of internal sources of heat or solar gain through glazing and through opaque wall sections. If these sources are considered, the effective heating load is reduced markedly for all of the houses analyzed above. The effect is most pronounced, however, in the case of the Brownell house, because. of its superior thermal envelope.

Internal heat sources include metabolic heat from occupants and heat from lighting and appliances. A representative figure for these sources, for a family of two adults and two children, is estimated at 59,800 Btu/day.* A breakdown is provided in the Appendix.

The solar gain from south-facing glass can be readily derived from available insolation data. For the Brookhaven National Laboratory location at Upton, New York (latitude $40^{\circ} 52^{\prime}$ ), the average solar gain through 250 square feet of vertical south-facing glass (as provided in the Brownell house) is $171,700 \mathrm{Btu} / \mathrm{day}$, assuming a transmission coefficient of 0.68 , for a heating season extending from september 1 to June $30 .{ }^{7}$ The $171,700-$ Btu/day figure applies to the comparison houses as well as to the Brownell house because they were all assumed to have 250 square feet of south glazing.**

The thermal performances of the Brownell house and the comparative houses are plotted against outside air temperature in Figure 17. Each load line passes through zero load at $68^{\circ} \mathrm{F}$. If internal heat sources and solar gain are not considered, no heating or cooling is required for any of the houses at $68^{\circ} \mathrm{F}$. Also each load line intersects the ordinate at the heat loss (Btu/ day) value appearing in Table 2 .

The assumed internal heat sources and solar gain provide a total of $231,500(59,800+171,700)$ Btu/day for each house. These sources, which are independent of outside air temperature, can be shown in Figure 17 as a uniform reduction of heating load of 231,500 Btu/day at all outside air temperatures.

The load line in Figure 17 for each house intersects the internal heat source and solar gain line at a different outside air temperature. The intersection point represents the outside air temperature at which the house requires neither heating nor cooling. It ie commonly refcrred to ac the

\footnotetext{
*Brownell's estimate of the internal heat sources, mentioned in the previous section, is $128,600 \mathrm{Btu} /$ day. The BNL estimate, based on lower metabolic heat rates and less use of electrical appliances, is considered to be conservative.

${ }^{*}$ The BNL location at Upton, NY was selected for purposes of house comparisons because of the availability of complete degree-hour weather data.
} 
"break-even temperature" or $\ddot{\mathrm{T}}_{\mathrm{BE}} \cdot{ }^{8} 8$

The detail of Figure 17 in the $50^{\circ}$ to $70^{\circ} \mathrm{F}$ temperature range is enlarged in Figure 18. As noted in Figure 18, the break-even temperatures are about $61^{\circ} \mathrm{F}$ for the inventory house, $58 \mathrm{~F}$ for the minimum property standards house, $56^{\circ} \mathrm{F}$ for the Arkansas house, and $51^{\circ} \mathrm{F}$ for the Brownell house. The internal heat sources figure of 59,800 Btu/day used in arriving at these break-even temperatures is considered to be conservative, as noted earlier, and is well below the figure used by Brownell. If a somewhat higher figure were used, it would reduce the break-even temperature of the LER house even further. With an additional 30,000 Btu/day, the break-even temperature would be reduced by about $2 \mathrm{~F}$.

As with the more common $65^{\circ} \mathrm{F}$ break-even temperature used in evaluating heating requirements of houses, these lower break-even temperatures can be used to evaluate and compare the thermal performance of the houses to which they apply. By: calculating the number of heating degree-hours below the break-even temperature for a specific location, and multiplying this figure by the building's NHR (in Btu/ ${ }^{\circ}$-hour), the annual heating requirement can be estimated for the particular building and location. The sáme method can be applied, of course, using degree-days instead of degree-hours.

The heating requirement was derived for each house for New York City area weather, using the method described above. The results appear in Table 3.

In earlier discussion, it was pointed out that the thermal performance of the Brownell building envelope is substantially better than that of the comparison houses. When heating requirements of the houses are examined (which take account of the varying break-even temperatures), the improvement offered by the Brownell house is even more striking. The figures presented in Table 4, based upon the data presented in Table 3, are for the presently configured Brownell house (without window shutters) in the New York City area.

In the preceding analysis, the requirement for and effects of thermal storage were dealt with only indirectly. The acceptance of the full available solar gain and internal heat sources presupposes adequate storage to deal with these sources without unacceptable excursions of inside temperature above the upper limit of the comfort range. A detailed discussion of thermal storage in the Brownell house appears later in this report. To the extent that thermal storage is not adequate in the comparison houses their relative

*The break-even temperature, $\mathrm{T}_{\mathrm{BE}}$, can be calculated from the relationship: $\mathrm{T}_{\mathrm{BE}}=68^{\circ}-\frac{\sum \text { Internal Sources and Solar Gain }}{24(\mathrm{NHR})}$,

where the NHR for the particular building is in units of Btu/ ${ }^{\circ}$ F-hour and the. sources and solar gain are in Btu/day. The $68^{\circ} \mathrm{F}$ figure represents the assumed mean interior temperature of the building. 


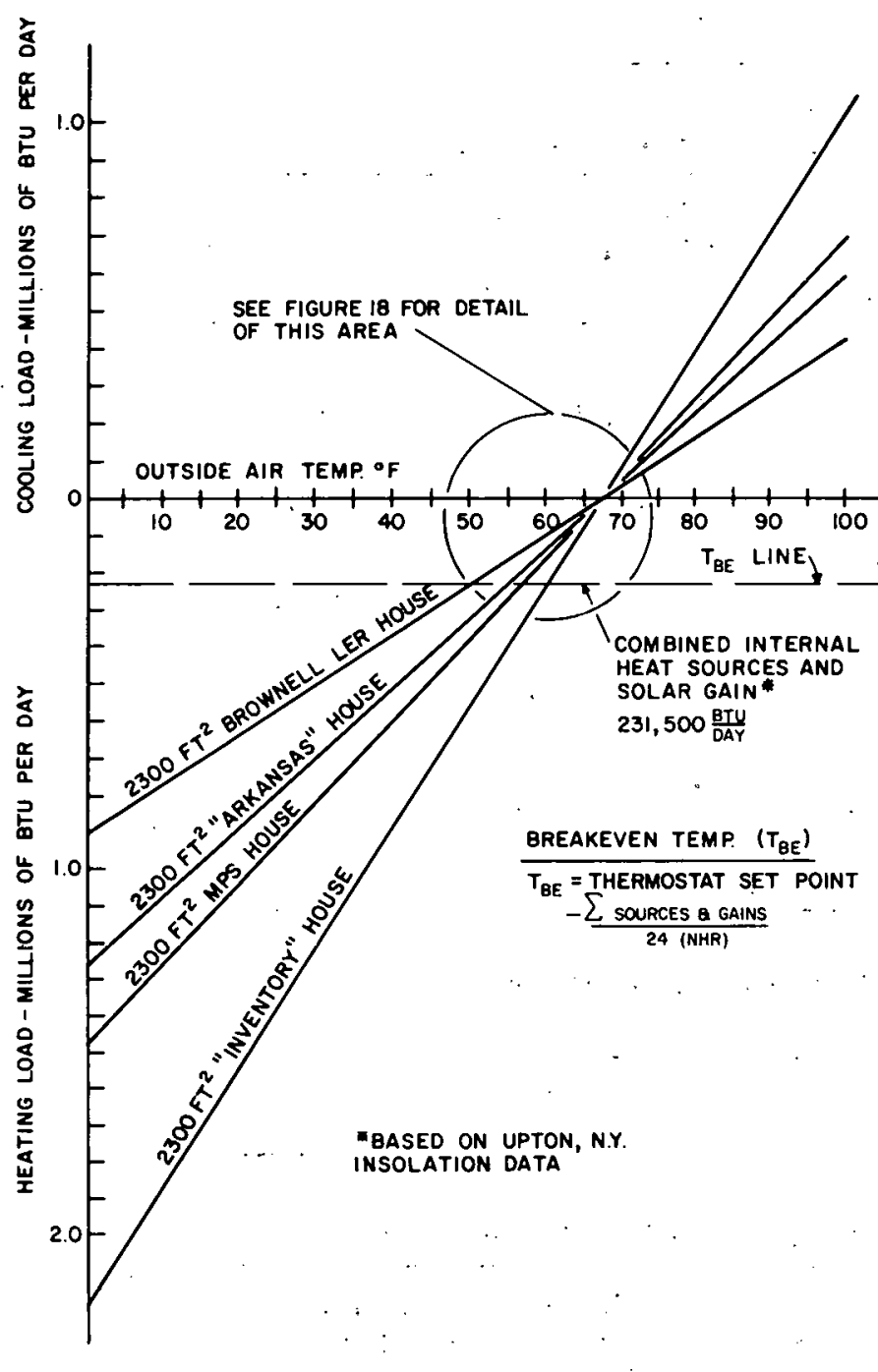
Figure 17. Comparative steady state thermal
performance.

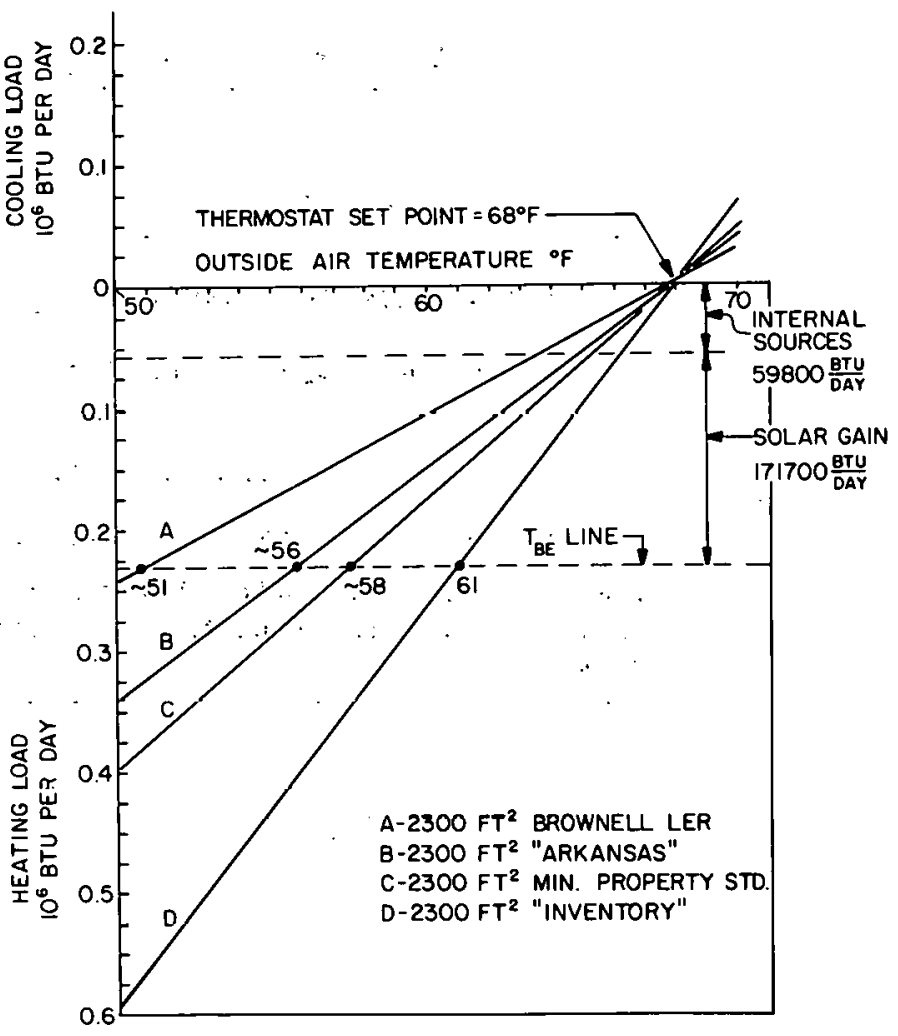

Figure 18. Detall of Figure 17 at break-even temperature. 
Table 3

Estimated Annual Fuel Usage for Space Heating

\begin{tabular}{|c|c|c|c|c|}
\hline & $\begin{array}{l}2,300 . \mathrm{ft}^{2} \\
\text { Brownell } \\
\text { house }\end{array}$ & $\begin{array}{l}2,300 \mathrm{ft}^{2} \\
\text { "Arkansas" } \\
\text { type house }\end{array}$ & $\begin{array}{l}2,300 \mathrm{ft}^{2} \text { HUD } \\
\text { minimum property } \\
\text { standards house }\end{array}$ & $\begin{array}{l}2,300 \mathrm{ft}^{2} \\
\text { inventory } \\
\text { type house }\end{array}$ \\
\hline NHR, Btu/ ${ }^{\circ} F-h r$ & 561 & 797 & 921 & 1,374 \\
\hline $\begin{array}{l}\text { Break-even } \\
\text { temp. }{ }^{\circ}{ }_{F}\end{array}$ & 50.8 & 55.7 & 57.5 & 61.0 \\
\hline $\begin{array}{l}\text { Degree hrs. below } \\
\text { break-even temp. }\end{array}$ & 56,158 & 77,479 & 86,929 & 102,182 \\
\hline $\begin{array}{l}\text { Annual heating } \\
\text { load, Btu/yr }\end{array}$ & $31.5 \times 10^{6}$ & $61.5 \times 10^{6}$ & $80.1 \times 10^{6}$ & $140.4 \times 10^{6}$ \\
\hline $\begin{array}{l}\text { Fistimated annual. } \\
\text { fuel oil usage, } \\
\text { gals. } 2\end{array}$ & 388 & $|2|$ & yष1 & $1,16 y$ \\
\hline $\begin{array}{l}\text { Annual fuel cost a } \\
55 \% / g a l, \$\end{array}$ & 213 & 416 & 543 & 951 \\
\hline $\begin{array}{l}{ }^{1} \text { Based on ten-year } \\
{ }^{2} \text { An oil-fired heati } \\
\quad 0.58 .\end{array}$ & $\begin{array}{l}\text { ourly weathe } \\
\text { g system is }\end{array}$ & $\begin{array}{l}\text { data for } \mathrm{Ne} \\
\text { ssumed with }\end{array}$ & $\begin{array}{l}\text { York City area. } \\
\text { seasonal efficien }\end{array}$ & $\left(n_{s}\right)$ of \\
\hline
\end{tabular}

Table 4

Comparative Heating Requirements of Brownell LER House

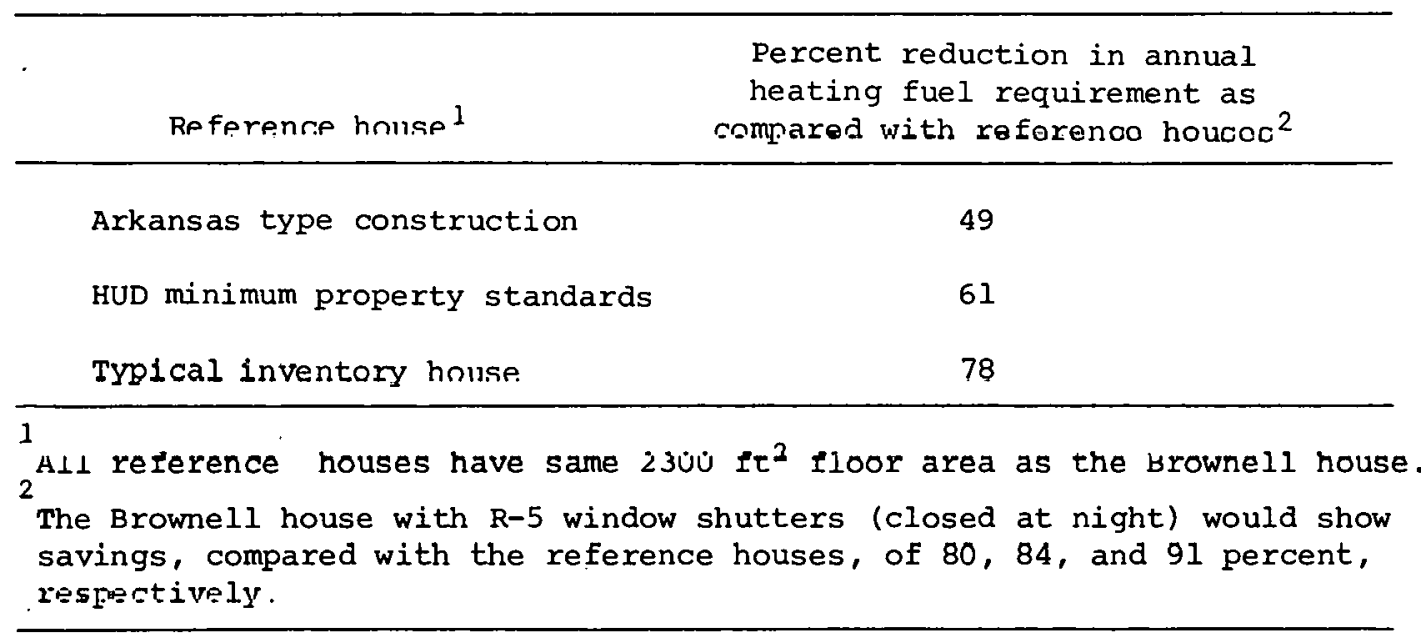


performance would suffer, since it would be necessary to "waste" or dispose of heat on some days in the heating season to prevent unacceptable inside temperatures.

It is evident from the above discussion that dramatic reductions in annual heating load and fuel usage can result from a combination of improvements in the building envelope and utilization of modest amounts of internal heat sources and solar gain, provided that adequate diurnal storage capability exists. As indicated in Table 4, the Brownell house would probably use only about 22 percent of the oil needed to heat a typical inventory house in the Northeast.

The low break-even temperature of houses like Brownell's can cause problems, however, outside of the heating season. The winter benefits of internal heat sources and solar gain can become liabilities when the ambient temperature exceeds the break-even temperature $\left(51^{\circ} \mathrm{F}\right.$ for the Brownell house) by a significant amount. The result would be overheating of the occupied space and, possibly, a need for cooling. However, with careful application of design features such as blinds, shades, and architectural roof overhangs, the effects of direct solar gain can be reduced. ${ }^{9}$ The remaining solar gain and internal source load can be dealt with through an economizer cooling mode (controlled ventilation) using outside air. This would be effective at outside temperatures up to about $78^{\circ} \mathrm{F}$. Above that temperature, some mechanical cooling would be required. The number of cooling degree-hours above $78^{\circ} \mathrm{F}$ is usually quite small in comparison with heating degree-hours, in regions where heating requirements are high. The cost for cooling, if any, would be relatively small. The cooling load would probably be largely latent rather than sensible.

4. Measured Building Performance. The Brownell house was tested by BNL staff during January, February, and March of 1978. Assistance in data collection and analysis was provided by Brownell staff members. A 4-kW electric heater was installed centrally to provide a controlled heat input. Sensors were provided for inside and outside temperatures, and a recorder was installed to record heater "on time" and the various temperatures. In the initial test period, from January 17 through March 4, the thermal storage bed was not instrumented. All of the testing in this period was conducted with the storage bed uncoupled from the house. This was accomplished by leaving the circulating fan controls off. The purpose of this was to permit evaluation of the performance of the house, including the thermal storage present in the house walls, chimney mass, etc., without the effects of the remote sand thermal storage bed.

The house was unoccupied during the entire test period except for visits of short duration for data collection and other reasons. The internal temperature was maintained at a nominal $60^{\circ} \mathrm{F}$, controlled by a thermostat which cycled the electric heater on and off as necessary to maintain the temperature. The thermostat had a relatively large dead band. Therefore, the temperature fluctuated appreciably around $60^{\circ} \mathrm{F}$. This did not affect the test results, however, because the actual inside air temperature was always used in arriving 
at $\Delta T$ values. The heater, equipped with a fan for circulating the heated air, was located on the first floor level of the house. There were no other heat inputs except for a small amount of metabolic heat and heat from lighting during the short visits to the house, and the passive solar gain, which was appreciable.

The instrumentation installed by BNL provided a printed record of data at 20-minute intervals (three times per hour). Temperatures were recorded at three locations: at approximately the center of the house on the first and second levels and in the shade near the outside of the house, on the north wall. In addition, the "on time" of the heater in seconds was recorded for the previous 20-minute period. Also, daily observations of the general weather conditions were recorded manually, i.e., sunny, cloudy, rain, etc. Data were collected and recorded from January 17 to March 31, 1978... A plot of the data taken for a representalive week, January 27 to Feburary 2, allyols in Figrus 17.



In the initial analysis of the recorded data, it was decided lo examilue the six-hour period each day between $12: 30 \mathrm{a} \cdot \mathrm{m}$. and $6: 30 \mathrm{a} \cdot \mathrm{m}$. This period was selected because (1) solar input would be absent; (2) the outside air temperature would be relatively constant during the period; and (3) any residual thermal storage effects of the house structure itself were expected to be minimal. (The latter assumption proved to be incorrect.) 
The heater hourly "on times" for each of the daily six-hour periods were averaged and converted. to a Btu per hour figure (at 100 percent conversion efficiency). This provided the rate of heat input to the house during the period. As noted previously, the house was maintained at a nominal inside temperature of $60^{\circ} \mathrm{F}$ during the test period. For the analysis, the actual interior temperature was compared with outside temperature and an average difference for the six-hour period was obtained. By dividing the rate of heat input from the heater by the average $\Delta \mathrm{T}$, a normalized heating requirement (NHR) figure was obtained for each period. These NHR figures are listed in Table 5 .

Two observations can be made about the NHR figures in Table 5 . First, the figures, which average $224 \mathrm{Btu} /{ }^{\circ} \mathrm{F}$-hour in the January 17 to February 28 period, are low compared with the calculated 561 value shown in Table 2 . second, there is a large variation in the figures from day to day during the test period.

The lower NHR for the house in the as-tested condition was believed to be due to two factors: (1) a lower infiltration rate than the 0.5 air changes per hour that was assumed for the as-lived-in calculation, and (2) the fact that the basement was essentially unheated in the as-tested condition.

The day-to-day variation in the NHR measured in the tests was at first thought to be due to varying infiltration due to changes in wind conditions. On further examination, however, it appeared that the principal contributing factor was probably thermal storage in the building structure.

In order to explore the thermal storage effects, the additional data in Table 5 were provided. The third column shows the temperature rise in the house each preceding day between $6: 30 \mathrm{a} . \mathrm{m}$. and 2:30 p.m. The fourth column shows the temperature drop in the house from 2:30 p.m. the same day to 6:30 a.m. the following morning. Also, in the fifth column, information was included to describe the weather prevailing on the day of the temperature rise.

Examination of Table 5 and Figure 19 shows that relatively large temperature rises usually occurred on days that were sunny or partly sunny. This was due, of course, to passive solar gain. Table 5 also shows that the heat required from the electric heater (the measured NHR) was generally lower than average in the night test periods following sunny or partly sunny days. The data demonstrate clearly that significant thermal storage was occurring in the house.

Next, an attempt was made to quantify the apparent thermal storage effects. This led to the figures in the final two columes of Table 5 . As mentioned earlier, the thermal storage bed below the basement floor was not operating during the initial period of these tests. It was not activated until March 5. Therefore, the thermal storage effects noted in the data up to March 5 are due to storage other than in the sand bed. The sand bed was acting as a passive cold sink below the basement slab, at a temperature estimated to be about $50^{\circ} \mathrm{F}$. The bed was instrumented later, and the thermocouples indicated a temperature of about $50^{\circ} \mathrm{F}$ when the storage bed was activated on March 5 . 
Table 5

Daily Norma-ized Heating Requirement (NHF)

January 17 Through March 31, 1978

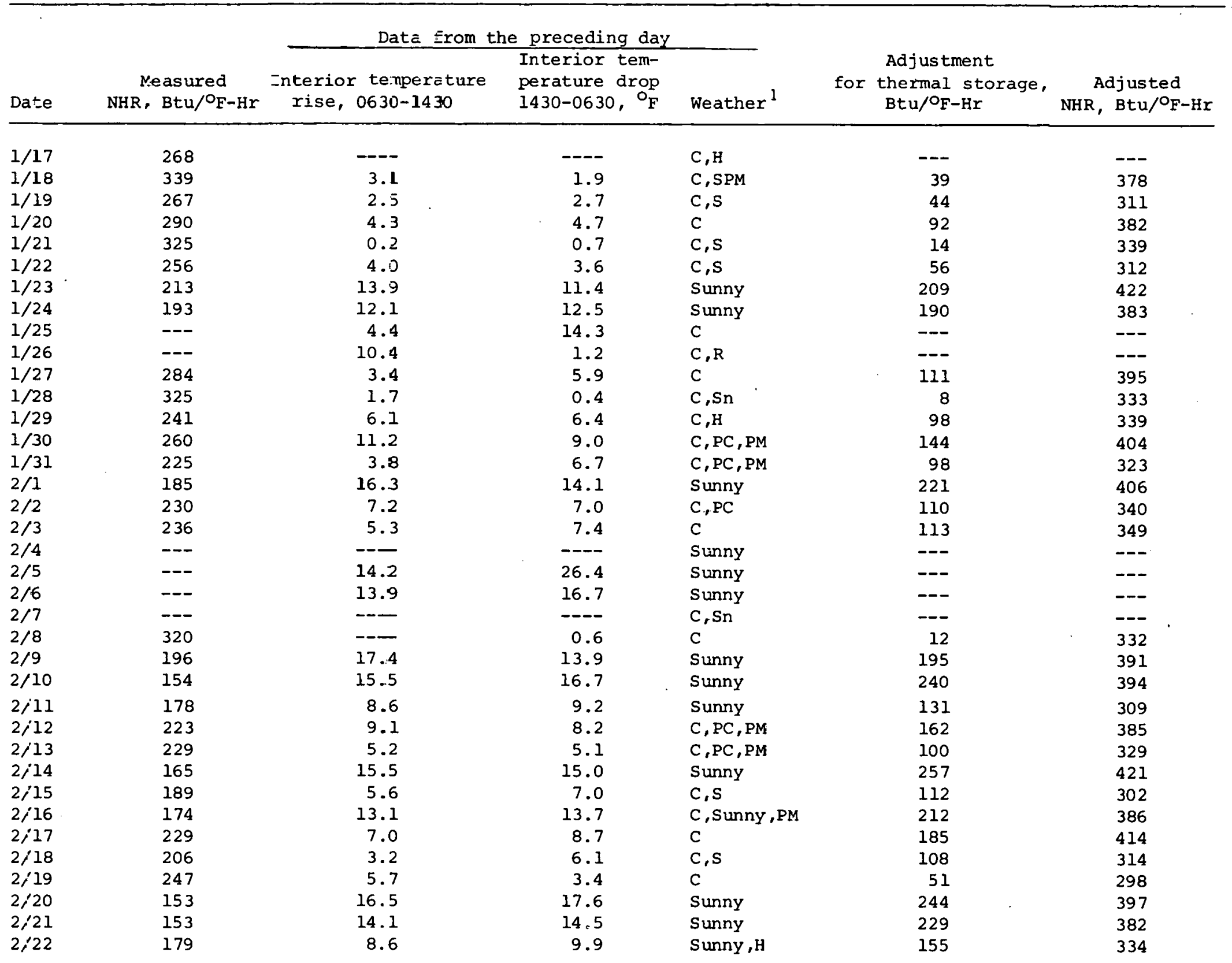


Table 5 (Continued)

\begin{tabular}{|c|c|c|c|c|c|c|}
\hline \multirow[b]{2}{*}{ Date } & \multirow[b]{2}{*}{$\begin{array}{c}\text { Measured } \\
\text { NHR, Btu/OF-Hr }\end{array}$} & \multicolumn{3}{|c|}{ Data from the preceding day } & \multirow[b]{2}{*}{$\begin{array}{l}\text { Adjustment } \\
\text { for thermal storage, } \\
\text { Btw }{ }^{\circ} \text { F-Hr }\end{array}$} & \multirow[b]{2}{*}{$\begin{array}{c}\text { Adjusted } \\
\text { NHR, Btu } /{ }^{\circ} \text { F-Hr }\end{array}$} \\
\hline & & $\begin{array}{l}\text { Interior temperature } \\
\text { rise, } 0630-1430\end{array}$ & $\begin{array}{l}\text { Interior tem- } \\
\text { perature drop } \\
1430-0630 \text {, OF }\end{array}$ & Weather ${ }^{l}$ & & \\
\hline $2 / 23$ & 228 & 7.9 & 8.2 & $C, P C$ & 163 & 391 \\
\hline $2 / 24$ & 173 & 13.0 & 11.7 & $C$, Sunny, PM & 218 & 391 \\
\hline $2 / 25$ & 213 & 6.5 & 6.9 & C & 147 & 360 \\
\hline $2 / 26$ & 198 & 6.6 & 6.3 & $\mathrm{C}, \mathrm{PC}, \mathrm{PM}$ & 114 & 312 \\
\hline $2 / 27$ & 220 & 6.7 & 6.4 & $\mathrm{C}, \mathrm{PC}$ & 117 & 337 \\
\hline $2 / 28$ & 155 & 16.1 & 16.0 & Sunny & 242 & 397 \\
\hline $3 / 1$ & 159 & 14.7 & 13.5 & Sunny & 205 & 364 \\
\hline $3 / 2$ & No Record & 7.4 & ---- & PC & -- & --- \\
\hline $3 / 3$ & 155 & --- & --- & Sunny & --- & --- \\
\hline $3 / 4$ & 203 & 3.5 & 5.3 & $C$ & 84 & 290 \\
\hline $3 / 5$ & 247 & 10.5 & 13.6 & PC & 221 & 468 \\
\hline $3 / 6$ & 214 & 14.8 & 12.7 & $C, P C$ & 228 & 442 \\
\hline $3 / 7$ & 202 & 13.4 & 13.3 & Sunny & 247 & 449 \\
\hline $3 / 8$ & 153 & 16.2 & 15.1 & Sunny & 234 & 387 \\
\hline $3 / 9$ & 140 & 15.7 & 14.4 & Sunny & 231 & 371 \\
\hline $3 / 10$ & 128 & 15.6 & 14.4 & Sunny & 278 & 406 \\
\hline $3 / 11$ & 132 & 10.0 & 10.6 & Sunny, $\mathrm{H}$ & 206 & 338 \\
\hline $3 / 12$ & 162 & 10.5 & 9.0 & PC & 232 & 394 \\
\hline $3 / 13$ & 143 & 7.2 & 7.8 & PC & 165 & 308 \\
\hline $3 / 14$ & 135 & 15.9 & 13.4 & Sunny, $\mathrm{H}$ & 322 & 457 \\
\hline $3 / 15$ & --- & --- & --- & $\mathrm{C}$ & --- & -- \\
\hline $3 / 16$ & 209 & 2.3 & 4.5 & $\mathrm{C}$ & 109 & 318 \\
\hline $3 / 17$ & 207 & 3.2 & 4.2 & $\mathrm{C}$ & 85 & 292 \\
\hline $3 / 18$ & 180 & 7.1 & 7.6 & $C, P C$ & 133 & 313 \\
\hline $3 / 19$ & 202 & 8.2 & 6.8 & Sunny & 151 & 353 \\
\hline $3 / 20$ & 203 & 5.9 & 6.6 & PC & 142 & 345 \\
\hline $3 / 21$ & 148 & 14.4 & 11.6 & Sunny, $\mathrm{H}$ & 271 & 419 \\
\hline $3 / 22$ & 173 & 7.2 & 6.6 & PC & 189 & 362 \\
\hline $3 / 23$ & 185 & 4.9 & 5.5 & $\mathrm{C}$ & 145 & 330 \\
\hline $3 / 24$ & 171 & 6.7 & 7.1 & $\mathrm{C}$ & 170 & 341 \\
\hline $3 / 25$ & 122 & 12.6 & 13.0 & Sunny & 219 & 341 \\
\hline
\end{tabular}


Table 5 (Continued)

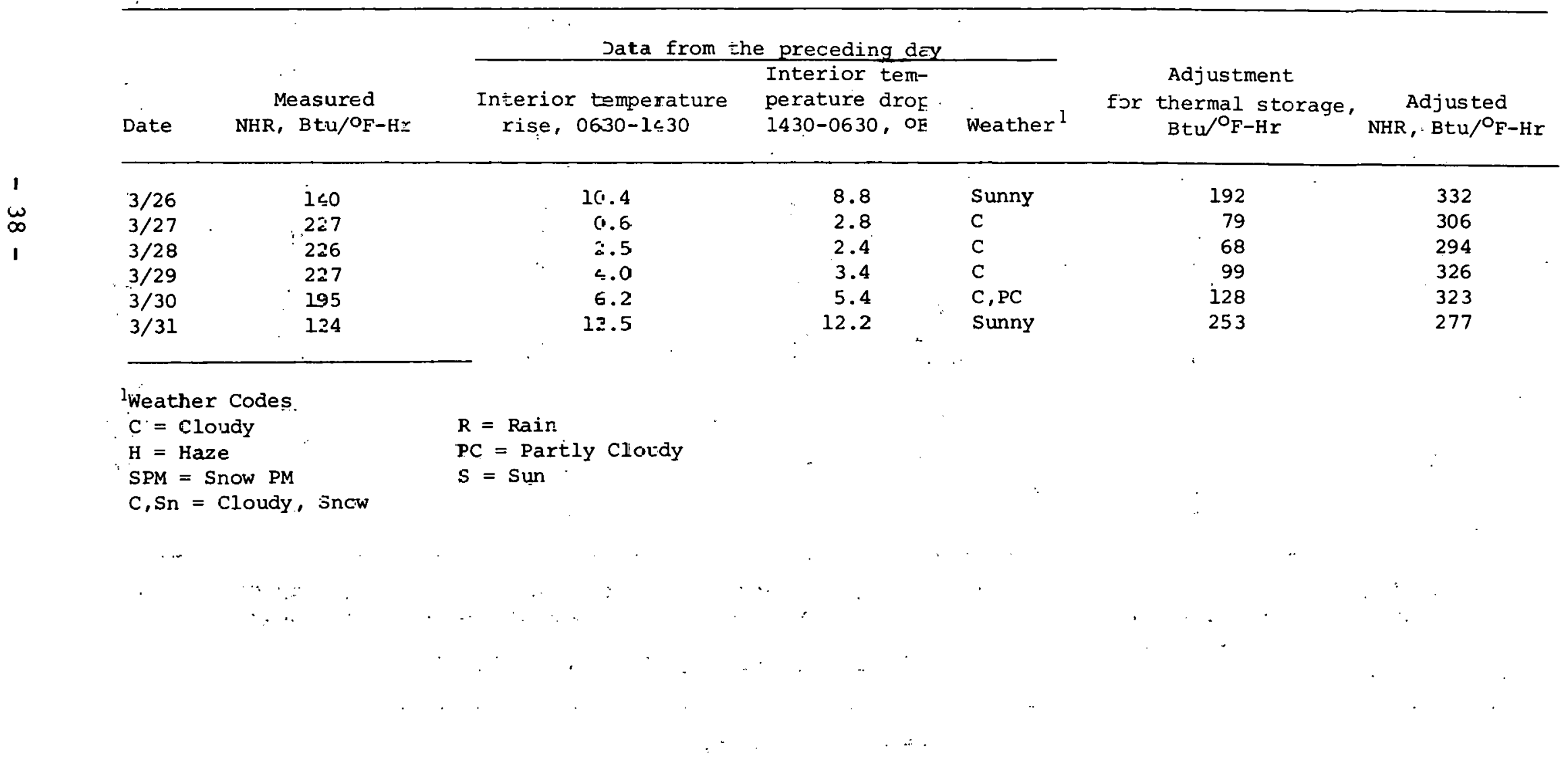


The building materials available for thermal storage within the house were analyzed to determine their ultimate heat capacity. The data are summarized in Table 6 . These materials have a total weight of some 168,000 $1 \mathrm{~b}$ and an ultimate heat storage capacity of about 39,000 Btu/ ${ }^{\circ}$. A heat transfer analysis was performed to estimate the thermal performance of these materials on a diurnal (daily) cycle. The procedure followed is described in the Appendix. ${ }^{10}$ The calculations show that the materials are remarkably effective, with about 75 percent of their ultimate heat capacity being utilized.

An attempt was made next to relate this natural thermal storage capacity to the measured daily NHR figures previously shown in Table 5 . In the heat transfer analysis utilized, the surface temperature of the materials was assumed to be essentially the same as the interior air temperature at all times. Storage elements were assumed to relax in temperature exponentially through the 16-hour period from 2:30 p.m. to 6:30 a.m. The relaxation between $12: 30 \mathrm{a} . \mathrm{m}$. and $6: 30 \mathrm{a} . \mathrm{m}$. (the six-hour data collection period discussed earlier) was estimated and translated into an hourly heat rate equivalent. The resulting heat rate figures for each day were normalized in the same manner as the measured heating requirements, that is, on the basis of the average difference between measured inside and outside temperatures on the particular night. These figures are shown in the Adjustment for Thermal Storage column of Table 5. When added to the Measured NHR they result in the "Adjusted NHR" figures in the final column of Table 5. The "Adjusted NHR" figures represent a measure of the actual building performance independent of thermal storage effects. In other words, they represent the heat input required from the heater to maintain the house at approximately $60^{\circ} \mathrm{F}$ during night hours, adjusted upward to eliminate the estimated effect of release of heat stored on the previous day in the building's structure and finishing materials. The average Adjusted NHR for the period January 17 to February 28 is 361. The average Measured NHR figure of 224 is about 62 percent of the average Adjusted NHR of 361. This suggests that the house was receiving about 38 percent of its heat from passive solar gain during the test period.

The Adjusted NHR figures in Table 5 depict the performance of the house over a range of wind-induced infiltration rates. The highest figure, $422 \mathrm{Btu} /{ }^{\circ}$-hour on January 23 , was assumed to reflect the worst statistical occurrence of infiltration and exfiltration for the period. The best performance was on March 4 when the Adjusted NHR was 290. By taking the difference between the high and low NHR values, it is possible to make an estimate of the air infiltration rate under the worst condition (assuming the rate is negligible at the best still-air condition). The calculation, presented in the Appendix, shows a rate of 7,300 cubic feet per hour under the worst condition. Since the volume of the house is about 23,000 cubic feet, this is equivalent to about. 0.31 air changes per hour. If the infiltration rate was negligible under the best condition and 0.31 air changes per hour under the worst condition, it is considered reasonable to assign a rate of 0.15 air changes per hour to the house under the average as-tested conditions. 


\begin{tabular}{|c|c|c|c|c|c|}
\hline & & $\begin{array}{r}\text { Tab } \\
\text { mal storage }\end{array}$ & $\begin{array}{l}\text { le } 6 \\
\text { Capacity Summary }\end{array}$ & & 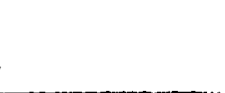 \\
\hline $\begin{array}{l}\text { Storage } \\
\text { element } \\
\text { material }\end{array}$ & $\begin{array}{l}\text { Total } \\
\text { weight, } \\
\text { pounds }\end{array}$ & $\begin{array}{l}\text { Ultimate } \\
\text { Capacity, } \\
\text { R+ } 11, \rho_{\mathrm{F}} \\
\end{array}$ & $\begin{array}{l}\text { Actual daily } \\
\text { capacity, } \\
\text { Rl } 1, \mathrm{o}_{\mathrm{F}} \\
\end{array}$ & $\begin{array}{c}\text { Effective } \\
\text { weight, } \\
\text { prounds }\end{array}$ & $\begin{array}{c}\text { Percent } \\
\text { utilizution }\end{array}$ \\
\hline Exposed $\frac{1}{2}-i n$. gypsum & 1,730 & 450 & 400 & 1,540 & 89 \\
\hline Wood paneling & 2,100 & 1,400 & 1,300 & 1,940 & 93 \\
\hline Exposed framing & 6,200 & 4,200 & 3,900 & 5,800 & 93 \\
\hline $\begin{array}{l}\text { Post and beam and } \\
\text { roof deck }\end{array}$ & 16,600 & 11,100 & 6,800 & 10,100 & 61 \\
\hline $\begin{array}{l}\text { Exposed chimney } \\
(4-\text { in. block--2 layers) }\end{array}$ & 24,200 & 3,800 & 3,800 & 24,200 & $\sim 100$ \\
\hline $\begin{array}{l}\text { Cellar wall } \\
\text { (8-in. hollow blook \& }\end{array}$ & $\begin{array}{l}39,600 \\
\text { nd) }\end{array}$ & 6.200 & 5,800 & 37,400 & 94 . \\
\hline $\begin{array}{l}\text { Cellar floor slab } \\
\text { (Perimeter grade beam) }\end{array}$ & 77,800 & 12,100 & 7,200 & 46,400 & 60 \\
\hline Totals & 168,230 & 39,250 & 29,200 & 126,790 & 75 \\
\hline
\end{tabular}


The preceding discussion is concerned with the measured performance of the Brownell house envelope during the period from January. 17 to March 31, : 1978. An attempt was made next to calculate the expected performance of the house under the test conditions to permit a comparison with the measured performance.

A NHR of $561 \mathrm{Btu} /{ }^{\circ} \mathrm{F}$-hour was calculated earlier for the Brownell house (see Table 2). This heating requirement value represents the losses through the building envelope in the "as-lived-in" condition. In order to arrive at a calculated NHR for comparison with the measured performance, it is necessary to correct for two differences in conditions. First, the infiltration rate in the as-tested condition of 0.15 air changes, discussed above, is only about one-third the 0.5 rate assumed for the as-lived-in calculation. Second, the basement was essentially unheated in the as-tested condition. This further reduces the envelope heat loss expressed in terms of a $\Delta T$ relative to the first floor temperature. A detailed calculation of the as-tested heat loss appears in the Appendix. The adjustments, shown below in Table 7, were derived from the detailed calculation.

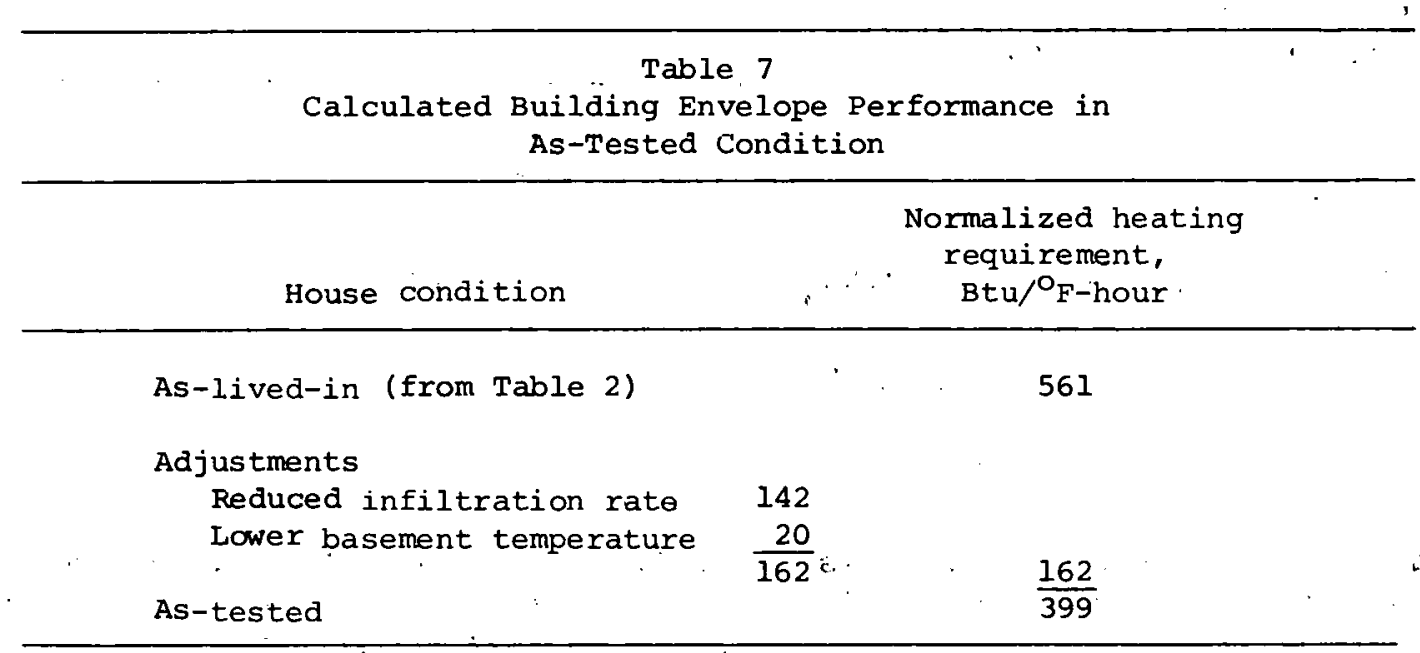

As discussed earlier, the house was maintained at a nominal first-fioor temperature of $60^{\circ} \mathrm{F}$ during the test period. A new calculation of break-even Lemperature was made for this lower inside temperature. To do this, it was necessary to estimate the internal heat sources and the solar gain during the test period at the building site in Edinburg, New York.

The internal gains were negligible since the building was not occupied or lighted except during infrequent visits of short duration. The incident solar flux for south-facing vertical surfaçes was taken from data for the nearest major city, Schenectady, New York. The average figure for January and February is $902 \mathrm{Btu} / \mathrm{ft}^{2}$-day. This radiation was assumed to be received by south-facing glass. In addition, some benefit was assumed from the incident radiation on the opaque surfaces of the south building wall, the area of 
which is sufficient to receive about 336,000 Btu per day. The net outward daytime heat flow through the south wall, in the absence of sunlight, would be about 4,600 Btu/hour. For purposes of the calculation. of break-even temperature, it was assumed that the solar radiation on the opaque surfaces serves to offset the daytime conductive loss through the wall in the absence of radiation. The summation of internal sources and solar gains can then be developed as follows.

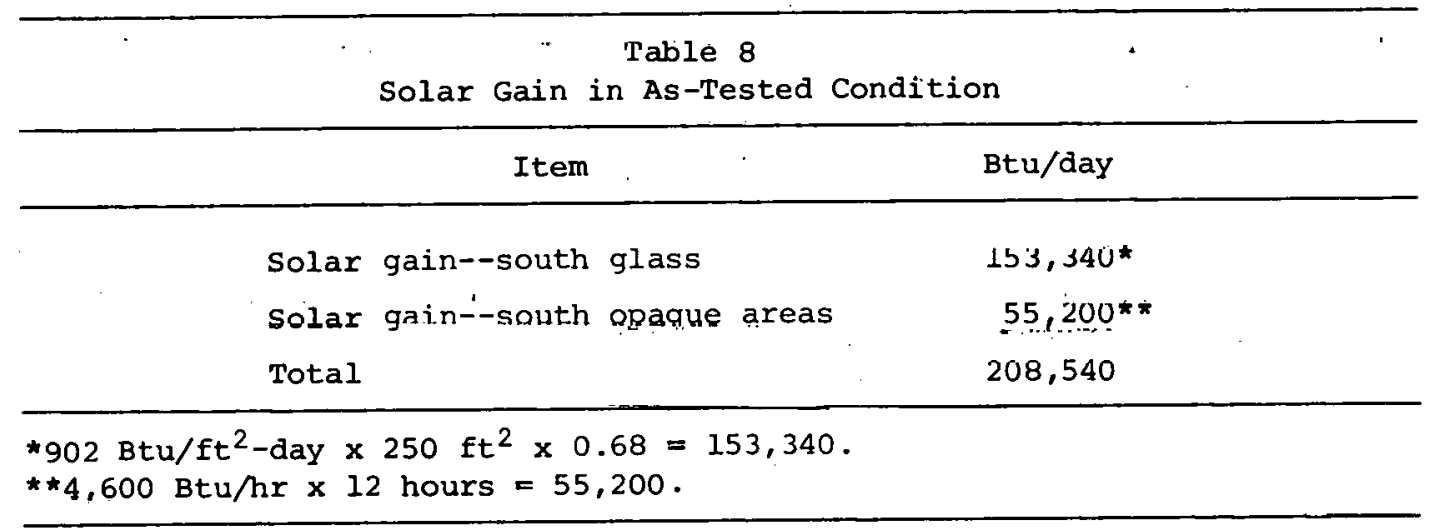

The break-even temperature can be calculated as before:

$$
\begin{aligned}
& \mathrm{T}_{\mathrm{BE}}=60^{\circ} \mathrm{F}-\frac{\sum \text { Tnternal sources and Solar Gains }}{24 \times \mathrm{NHR} \text { in Btu/OF-hour }}, \\
& \mathrm{T}_{\mathrm{BE}}=60^{\circ} \mathrm{F}-\frac{208,540}{24 \times 399}, \\
& \mathrm{~T}_{\mathrm{BE}}=38.2^{\circ} \mathrm{F} .
\end{aligned}
$$

This temperature of $38.2^{\circ} \mathrm{F}$ is the calculated temperature above which no heat is required from the electric heater to maintain a nominal $60^{\circ} \mathrm{F}$ interior first-floor temperature on a day with average insolation in the months of January and February.

Having calculated the break-even temperature for the as-tested condition, it is possible to calculate the heat input required by identifying the degree days for the actual test period. By examination of the outside air temperatures for the period January 18 to Febraury 28, the number of degree-days below a break-even temperature of $38.2^{\circ} \mathrm{F}$ was found to be 979 . 'l'he electric energy that would have been required to heat the house in this period can then be calculated to be $2,747 \mathrm{kWh}$.* The actual energy consumed, based on readings of the house's watt-hour meter, was $2,320 \mathrm{kWh}$. 'I'he actual flgure is' about 15.5 percent less than the calculated performance of the house. The calculated performance, as noted above, corresponds to the NHR value of 399

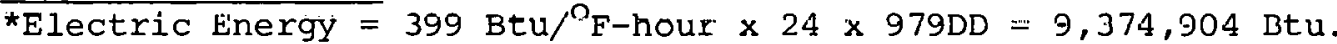
$9,374,904 \mathrm{Btu} \div 3,413 \mathrm{kWh} / \mathrm{Btu}=2,747 \mathrm{kWh}$.
} 
from Table 7 and the estimated solar gain received by the house during the test period. This agreement is considered to be fairly good:

Another comparison can be made, between the house's watt-hour meter consumption figure and the measured performance of the house, as adjusted for thermal storage effects, from Table 5. As noted in Table 5, the average adjusted NHR was 361. This figure represents an upward adjustment of the average measured NHR for the period of 224 to account for heat estimated to be received from thermal storage. This heat was, in turn, placed in thermal storage in the form of heat from solar gain.

In this comparison, the expected electric energy required to heat the house is $2,485 \mathrm{kWh}$.* When compared with the $2,320-\mathrm{kWh}$ reading from the watthour meter, the difference is only 6.6 percent.

The latter comparison shows that the actual performance of the house, as measured by the energy consumed by the electric heater over the test period, is about 7 percent better than the performance estimate derived from measured nightly performance data modified by the estimated benefits of prior days' passive solar gain, captured and released by the natural thermal storage capacity of the building. This agreement is considered to be very good, considering the relatively unsophisticated method of modeling the thermal storage effects. For a more rigorous approach to this analysis, refer to the work of Arumill and Sonderegger ${ }^{12}$.

In summary, a principal conclusion that can be drawn from the testing of the Brownell house in January and February 1978 is that the energy required to heat the house is about 16 percent less than the amount calculated to be required. While the source of the difference is not known, it is believed to be due in part to a conservative estimate of the passive solar gain used in the performance calculation. Significant additional gain is possibly being received through glass orientations other than on the south wall and through snow-covered reflectance. Also, the gain through the opaque parts of the south wall may be greater than estimated. In any case, the performance testing suggests that the calculated thermal performance is conservative.

The calculation method used in arriving at the as-lived-in performance figures in Tables 2 and 4 is similar to that for the as-tested condition. Therefore, it is believed that the performance data for the Brownell house in Tables 2, 3, and 4 are more. likely to be conservative than optimistic.

While the performance discussed above is impressive, it is important to recognize that the low heating requirement results in part from acceptance by the house of a significant amount of passive solar gain. The ability to take advantage of this solar gain without experiencing unacceptably high temperature excursions on sunny days requires a good thermal storage capability. The thermal storage must not only have an adequate heat capacity but, equally

\footnotetext{
*Electric Energy $=361 \mathrm{Btu} /{ }^{\circ} \mathrm{F}$-hour $\times 24 \times 979 \mathrm{DD}=8,482,056 \mathrm{Btu}$. $8,482,056 \mathrm{Btu} \div 3,413 \mathrm{kWh} / \mathrm{Btu}=2,485 \mathrm{kWh}$.
} 
important, it must have a sufficiently high "charging rate" and "discharging rate" to operate effectively on a diurnal basis.

The thermal storage characteristics of the Brownell LER house are discussed in detail in the following section.

5. Performance of Thermal Storage Bed. As discussed previously, the thermal storage bed was inactive (not coupled to the house) in the first part of the test period, from January 17 to March 4. Additional instrumentation was installed in the house on March 5, in the form of a 24-channel recorder. This permitted readings to be taken of nine temperatures relating to the thermal storage bed and several other temperature points as well. The points are listed in Table 9. The bed was activated on March 5 and temperature readings were recorded from then until March 31, when testing was discontinued.

Table 9

Thermocouple Locations

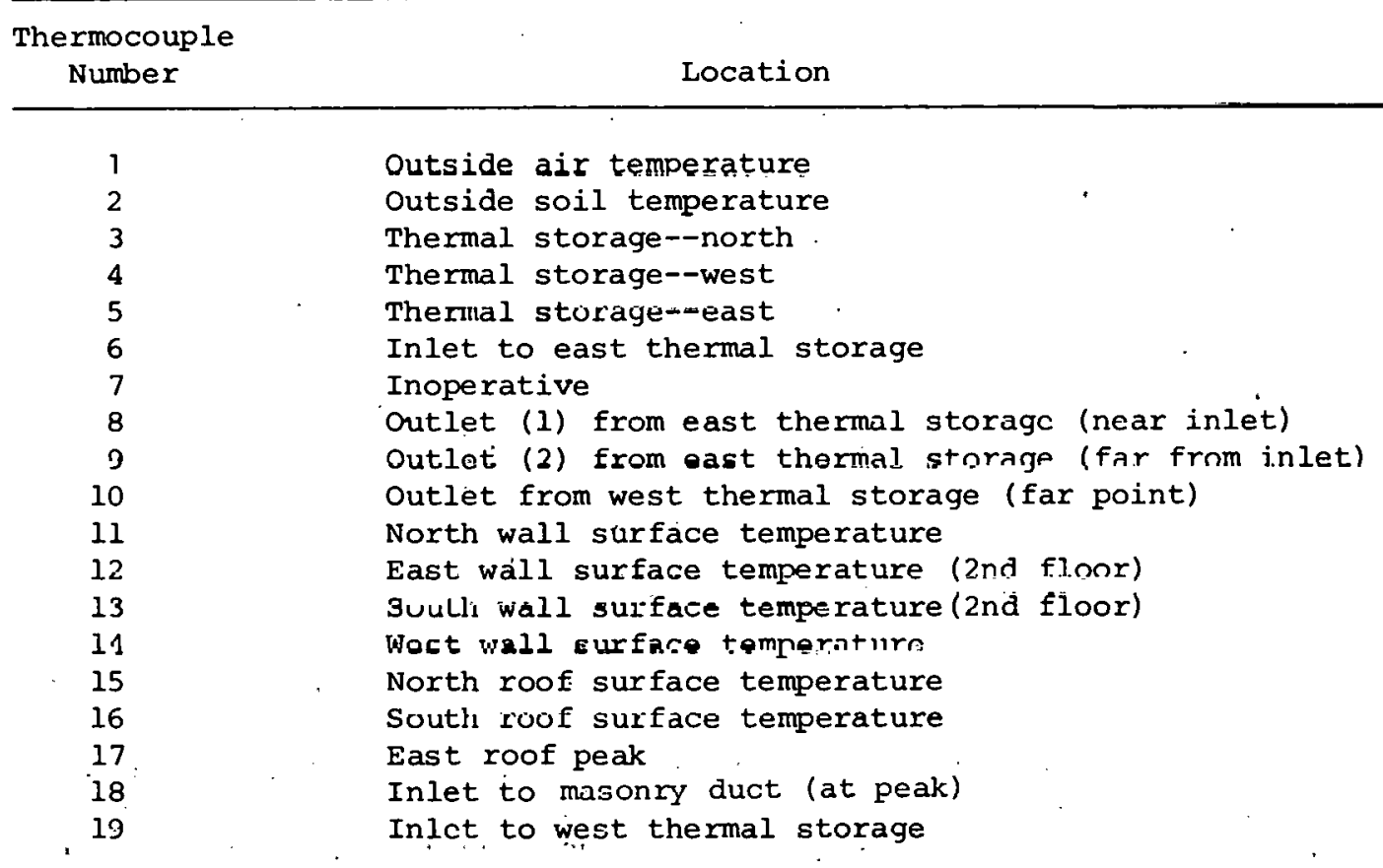

A dimensioned plan view of the thermal stornge bed and the metal ductwork in the bed in shown in Figure 20. The locations of thermocouples are shown, corresponding to the numbers in Table 9. As noted, the ducts are spaced at 4- to 6-ft intervals, and they are placed about midway down in the 2-ft thick, bed of sand. 


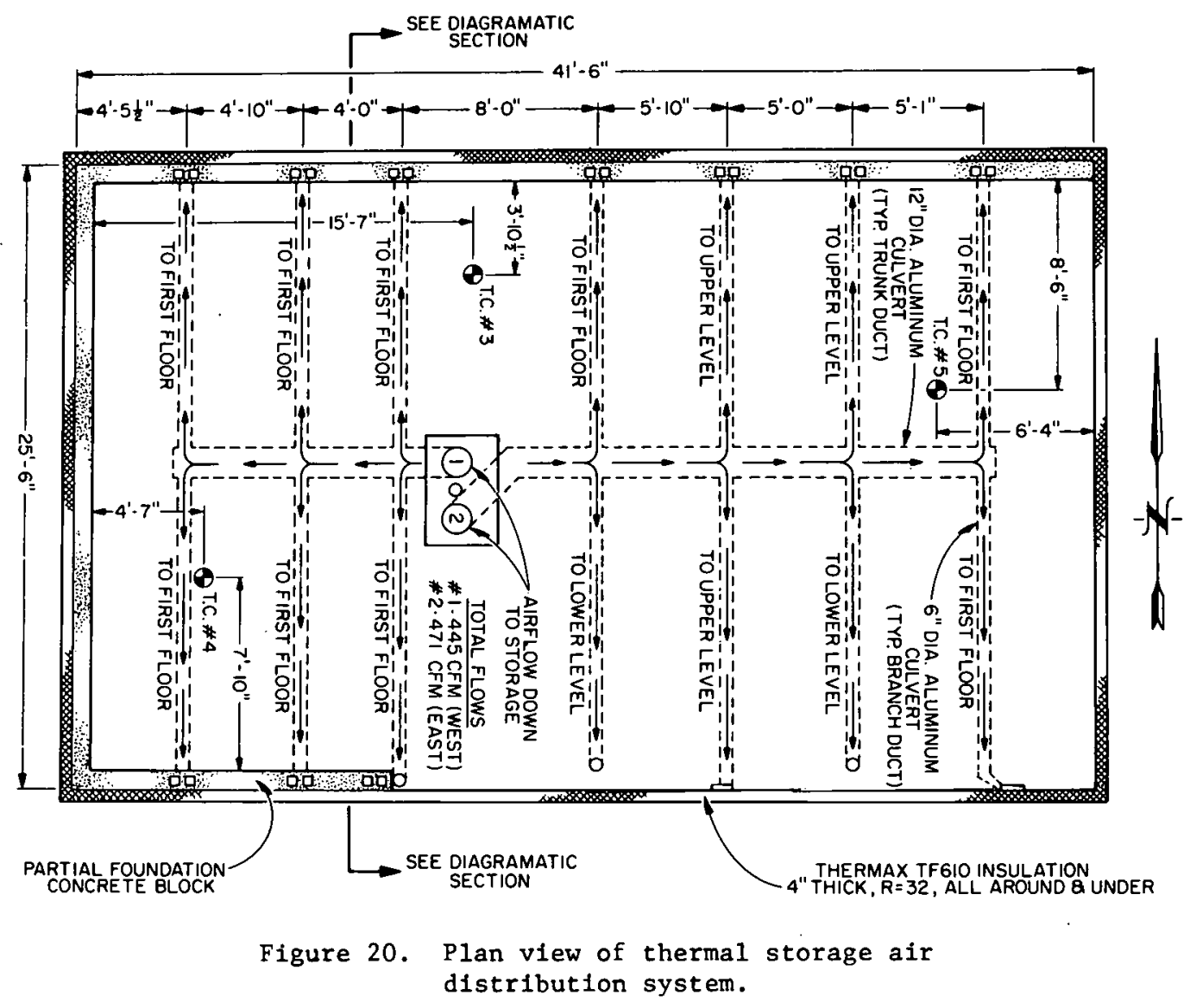


The temperatures at the three locations in the sand bed during the period March 5 to March 31, when the bed was connected to the house, are plotted in Figure 2l. Temperatures at inlet and outlet points are plotted in Figure 22 for the first week of operation of the bed, from March 6 to March 13. Figure 23 provides a plot of temperatures inside and outside the house, and heat provided by the electric heater for the same March 6 to 13 period.

As discussed earlier, the thermostat was set to maintain a nominal $60^{\circ} \mathrm{F}$ interior temperature during the entire test period. In practice, the thermostat performed a bottoming function to keep the temperature from dropping below $60^{\circ} \mathrm{F}$. The actual house temperature, as indicated in Figure 23, fluctuated on a daily cycle from around $60^{\circ} \mathrm{F}$ to $70^{\circ}$ to $75^{\circ} \mathrm{F}$.

On the basis of the observed house temperalures, the sand bed tompcrature would be expected to rise to the mean house air temperature of about. $65^{\circ} \mathrm{F}$. This would be the mean of the air temperatures which would be available to charge the bed with moderate swings about $65^{\circ} \mathrm{F}$, say in the order of $5^{\circ}$. Figure 21 shows that the bed temperature did rise from about $50^{\circ} \mathrm{F}$ on March 6 to almost $60^{\circ} \mathrm{F}$ on March 14 , but the temperature then relaxed to about $56^{\circ} \mathrm{F}$ to the end of the test period on March 3.1, though the data were not complete in the period after March 22 because of the recorder tape running out. It appears that the heat lost from the sand bed to the ground is sufficient to cause depression of the bed temperature during periods of cloudy weather.

In Figure 22, the points for thermocouple number 18 show the temperature of air entering the duct which takes air from the highest area of the house and moves it into the thermal storage bed. The temperatures for thermocouples 6 and 19 represent the air leaving the masonry supply duct as it enters the bed. Thermocouples 9 and 10 represent air leaving the sand bed. Examination of the points in Figure 22 shows a lack of any substantial mitigation of house air temperature excursions on strong solar days during the first. week of operation of the storage bed. This is particularly curious, because, during this startup period, the available temperature ditterences between the air stream and the sand bed were at a maximum, far exceeding the temperature differences which could be expected after the bed was charged and operating normally.

It can also be noted from the late morning readings of figure 22 that the temperature drop from inlet to outlct of the masonry supply ducts in the chimney is almost as great as the temperature drop from the inlet to the outlets of the entire sand bed. This is surprising.

A third appraisal of the ability of the storage bed to store heat can be made by comparing the daytime temperature rise in the house on sunny days when the storage bed was operating, with the temperature rise on sunny days when the bed was not operating. These data are shown in Table 10. As indicated, the average temperature rise with the bed operating was $13.2^{\circ} \mathrm{F}$, compared with $13.9^{\circ} \mathrm{F}$ when the bed was not connected to the house. The difference is very small. 


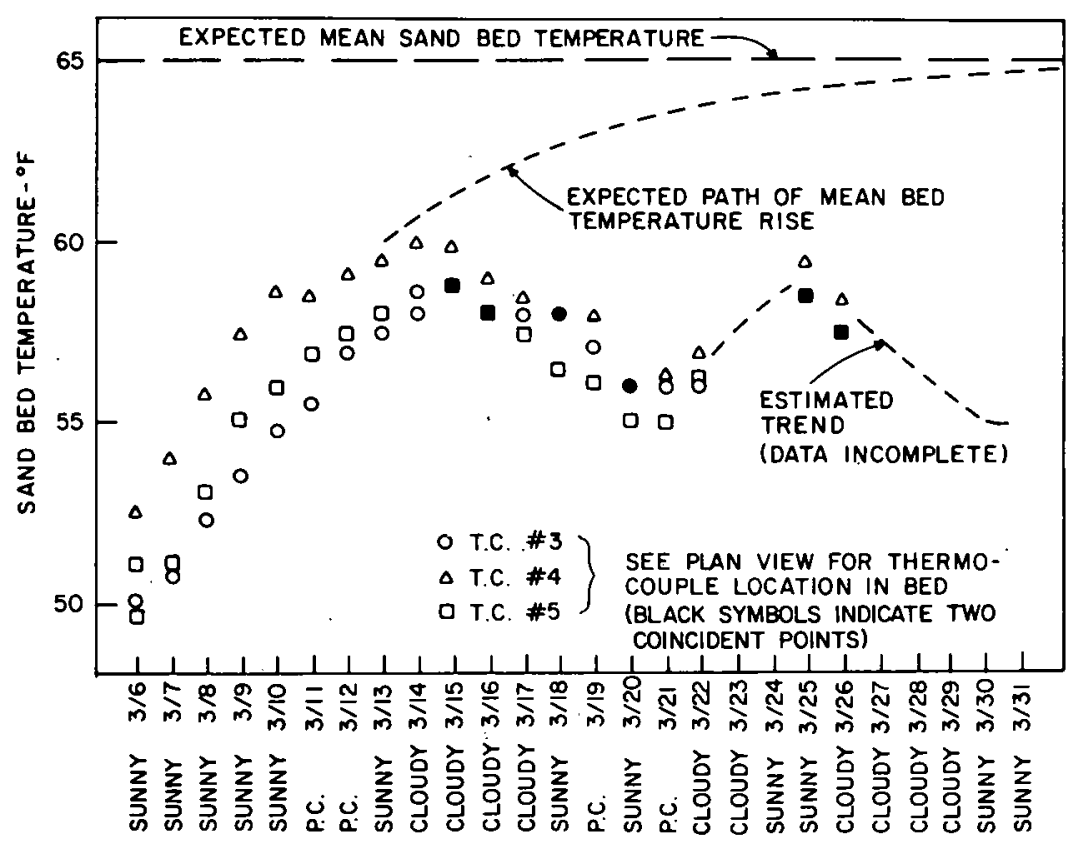

DATE AND WEATHER CONOUITIÓN

Figure 21. Recorded sand bed temperatures, $3 / 6 / 78$ to $3 / 31 / 78$. 


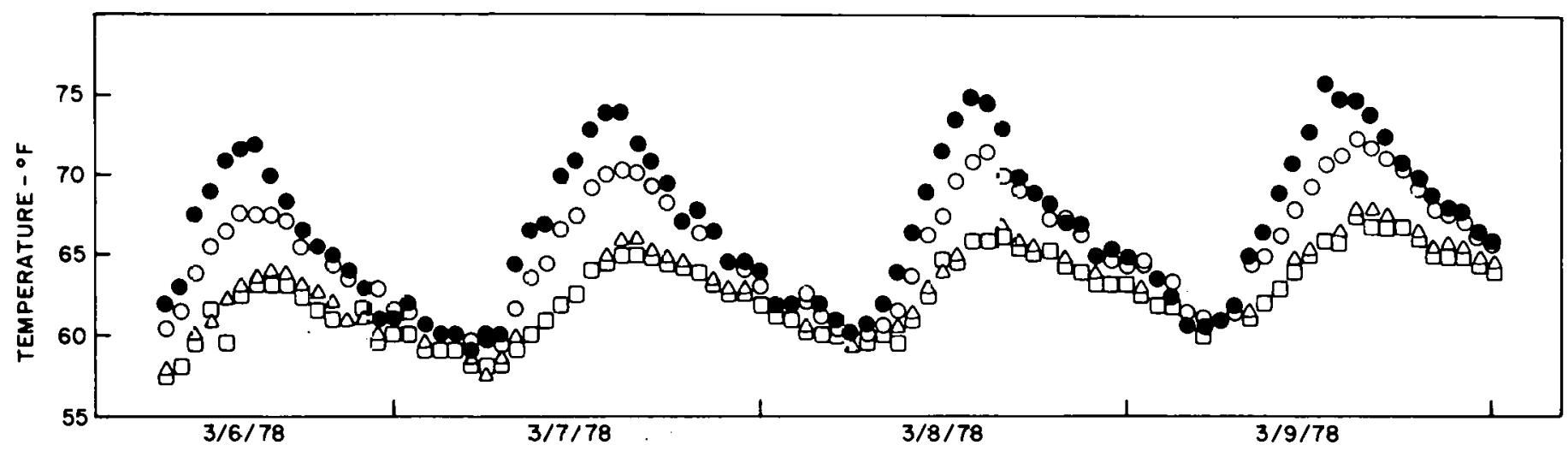

- T.C. \# 18 INLET TO MASONRY SUPPLY DUCT (AT ROOF PEARI

O T.C. \# 6 a 19 AVERAGED, INLETS to the rmal storage

$\triangle$ T.C. \# 9 DUTLET EAST THËRAL STORAGE (D SCHAFGE PONT AT FIRST FLOOR)

D T.C. \# 10 OUTLET WEST THERMAL STORAGE (DISCHARGE ROINT AT FIRST FLOOR)

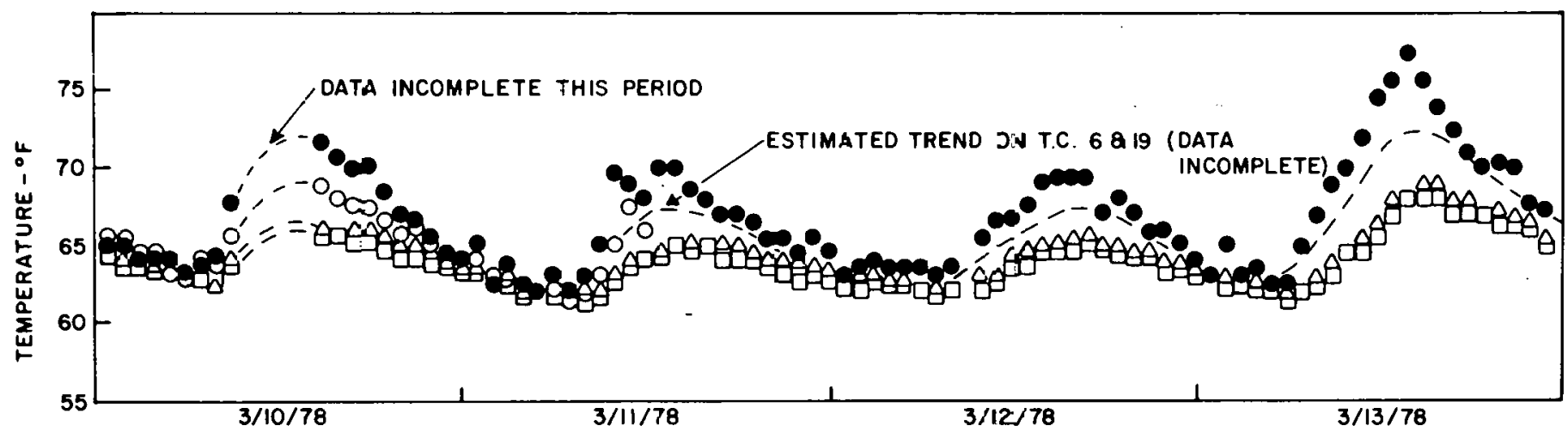

Figure 22. Measured thermal storage system performance data, $3 / 6 / 78$ to $3 ; 31 / 78$. 


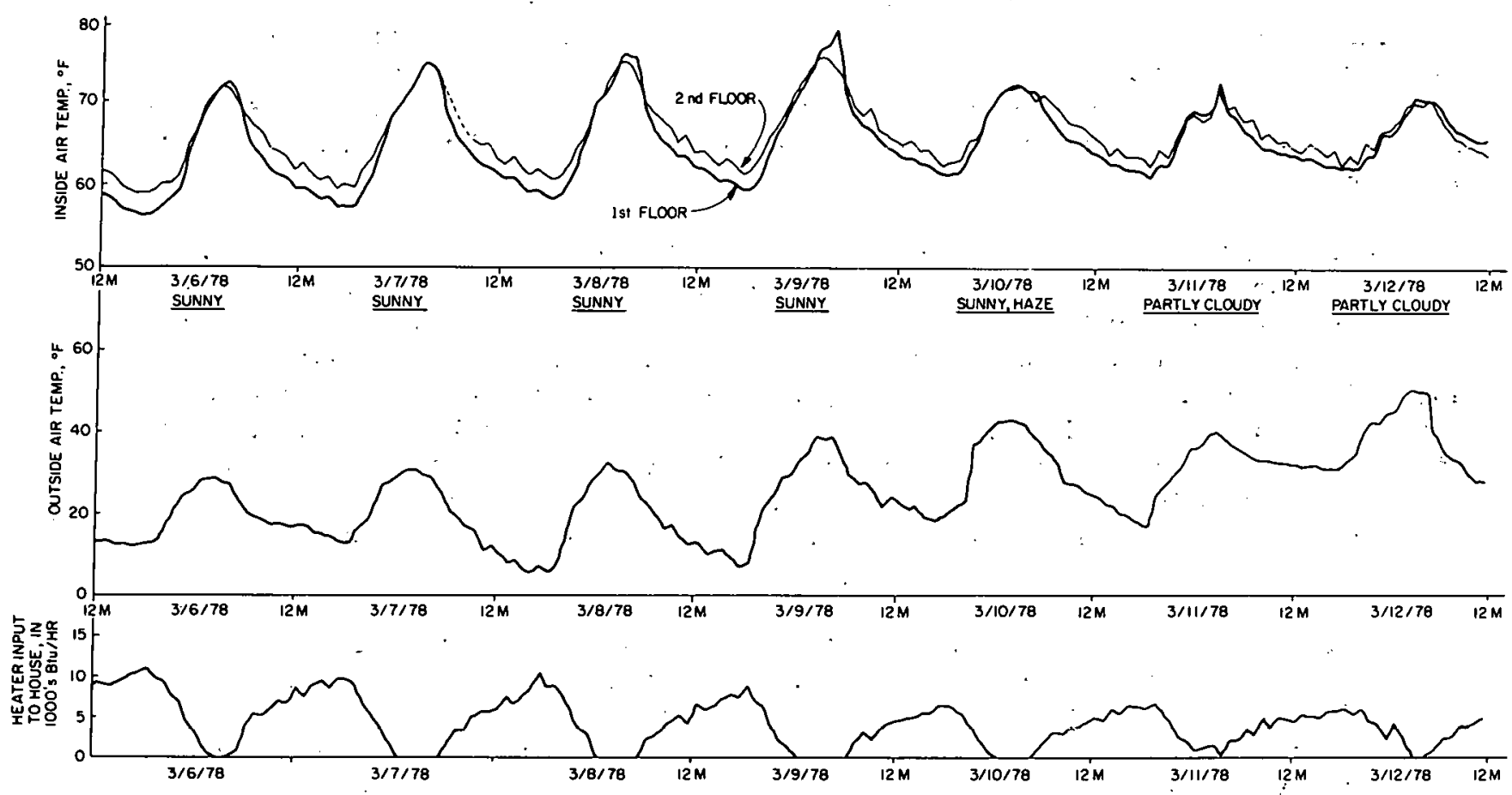

Figure 23. Measured house thermal performance data, week of $3 / 6 / 78$ to $3 / 13 / 78$.

\section{Table 10}

Interior Temperature Rise on Sunny Days*

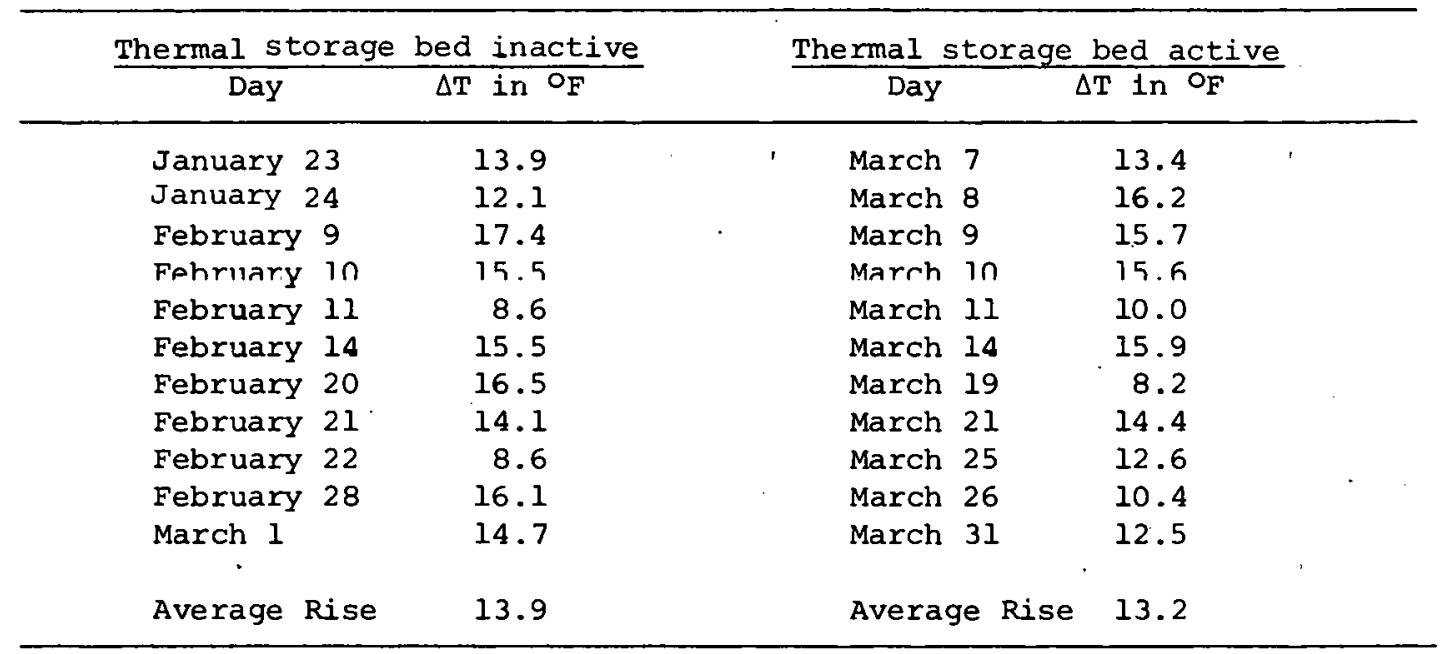

*Temperature rise from 0630 to 1430 from Table 5. 
The implication of these factors is that either the coupling between the house and bed was poor, or the rate of heat transfer into the bed was inadequate, or both. Poor coupling could be due to insufficient airflow to the bed from the house and a relatively low film heat transfer coefficient between the air and duct wall. The rate of heat transfer into the sand is directly related to the film coefficient and the total heat transfer surface area in the ducts.

Referring to Figure 20, the inlets to the thermal storage bed from the masonry supply duct are indicated by the trunk ducts marked 1 and 2 . Tests were conducted on both System \#1 (west) and System \#2 (east) to determine the airflow rates and static pressure drops across each bed system. Since each of the systems had its own fan, static pressure and airflow could be measured right at the bed inlets, using a Dwyer Pitot tube velometer. Each of the fans had separate continuously variable speed controls. During January through March, each fan was set at about $50 \%$ of the control range. Flow tests were performed at this setting and also at higher and lower settings.

Figure 24 is a plot of the east and west system flows versus static pressure. The range available from the controls is. shown as a darkened portion of each curve. The test points mentioned above are shown. The east system had a total flow of $471 \mathrm{CFM}$ at a static pressure of 0.165 in. $\mathrm{H}_{2} \mathrm{O}$, while the west system flow was $445 \mathrm{CFM}$ at 0.28 in. H. O. These figures were taken at the $50 \%$ control setting.

The notable difference between the systems is the apparent higher resistance to flow in the west system. This was probably due to the slightly higher flow velocities in the branch ducts and the resistance of the risers due to rough and partially grout-filled concrete block cores. High resistance terminations of the branch ducts in both systems could adversely affect the efficiency of heat transfer to the bed.from these ducts by reducing flow velocity and, consequently, the film coefficient of heat transfer.

Calculations were performed of the achievable turbulent film coefficient for a 6-in. round duct at a variety of airflow rates. The results of these calculations are shown in Figure 25. To achieve a duct wall temperature of about $90 \%$ of the free stream temperature, the film coefficient should be about $6.0 \mathrm{Btu} / \mathrm{hour}-\mathrm{ft}^{2} \mathrm{O}_{\mathrm{F}}$ for a bed using sand with a thermal diffusivity of $\alpha=0.105 \mathrm{ft}^{2} /$ hour and a thermal conductivity of $0.19 \mathrm{Btu} /$ hour-o $\mathrm{F}-\mathrm{ft}$. For the typical branch flow in each system the film coefficients appear to be higher, 6.35 for the east system and 7.6 for the west system. These high film coefficients from flow, combined with the turbulence induced by the spiral wall corrugations in the ducts, indicate that the duct wall temperatures can be considered to be essentially equal to the airflow temperatures.

The more than ample spacing of the branch air ducts as shown in Figure 20 would suggest that the sand bed might be treated as a semi-infinite solid for heat transfer analysis purposes. An evaluation of the time variant temperature distribution around a 6-in.-diameter duct imbedded in sand is shown 


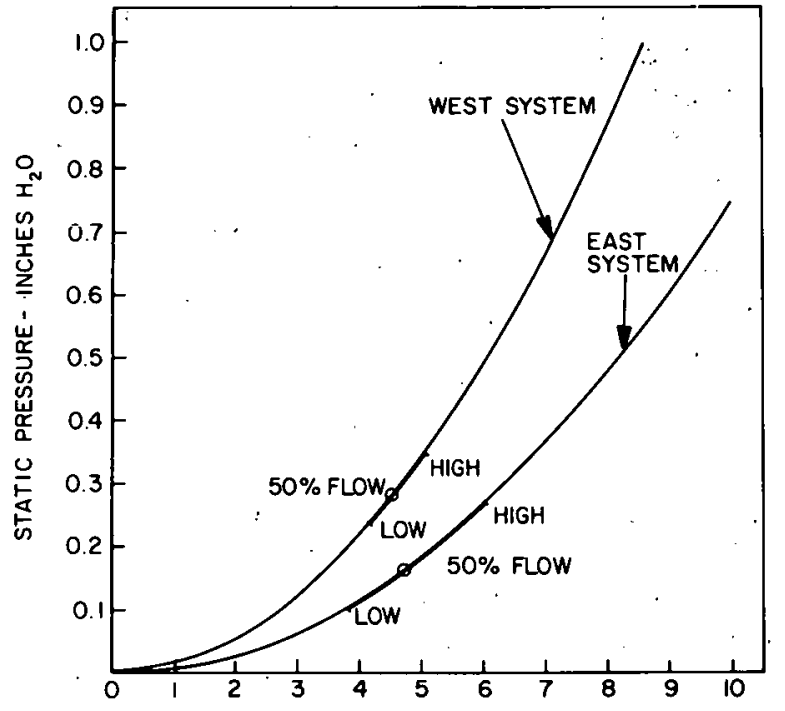

TOTAL SYSTEM FLOW - CFM IN HUNOREOS

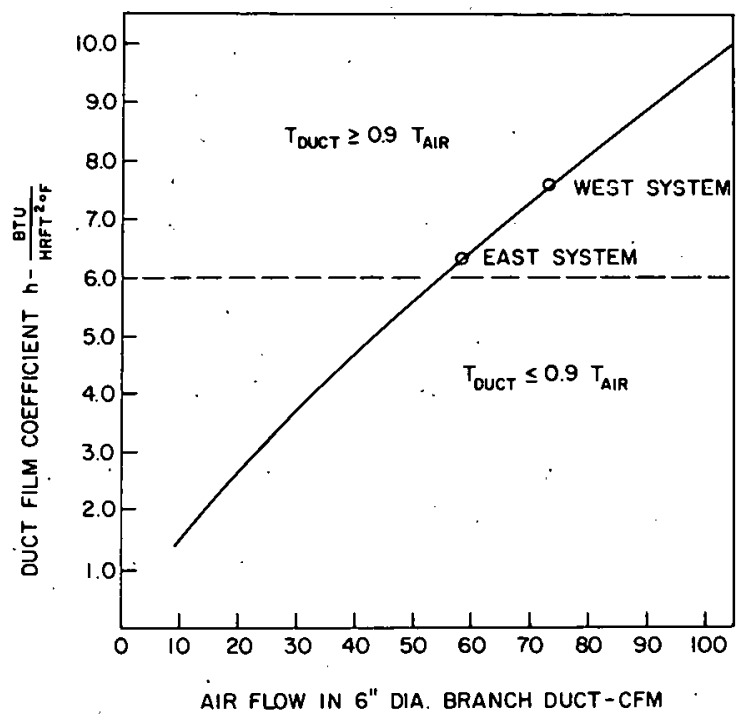

Figure 25. Branch duct air film coefficient.

Figure 24. Air distribution system performance.

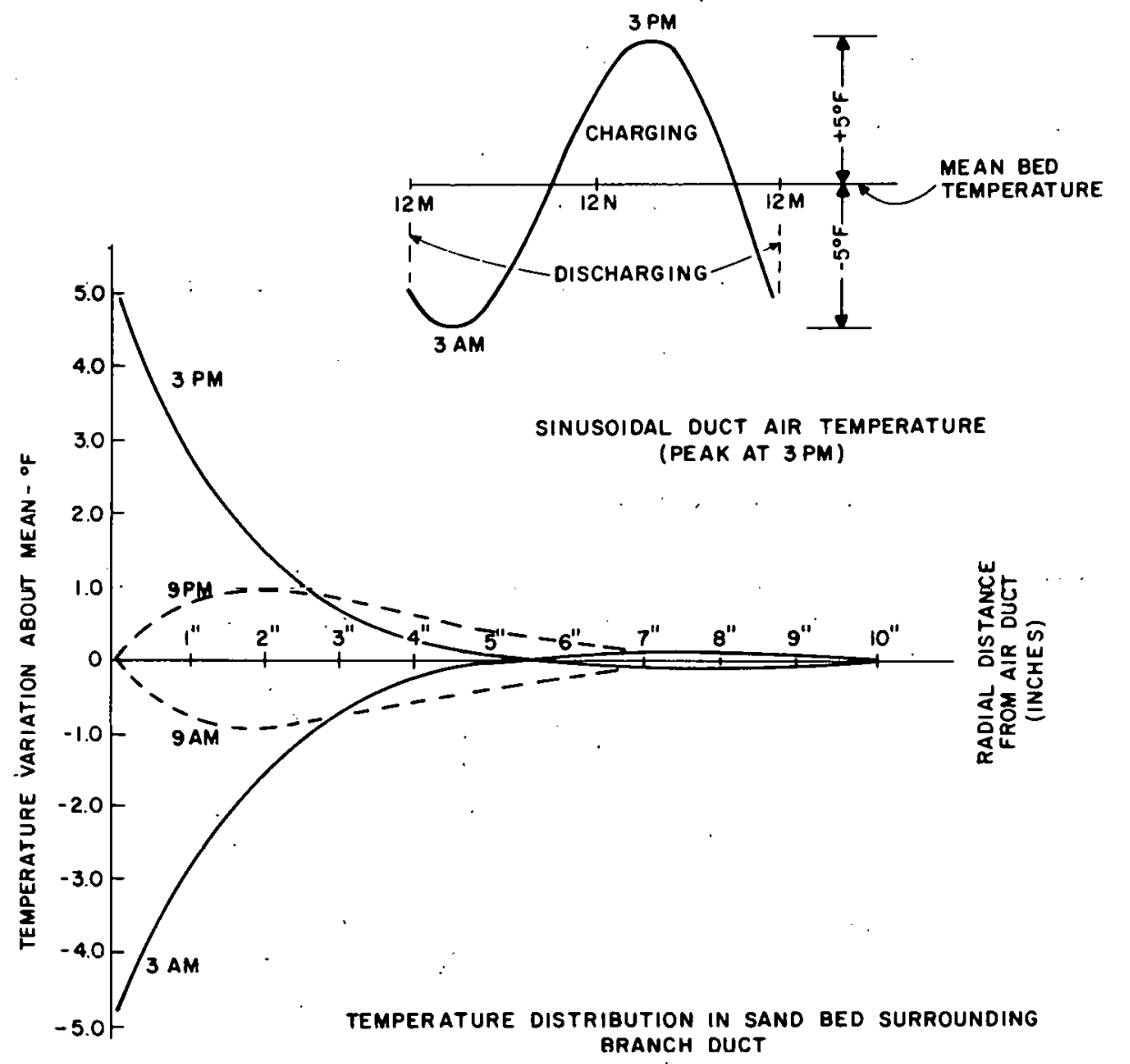

Figure 26. Sand bed and duct air temperature variation. 
in Figure 26. The air temperature in the branch duct varies in a sinusoidal approximation of the daily house air temperature swing. The mean bed temperature should equal the mean house air temperature at all locations in the bed well away from the duct. Under these conditions, the bed charges during positive swings in duct air temperature and discharges during negative swings in duct air temperature. Under the influence of these daily fluctuations it is interesting to note, from Figure 26, that the sand temperature disturbances are very small at 8 to 10 inches from the duct wall. In fact, most of the storage activity occurs within a distance of 6 inches from the duct wall. There are similarities between large sand bed heat exchange and earth heat exchange. For information on earth heat exchange, see refs. 13 and 14 .

In order to permit relaxation of the sand bed temperature to greater depths during periods of little or no charging (cloudy days), the mean house temperature would have to be depressed for periods longer than 12 hours. This longer term storage utilization would lead to excessively long periods of house operation below the comfort range to obtain a relatively small hourly heat rate extraction from the bed.

The cumulative heat flux into or out of a semi-infinite solid under the influence of periodic surface temperature variation can be calculated using the following relationship ${ }^{15}$ :

where:

$$
Q_{1}=2 A_{1} t_{01} \sqrt{\mathrm{kC} w / \omega}
$$

$$
\begin{aligned}
& \mathrm{A}_{1}=\text { heat transfer surface area, } \\
& \mathrm{t}_{0 \mathrm{l}}=\text { peak surface temperature excursion, } \\
& \mathrm{k}=\text { thermal conductivity of sand }=0.19 \mathrm{Btu} / \mathrm{hour}-\mathrm{ft}-\mathrm{U}_{\mathrm{F},} \\
& \mathrm{C}=\text { specific heat of sand }=0.19 \mathrm{l} \mathrm{Btu} / \mathrm{lb}-\mathrm{O}_{\mathrm{F}}, \\
& \mathrm{w}=\text { weight Hensity } n \\
& \omega=\text { cycle rate in radians per hour }=2 \pi / \text { period. }
\end{aligned}
$$

For the calculation, $A_{1}$ was set equal to $1 \mathrm{ft}^{2}, t_{01}:=1 \dot{\circ}_{\mathrm{F}}$ and the perind set at 24 hours reflecting the diurnal cycle. Then the equation becomes

$$
\begin{aligned}
\because & Q_{1}=2(1)(1) \sqrt{\frac{(0.19)(0.191)(94.6)}{0.262},} \\
Q_{1} & =7.24 \mathrm{Btu},{ }_{\mathrm{F}-\mathrm{ft}^{2} .}
\end{aligned}
$$

The heat exchange surface areas for duct systems 1 and 2 were calculated as 146 and $215 \mathrm{ft}^{2}$ respectively for a total of $361 \mathrm{ft}^{2}$. 
The thermal storage capacity of the existing Brownell sand bed, on a diurnal cycle, can then be calculated as follows:

$$
\text { Storage Capacity }=7.24 \mathrm{Btu} /{ }^{\circ} \mathrm{F}-\mathrm{ft}^{2} \times 361 \mathrm{ft}^{2}=2,600 \mathrm{Btu} /{ }^{\circ} \mathrm{F} .
$$

This calculated value of the "charging rate" or thermal capacity of the storage bed is quite low compared to the actual passive diurnal thermal capacity of the individual structural elements shown in Table 6. This is somewhat disappointing considering the effort expended to achieve this storage. It does, however, offer a clue to the apparent inability of the sand bed to charge to the expected mean temperature during the month of March as shown in Figure 21.

An analysis was made of: the storage bed performance on a typical sunny day in March, with an average daytime outside air temperature of about $32^{\circ} \mathrm{F}$. It was assumed that the sand bed was already charged to a mean temperature of $65^{\circ} \mathrm{F}$ and the duct air temperature experienced a daily. peak to trough variation of $10^{\circ} \mathrm{F}$, or $\pm 5^{\circ} \mathrm{F}$ about the mean. Under these idealized conditions $t_{01}$ would be $5^{\circ} \mathrm{F}$ and the total heat transfer into storage during the day would have been:

$$
\text { Heat Stored }=2,600 \mathrm{Btu} /{ }^{\circ} \mathrm{F} \times 5.0^{\circ} \mathrm{F}=13,000 \mathrm{Btu} .
$$

From Table A-1, in the Appendix, the normalized heat loss from the sand bed walls and floors through the soil to grade level would be about $28.7 \mathrm{Btu} /$

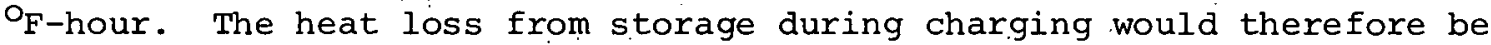

Heat Loss for 12 hours $=28.7 \mathrm{Btu} /{ }^{\circ} \mathrm{F}-\mathrm{hr} \times 12 \mathrm{hr} \times(65-32)^{\circ} \mathrm{F}=11,300 \mathrm{Btu}$.

Thus, it would appear that little net heat would be stored in the bed. In fact, over the next 12 hours, the combination of a demand for heat by the house air and the heat loss to the soil would cause the sand bed mean temperature to drop. This drop would continue until an equilibrium would be reached between the heat stored and the heat lost in a diurnal cycle. Unfortunately, this probably would occur at a mean bed temperature below the mean house temperature, rendering the bed relatively useless for diurnal storage, as appears to be the case during the March 1978 test period.

One approach to improving the "charging rate" of the Brownell storage system, while retaining the sand bed configuration, would be to increase the heat transfer surface area. Such a system is shown in the lower part of Figure 27. This system utilizes the same size branch ducting as the existing system but. decreases the spacing between ducts. from four to six. feet to about two feet on centers. This spacing permits a more effective utilization of the sand within the same overall bed volume. The end view of the bed reveals the double-tiered duct arrangement to permit achieving a total transfer surface of $1,573 \mathrm{ft}^{2}$, as compared to $361 \mathrm{ft}^{2}$ in the existing bed.

The effective "charging rate" or storage capacity of such a bed during a period of one-half the diurnal cycle would be 

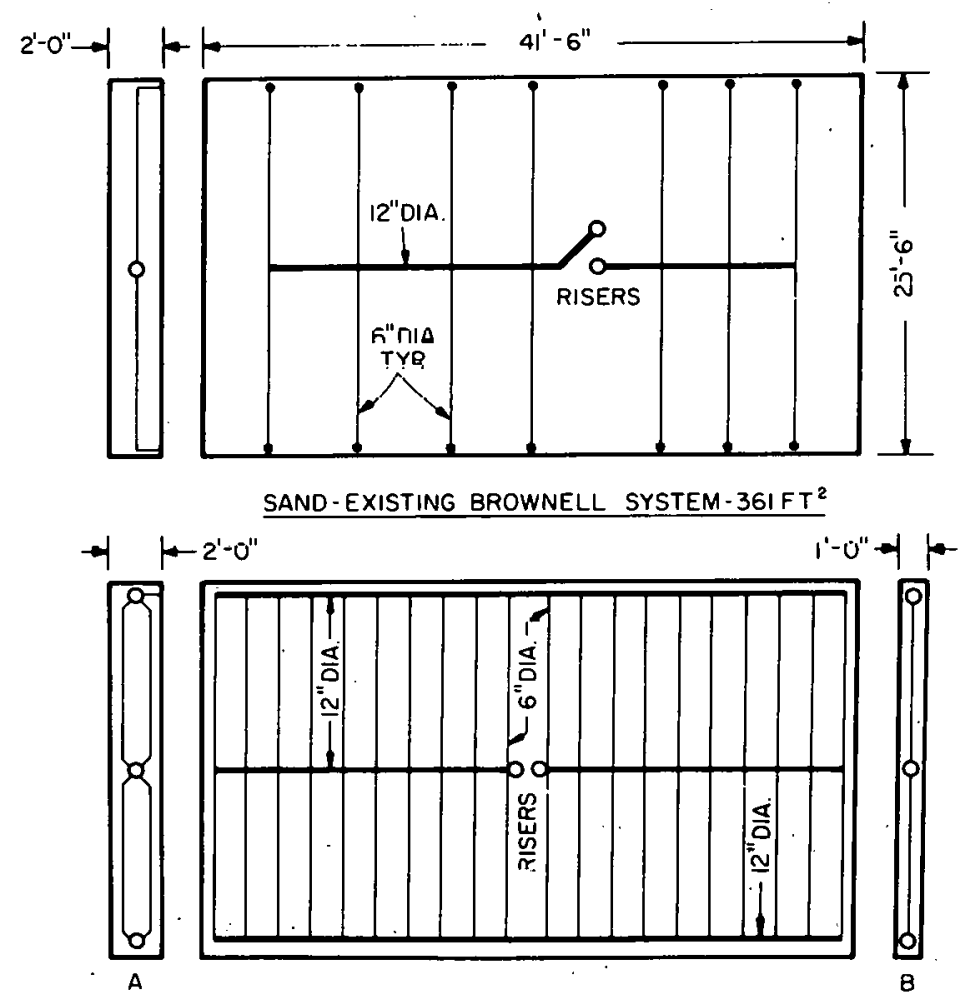

(A) SAND - ENHANCED BRQWNELLLSYSIEM-1573 EI

(B) CONCRETE - MODIFIED BROWNELL SYSTEM - $787 \mathrm{FT}^{\text {? }}$

Figure 27. Diagrammatic view of existing and modified thermal storage systems. 
Storage Capacity $=7.24 \mathrm{Btu} / \mathrm{O}_{\mathrm{F}-\mathrm{ft}^{2}} \times 1,573 \mathrm{ft}{ }^{2}=11,400 \mathrm{Btu} / \mathrm{O}_{\mathrm{F}}$.

The total airflow to this system would have to be about $6,000 \mathrm{CFM}$ to maintain each branch leg at $75 \mathrm{CFM}$. This would insure an air film coefficient of at least $7.7 \mathrm{Btu} / \mathrm{hour}-\mathrm{ft}^{2}-\mathrm{O}_{\mathrm{F}}$. This flow could be reduced by 50 percent to 3,000 CFM, however, and still achieve 80 percent of the above heat transfer capacity.

Another method of improving the storage system would be to change both the duct arrangement and the storage material. Concrete could be used instead of sand. The storage bed could then serve as the structural slab in the basement. This hypothetical storage system'is also shown in Figure 27. The duct sizing is the same as in the $A$ system and the plan arrangement is the same, but in this case the bed or slab is only one foot thick. For concrete, the cumulative half cycle heat storage in a semi-infinite solid is calculated. to be $13.6 \mathrm{Btu} /{ }^{\circ} \mathrm{F}-\mathrm{ft}^{2}$, or almost twice as great as the 7.24 figure calculated for sand. The B system has a transfer surface area of $787 \mathrm{ft}^{2}$. The "charging rate" or storage capacity at a total flow of 3,000 CFM is, therefore,

$$
\text { Storage Capacity }=13.6 \mathrm{Btu} /{ }^{\circ} \mathrm{F}-\mathrm{ft}^{2} \times 787 \mathrm{ft} t^{2}=10,700 \mathrm{Btu} /{ }^{\circ} \mathrm{F} .
$$

Thus, the concrete B system achieves almost the same "charging rate" as the improved sand system at half the size and airflow. Obviously, these enhanced systems and other possible systems must be evaluated for cost effectiveness against the original system, which was designed for ease of construction with low initial cost.

The "charging rates" of the various storage systems are plotted in Figure 28 as a function of the air to sand temperature differential. The performance of the enhanced Brownell sand bed is shown at four different airflow rates. The performance of the modified system at 3,000 CFM is about the same as that of the enhanced sand bed at 6,000 CFM.

Table 11 provides a comparison of the ultimate storage capacity (given infinite charging time) of the three storage beds and the amount of heat they can accept in a 24-hour cycle. The figures indicate that, while only 8 percent of the existing Brownell storage bed thermal capacity is utilized in a diurnal cycle, that figure improves to 38 percent if the duct area is increased (enhanced bed). With the concrete bed, 61 percent of the ultimate storage capacity is available on a diurnal basis.

In order to compare the natural (integrated into the structure) thermal storage capacity of the Brownell LER house, its active thermal storage system, and other possible systems discussed above, a parameter was chosen against which each thermal storage capacity can be examined. This parameter is the volume of material required to achieve the storage capacity in a daily cycle. Figure 29 provides this comparison. The diurnal thermal storage capacity of each system is plotted against dedicated storage volume. One additional scheme, a rock bed, is represented for purposes of comparison. The rock bed system of Calthorpe, Wilcox, and Stauffer (Farallones 


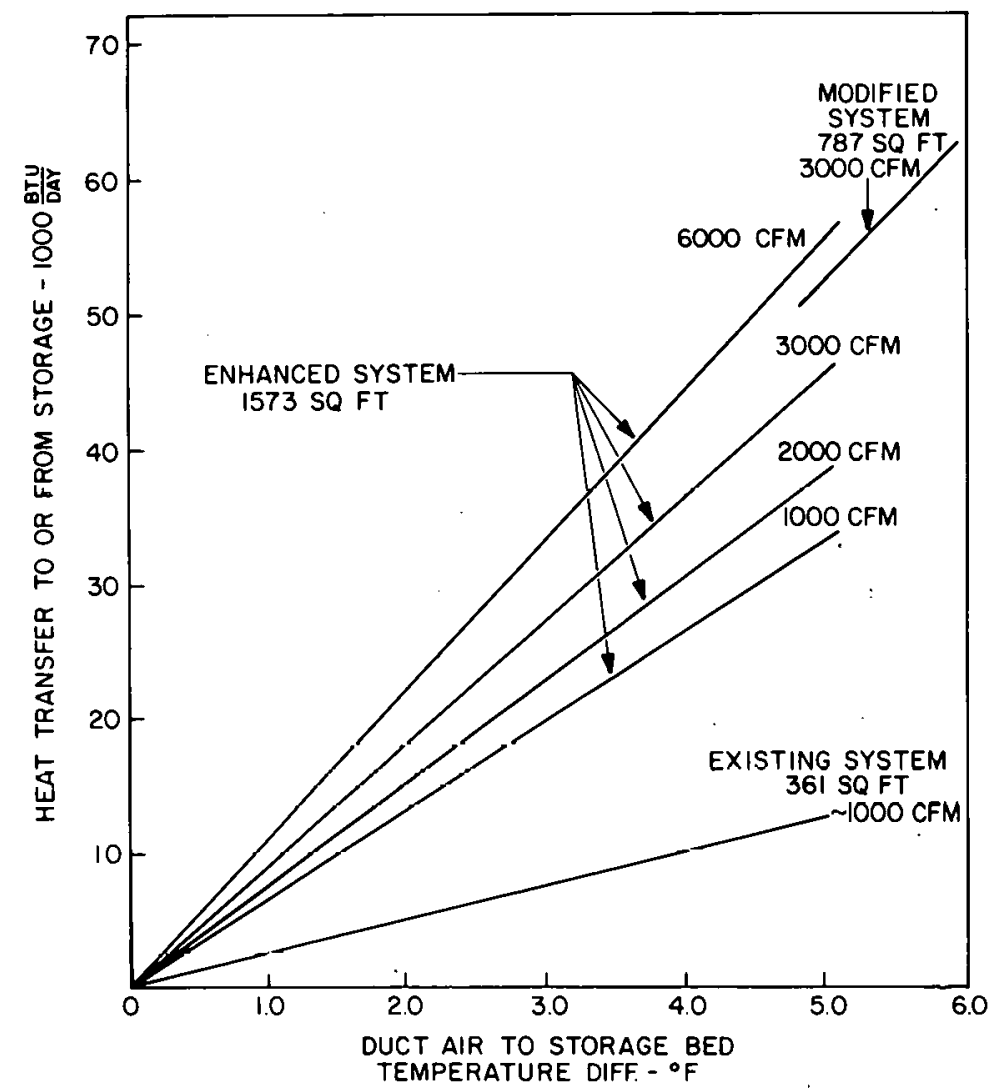

Figure 28. Comparative performance curves for existing and modified thermal-storage systems.

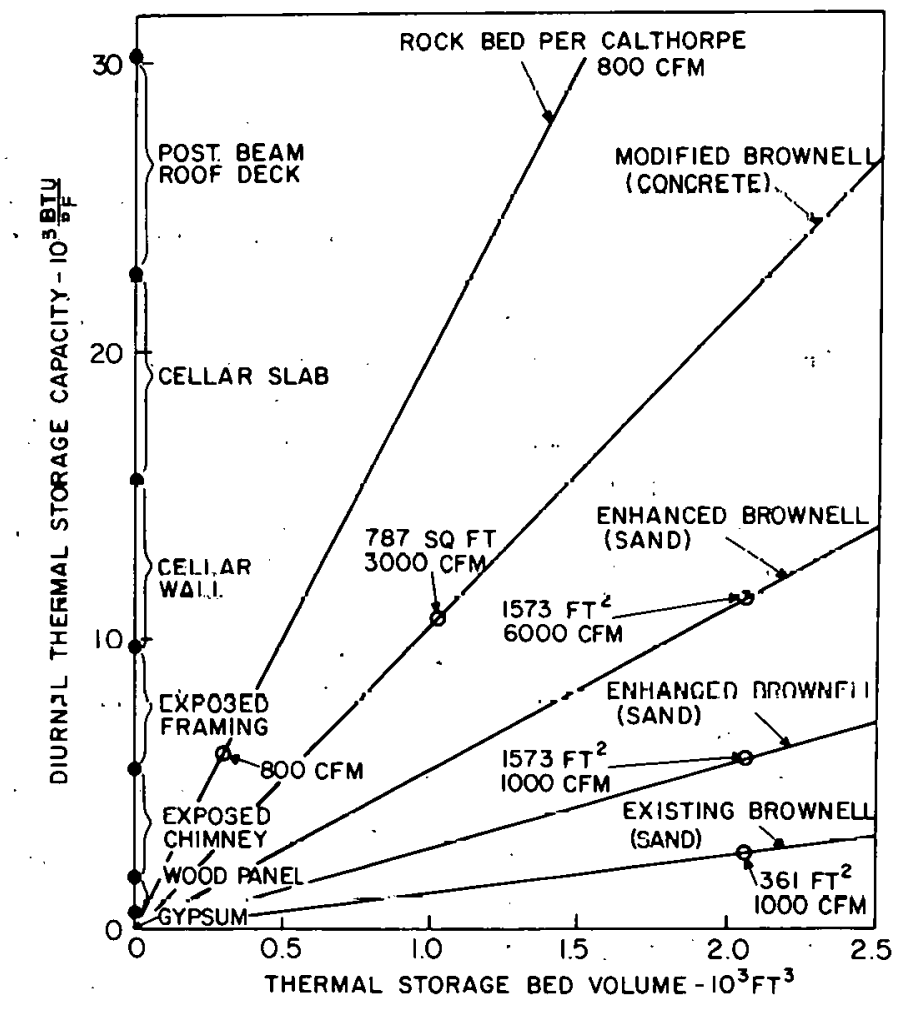

Figure 29. Thermal capacity vs. storage volume for varfous storage bed designs. 
Table 11

Diurnal storage Capacity Summary

Active thermal storage using forced convection with periodic temperature variation over 24 hours

\begin{tabular}{lccccc}
\hline $\begin{array}{l}\text { Storage bed } \\
\text { and material }\end{array}$ & $\begin{array}{c}\text { Total } \\
\text { wt, lb }\end{array}$ & $\begin{array}{c}\text { Ultimate } \\
\text { capacity } \\
\text { Btu/ }{ }^{\circ} \mathrm{F}\end{array}$ & $\begin{array}{c}\text { Half-cycle } \\
\text { capacity } \\
\text { Btu/ }{ }^{\circ}\end{array}$ & $\begin{array}{c}\text { Effective } \\
\text { wt, lb }\end{array}$ & $\begin{array}{c}\text { \&tili- } \\
\text { ization }\end{array}$ \\
\hline $\begin{array}{l}\text { Existing bed } \\
\text { (sand) }\end{array}$ & 176,000 & 33,600 & 2,600 & 13,600 & 8 \\
$\begin{array}{l}\text { Enhanced bed } \\
\text { (sand) }\end{array}$ & 155,300 & 30,000 & 11,400 & 60,000 & 38 \\
$\begin{array}{l}\text { Modified bed } \\
\text { (concrete) }\end{array}$ & 111,800 & 17,400 & 10,700 & 68,600 & 61 \\
\hline
\end{tabular}

Institute, California) appears to have significant diurnal thermal capacity and volume advantages over all the other active systems discussed.16 Also plotted, at the left, is the storage capacity of the structural elements of the house. The total diurnal capacity of all elements is about 30,000 Btu/ OF. The rock bed matches this capacity in a volume of about 1,500 cubic feet. By contrast, the best of the other systems, using concrete, requires almost twice that volume, and a much higher airflow. The capacity of the existing Brownell storage bed is less than the cumulative capacity of the house's exposed gypsum, wood paneling, and chimney. The sand bed system with a fourfold increase in duct area (enhanced Brownell system) and a sixfold increase in airflow, stores only about $11,000 \mathrm{Btu}$ for each degree difference between air and sand temperatures, on a diurnal basis. This is only about one-third the storage capacity available in the exposed house structure and finishing materials.

The slructure of a rock bed, with its natural system of multiple air passages and the large ratio of exposed surface, holds many obvious benefits, but there may be some problems with rock beds in long-term service. More work should be done in comparing active thermal storage systems in order to give the designer the tools necessary to select and evaluate the most ideal storage system for his particular application.

\section{B. Architectural Features}

The thermal performance data illustrate how well the Brownell residence outperforms the conventional $2 \times 4$ stud-framed tract residence presently being constructed in large numbers throughout the country. The low breakeven temperature adds reinforcement to an ever increasing body of evidence, 
which indicates that large amounts of energy can be saved with relatively small technological construction modifications. 17

Although Brownell's house does not represent a totally radical departure, there are several major areas of innovation in which this house differs from its conventional counterpart. These major areas are the structural framework, the exterior building envelope or skin, and the mechanical systems.

The massive post and beam structural system, utilizing heavy 6 x 6 timber posts with $6 \times 8$ beams in a 4-ft module, is a system that has been used for many years in rural areas where timber is readily available. While this system is quite appropriate for a rustic Adirondack mountain retreat with considerable regional charm, its application is limited. Utilization for mass housing in urban or suburban areas would be costly in terms of labor and materials. The elimination of interior bearing walls does offer layout flexibility. However, thero axe probloms with regard to structural. wind bracing, routing of services, and general lack of flexibility to accommodare future renovation which have, in the past, precluded widespread implementation of this system. It seems likely that Brownell's performance can be achieved in large part with a more conventional framing system.

The structural system used by Brownell is not significant to the thermal performance of the house, except that it provides additional therilal storage mass and allows the building to be completely sheathed in insulation attached to the exterior, with no thermal short circuits at framing meituers or services. The usual wall cavity and fiber glass installation problems are elim- inated. Careless workmanship in the installation of batt-type insulation in cavities provides void spaces or passages where cold, wind-driven air can penetrate the exterior siding and circulate at low velocities. This degradation, together with moisture absorption and lie sesultant condensation buildup over the heating season, probably accounts for the inability of conventional wall systems to perform in accordance with hot box test ratings. Convection inside the wall cavity, as well as air leakage in and out, have a large adverse effect on thermal performance.

The building envelope or skin is the most important element in Brownell's system. The thermal integrity of his exterior wall with its low infiltration rate and high insulation value enables the harvesting of various energy sources such as solar gain, living cycle input, metabolic lodd, and wood stove heat. These energy sources might otherwise be considered inconsequential. There are construction problems, however, which need solution. One of the problems is the lack of a continuous nailable sheathing base which would allow for the application of the large variety of exterior finishes that the mass markct roquires. Another is that the foamed insulation panels are nonstructural other than in compression, requiring the insertion of wood nailers to accommodate siding options. Also, careful attention to detail in construction is absolutely essential.

The glass-reinforced polyisocyanurate foam, with 1 -mi.1 foil facing and an $R$ value of 8 per inch, is obviously a superior thermal insulation. Its en- 
closed cell structure together with foil on both sides provides a very effective barrier to the passage of moisture or air. It will burn, however, if exposed to a fire of sufficient heat, and has a UL flame spread rating of 25 with a smoke developed rating of 110-145 per 1-in. thickness. For those unfamiliar with these ratings, they are based on 100 for red oak. Polyisocyanurate sheathing (Thermax) complies with the three model building codes BOCA, CBO, and SBCC for certain concealed applications installed behind 1/2-in. type- $x$ gypsum board to protect the interior. Also, the durability of the adhesive duct tape used to seal the panel joints is open to question. A better, more permanent system of sealing would be desirable. Brownell's experience to date has shown duct tape to be superior to the foil-faced tapes recommended for this application by the manufacturers.

The mechanical systems employed by Brownell represent another important area of innovation. For purposes of discussion, they include the thermal mass sand bed under the slab with its internal duct work system, the vertical central mass and its circulation system, which is combined with the chimney, and the wood stove. From an architectural standpoint, this arrangement is quite restrictive since it is dependent on an open plan for collection and recirculation of heated air, or will require duct work if an open plan is not used. The open plan with a two-story living room functions very well in this case but is not appropriate for a smaller, more conventional floor plan where space is at a premium. The central masonry mass, which houses the return air ducts to the sand bed and the chimney flue, is quite restrictive in a planning sense since it requires a central location. A protected weather vestibule entrance has not been provided. It would seem to be desirable in view of the considerable attention given to control of infiltration.

The house does not have a permanent auxiliary heating system. The 4-kW electric heater was installed by Brownell as a surrogate means of providing supplemental heat, and was used by BNL to facilitate performance monitoring of the house. Individual electric baseboard space heaters would be an appropriate selection as a permanent backup system and, with the wood-burning stove, might be an optimal system.

There is a possibility of contamination of the duct work system or the sand mass itself either by liquid leakage from within the house or by rodents or other sinall animals inside the ducts. The sand bed also might possibly sustain some form of growth, though it is not considered likely. It would be difficult to investigate a contamination problem should one develop, without providing floor access panels.

The tightness of the building envelope, with the resultant low infiltration rate, is a definite energy saver. However, the air quality seems dependent on incidental door opening and the owner's operation of the kitchen fan or windows. Infiltration rates are presently being restudied and new codes are being developed based on minimum health-related requirements. Brownell's system, with low infiltration, high humidity, and continuous recirculation through a duct work system, which could itself become contaminated, has a potential for health hazards which deserves more study. Brownell has made provision for and recommends use of electronic air cleaning in the LER house. 
Investigations conducted in Great Britain on acceptable levels of ventilation have led to a minimum standard of one-half air change per hour. ${ }^{18}$ This rate is consistent with that recommended in the latest studies in this countiy. For a house with as little infiltration as Brownell's, it might be advisable to consider a ventilation system incorporating heat exchange between the exhaust air and the fresh intake air.19,20 Mitsubishi Electric Company has developed a clever heat exchanger for residential use which is now being introduced in the United States. It employs specially treated paper heat transfer sections which are capable of exchanging latent heat (humidity) as well as sensible heat.

The large areas of glass on the south elevation allow for considerable solar gain. It would be helpful if more of this solar gain impinged directly on interior surfaces with substantial storage capacity, such as the central masonry mass. As in other houses employing direct solar gain, there is a problem of a degradation of furniture and fabries due to UV exposuie, which has not been successfully dealt with by the home furnishing industry. The increasing emphasis in passive solar design on south-facing glass should encourage research in this area. From an aesthetic standpoint, the large areas of glass impose restrictions on the stylistic options available to the designer. In this particular case, the traditional New England saltbox design becomes a hybrid contemporary.

Brownell is presently utilizing a single underground pipe system, in which exterior air, cooled by running through 100 feet of buried pipe, is brought into the lower level of the house and drawn into the sand bed duct system through a damper. This airflow discharges the mass for summer cooling. A continuous loop of buried pipe with adequate surface area might be a more effective means of removing heat from the house and the sand mass, since it would not increase humidity in the house. However, cooling is not a major problem in Brownell's location.

The Brownell house responds remarkably well to a very definite set of criteria. It is a rustic vacation home in a very cold region having an ample supply of lumber. No attempt is made to apply the house to the mass housing market. However, there are many important features which are readily adaptable. The basic lessons to be learned are the importance of a building envelope with very low infiltration and thermal loss. Once a low-loss thermal envelope has been provided, the integration of some form of thermal storage into the structure is relatively easy. The thermal storage allows harvesting of various encrgics of opportunity without extreme temperature excursions.

\section{CONCLUSIONS}

\section{A. Introduction}

The 2,300-ft ${ }^{2}$ LER house described in this report can be heated for less than 25 percent of the cost to heat a typical inventory house in the Northeastern part of the United States. The feature of the house that contributes most to its thermal performance is the tightness of the building envelope. 
This produces an extremely low-loss building. With a low-loss building it is possible to take advantage of various incidental heat sources such as solar and living cycle input. They can provide a large fraction of total needs, but they require appreciable thermal storage to absorb heat and reduce temperature fluctuation. Thermal storage is necessary because these heat sources are of a variable nature. Solar gain, for example, is available on a diurnal cycle.

Brownell's house benefits from the "natural" thermal storage capacity of the exposed structural and finishing materials in the house, including the outside of the large central concrete mass. He also employs an active thermal storage system consisting of the inside of the central concrete block mass and the ducted sand bed below the basement floor. Fans, which provide continuous circulation of 1,000 CFM of air through the active storage system and the living space, provide a near isothermal state throughout the building. The temperature fluctuates approximately $\pm 5^{\circ} \mathrm{F}$ around a mean temperature on a daily cycle. This is the differential required for reasonably effective "charging" and "discharging" of the thermal storage. It was found that the natural thermal storage capacity is substantial and functions effectively. The active storage system, particularly the sand bed, is relatively ineffective in the configuration used in this particular house. Its performance could be improved considerably by increasing the duct surface area and/or using concrete for the storage mass rather than sand.

Brownell has utilized the materials and labor force available to him to create a building with these special characteristics. His approach is appropriate to his situation but is not in any way aimed at the mass housing market or toward direct translation into the retrofit market. There are many features of his construction, however, that would lend themselves to mass production and, to a lesser extent, to individual retrofit adaptation. The performance figures are impressive and the energy conservation implications are quite obvious. Large-scale implementation of such simple low-technology design approaches by the building industry could effect a substantial reduction in the energy requirements of the residential sector.

\section{B. Construction Adaptation for Mass Market}

Some of the problems a Brownell-type residence would impose on a larqe tract developer have been indicated earlier. The post and beam framing system, with costly and cumbersome framing members, requires nailing with 12-in. spikes driven by five-pound hammers. This would obviously not be acceptable to most builders or their carpentry crews. It would be necessary to utilize the rigid foam insulation panels in a more conventional stud-framed wall system while retaining the thermal integrity achieved by Brownell's building envelope. Another constraint that should be remedied is the lack of flexibility in application of exterior finish materials because of the fixed location of nailers and lack of structural sheathing.

The use of a standard stud-frame wall with either two-by-fours 16 inches on centers or two-by-sixes 24 inches on centers, with friction-fit fibrous 
glass insulation between the studs sealed at sill and plate with adhesive, an exterior layer of 2-in. polyisocyanurate and a continuous 6-mil polyethelene vapor barrier with 1/2-in. gypsum wall board on the interior, would provide an $\mathrm{R}$ of approximately 35 for the two-by-six or 27 for the twoby-four wall. Another option would be a similar stud wall with the foam insulation panels on the interior under the sheetrock without the polyethylene vapor barrier. This interior application can also apply to ceilings.

There are many possible combinations of various types of insulation materials within the conventional stud wall construction, but each requires a different design to meet individual conditions. Careful attention to vapor conditions and venting is one of the more important design criteria. Brownell's work demonstrates the importance of the integrity of the thermal envelope, careful construction detailing, and meticulous execution in the field. These should be given high priority in residential construction. The sealing of all openings in the ervelope also requires strict attention.

The adaptation of Brownell's "heat energy battery", or integration of thermal mass into the residential structure, is a much more difficult task. Sand is readily available at a reasonable cost and is relatively easy to handle, which influenced its sclection as thermal mass. However, it is a very poor conductor of thermal energy with a $K$ of only 2.3 compared to 4.1 for water and 12 for concrete. The specific heat of sand is also very low, 0.19 compared to 1.0 for water. Therefore, its storage potential for heat is poor. Heat storage capacity is a function of the-specific heat and mass of the material. When selecting a storage mass, the objective is usually to contain as much heat as possible per unit volume. However, cost, performance, and construction practicality must also be considered. .

As discussed earlier, the Brownell house does not have sufficient duct heat transfer surface to utilize the amount of sand mass available on a diurnal basis. A low heat transfer rate can cause sizable temperature excursions in the room air. The effectiveness of the remote storage bed could be greatly improved by increasing the duct surface area, increasing the airflow, and using concrete instead of sand. The volume of the storage bed could then be reduced significantly.

It might be simpler, more efficient, and less expensive for the mass builder if most if not all of the storage could be integrated into the building structure itself, providing the double benefit of building structure and heat storage: Such "natural" or "passive" thermal storage can be achieved by use of masonry walls with exterior insulation, concrete floor slabs, freestanding tubes containing water or plastic bags of water in the ceiling, phase-change substances encapsulated into finish building materials, increased thickness of conventional finish materials such as gypsum board, and a wide variety of other devices. Brookhaven is presently managing a project funded by the DOE to develop and assess various methods of natural thermal storage such as these for incorporation into small residential structures. Brownell has effectively provided a substantial amount of natural thermal storage in his house, particularly in the large exposed central block mass, the cellar 
walls and floor, and the large amount of exposed wood of greater-than-normal thickness.

Some of Brownell's construction techniques, such as foaming of the open spaces between the exterior wall and window frames, are immediately available to all builders and should be adopted.

\section{Retrofit Possibilities}

The main elements of Brownell's design are an excellent thermal envelope, passive solar heating, a substantial amount of passive thermal storage, and active thermal storage using continuous fan-induced air circulation through the storage mass and the living space. None of these features lends itself readily to retrofit of existing structures. There are, however, some limited retrofit possibilities.

While Brownell places his insulation on the outside of the house, it would be possible in some instances to approach his envelope thermal performance in an existing house by applying rigid foam board to the inside. For specific retrofit applications the application of polyisocyanurate panels to the interior face of the exterior walls and ceiling would seem to have several benefits. The panels have an efficient foil vapor barrier on both faces and have an excellent thermal resistance factor per inch (R8). The inside application would obviously facilitate construction. The panels are easily cut to shape, and they have a physical rigidity combined with a lack of weight that make handling quite simple. However, this installation would require a new layer of 1/2-inch type-X gypsum board as a finish surface for fire protection of the interior. It would also require special treatment around windows and doors. In addition to the application of new insulation, the home owner would be well advised to seal all cracks and apertures in the exterior wall in an attempt to eliminate infiltration of air into the existing stud cavity. The insulation panels should be taped at the joints and caulked at the top and bottom. The interior humidity will be improved for winter, and should it become excessive, it can be easily controlled by opening windows.

Brownell's utilization of thermal mass for storage of heat and temperature leveling is an essential part of the system, but is not easily accomplished in existing construation. It is cunceivable that an existing residence on a crawl space foundation could have its wood floor structure replaced to create a "heat energy battery" with an insulated bed of sand, rock, or concrete, and a concrete floor slab similax to Brownell's. It would probably also be possible to provide remote thermal storage mass in an adjoining substructure, such as a garage, which could be decoupled during the summer. Another possibility would be to convert one-third to one-half of an existing conventional cellar to use as remote thermal storage.

There are many other thermal storage options such as water in plastic bags between joists in the floor or ceiling or in free-standing cylinders, and rock beds installed in under floor areas or in open wall chases. Mass 
can also be added by concrete masonry or exposed masonry finish surfaces, and by insulating the exterior of existing masonry walls. Adding extra mass to wall surfaces with additional gypsum board is another possibility.

The objectives of retrofitting should be to add to the thermal resistance of the building envelope, including reduction of infiltration, and to add thermal mass to the structure to store free heat and level temperature extremes. Finally, if the orientation and plan layout will allow, the addition of multiple glazing to existing fenestration would be beneficial. The addition of new glazed openings on the south face and blocking up of excessive north-face glazed openings should be considered.

\section{Other Brownell Projects}

This report is concerned with one specific $2,300 \mathrm{ft}^{2}$ house built by Brownell in Edinburg, New York, in 1977. It represents one model in a continuing series. Brownell states that he has subsequently built several other houses with modification to the active thermal storage system. These include more extensive air duct systems with higher airflow and more duct area. He is also developing zoned ducting systems within the sand mass, and is considering various storage materials other than sand. Brownell's primary objective remains the development of the most simple and efficient system compatible with the local materials and labor force available to him, and which meets the demands of his market. 
REFERENCES

1.: A. L. Berlad et al., Enthalpy Management in Buildings: An Analysis: and an Integrated Approach, BNL 20572, 1975.

2. A. L. Berlad et,al., Comfort Range Thermal. Storage, ASME Winter. Annual Meeting, BNL 21591, 1976 .

3. Article, .The Times Record, Troy, NY, December 8, 1973.

4. D. I. MCClenahan, Minimum Energy Building--Solar Heated, State University of New York at Albany, ASRC Publication No. 371, June 1975.

5. A. L. Berlad et al, Air Intrusion Effects on the Performance of Permeable Insulation Systems, ASTM Thermal Insulation Conference, October 1978.

6. The Arkansas Story, Owens-Corning Fiberglas Corp., Report No. 1, 1978.

7. C. M. Nagle, Climatology of Brookhaven National Laboratory 1974 Through 1977 , BNL 50857, 1978 .

8. ASHRAE Guide and Data Book--Systems, Chapter 7, ASHRAE, New York, 1977.

9. R. P. Stromberg and S. O. Woodall, Passive Solar Buildings: A Compilation of Data and Results, Sandia Laboratories, SAND 77-1204, 1977.

10. P. J. Schneider, Conduction Heat Transfer, Chapter 10, Addison-Wesley, Reading, Massachusetts, 1957.

11. F. N. Arumi, Thermal Inertia in Architectural Walls, University of Texas, 1976 .

12. R. C. Sonderegger, Harmonic Analysis of Building Thermal Response Applied to the Optimal Location of Insulation Within the Walls, Energy and Buildings, Vol. 1 No. 2, October 1977.

13. M. Hourmanesh and R. Hourmanesh, Earth-Air Heat Exchanger, Proceedings of 1978 Annual Meeting, American Section of the International Solar Energy Society, Inc., Denver, Colorado, 1978.

14. S. W. Yvan and A. M. Bloom, Long Duration Earth Storage of Solar Energy, Proceedings of Second Annual Thermal Energy Storage Contractors Information Exchange Meeting, Gatlinburg, Tennessee, 1977.

15. P. J. Schneider, Conduction Heat Transfer, Chapter 11, Addison-Wesley, Reading, Massachusetts, 1957.

16. P. Calthorpe, B. Wilcox, and D. Stauffer, A Comparison Study of Four Passive and Hybrid Space Heating Systems, The Farallones Institute, Occidental, California, 1978. 
17. F. Sinden, A Two-Thirds Reduction in the Space Heat Requirement of a Twin Rivers Townhouse, Princeton University, Report PU/CES 56, 1977.

18. R. D. Heap; Heat Requirements and Enërgy Use in British Houses, Energy' and Buildings, Vol. I No. 4, June 1978.

19. F. W: Hutchinson, Energy Savings Due to Changes in Design of Ventilation and Air Flow System, Energy and Buildings, Vol. I No. 1, May 1977.

20. D. A. Robinson, Insulating a Solar House, Proceedings of the 1978 Annual Meeting, American Section of the International Solar Energy Society, Inc.; Denver, Colorado, 1978.: 


\section{APPENDIX}

\section{Performance Calculations}




\section{A. Building Envelope Heat Loss}

The calculation for steady state heat loss of the Brownell house and comparison houses, in the as lived in condition, is presented in Table A-l. Table A-2 presents a modified calculation for the Brownell house in the astested condition.

\section{B. Internal Sources of Heat}

The calculation of internal heat gain from occupants and appliances used in the report appears in Table $\mathrm{A}-3$. The calculated figure of 59,800 Btu/day is believed to be conservative.

\section{Passive Thermal Storage Capacity}

The following procedure was used to estimate the thermal storage effects of the building's structure and finishing materials, on a diurnal basis.

1. The temperature drop in the house each day, over a period of about 16 hours, was assumed to occur as a series of small hourly step changes which, in total, equal the measured temperature drop.

2. The surface temperature of the materials was assumed to be equal to the inside air temperature at all times.

3. The internal temperature distribution of the exposed materials was assumed to be essentially uniform after each hour of exposure.

4. The exposed materials in the building envelope can be approximated by semi-slabs with thicknesses of 1/2 inch for gypsum, 3/4 inch for wood sheathing, and 4 inches for the posts and beams.* The concrete blocks in the chimney can be approximated by a full slab of 8 inch thickness, since both sides of the material are exposed to the air.

5. The stored heat transfer out of the exposed building materials was then calculated by applying the methods in Conduction Heat Transfer, by $P$. J . Schneider, Addison-Wesley Publishing Company, Reading, Massachusetts, 1957. The cumulative heat transfer calculations were based on the surface heat rates presented in Figure 10-6 of that reference.

The total cumulative heat transfer out of the exposed matcrials in the 16 hour periods is the sum of the individual cumulative heat transfer resulting from each hourly step reduction in material surface temperature over its particular fraction of the total 16 hour period.

The heat transfer occurring during the midnight to $6 \mathrm{a} . \mathrm{m}$. period is developed from the total cumulative heat transfer apportioned over the early morning period and evaluated under those specific incremental temperature reductions each day.

*The surface exposed to the interior of the house is gypsum on the east walls and wood on the other walls. 
The thermal properties of the materials available for thermal storage are provided in Table A-4.

\section{Infiltration Rate}

The heat loss associated with infiltration (and exfiltration) can be represented by the following equation.

$$
Q=\dot{m} \times C_{p} \times \Delta t
$$

where $Q=$ heat loss, Btu/hour; $\dot{\mathrm{m}}=$ mass flow rate of air, $1 \mathrm{~b} / \mathrm{hour} ; \mathrm{C}_{\mathrm{p}}=\mathrm{spe}-$ cific heat of air, Btu/lb $-{ }^{O} F$; and $\Delta t=$ temperature difference between infiltrated and exfiltrated air, $O_{F}$.

Solving the equation for $\dot{m}$,

$$
\dot{\mathrm{m}}=\frac{1}{\mathrm{C}_{\mathrm{p}}} \times \frac{\mathrm{Q}}{\Delta \mathrm{t}},
$$

where the units for $\frac{Q}{\Delta t}$ are Btu/OF-hour.

The observed high and low NHR values in the test period were 422 and 290 , with a difference of 132. Then

$$
\dot{\mathrm{m}}=\frac{1}{\mathrm{C}_{\mathrm{p}}} \times 132=\frac{1}{.24} \times 132=550 \mathrm{1b} / \text { hour } .
$$

Converting to CFM,

$$
\mathrm{CFM}=\frac{550}{.075 \mathrm{lb} / \mathrm{ft}^{3}} \cong 7,300 \mathrm{ft}^{3} \text { /hour. }
$$


Table A-1

Steady State Heat Loss Calculation

\begin{tabular}{|c|c|c|c|c|c|c|c|c|c|c|}
\hline \multirow[b]{2}{*}{$\begin{array}{l}\text { Envelope } \\
\text { component }\end{array}$} & \multirow[b]{2}{*}{$\begin{array}{c}\text { Net arəa } \\
\left(f t^{2}\right)\end{array}$} & \multirow[b]{2}{*}{$\begin{array}{c}\Delta \mathrm{T} \\
\left({ }_{\mathrm{F}}\right)\end{array}$} & \multicolumn{2}{|c|}{ Brownell LER } & \multicolumn{2}{|c|}{ Arkansas ${ }^{a}$} & \multicolumn{2}{|c|}{$\begin{array}{l}\text { HUD minimum } \\
\text { property standards }\end{array}$} & \multicolumn{2}{|c|}{$\begin{array}{c}\text { Typical inventory } \\
\text { house }\end{array}$} \\
\hline & & & $\mathrm{U}^{\mathrm{b}}$ & $\begin{array}{l}\text { Heat } \\
\text { loss }\end{array}$ & $u^{b}$ & $\begin{array}{l}\text { Heat } \\
\text { loss }\end{array}$ & $\mathrm{L}^{\mathrm{b}}$ & $\begin{array}{l}\text { Heat } \\
\text { loss }\end{array}$ & $u^{b}$ & $\begin{array}{l}\text { Heat } \\
\text { loss }\end{array}$ \\
\hline $\begin{array}{l}\text { First-and second- } \\
\text { level walls }\end{array}$ & 1,399 & 68 & .028 & 2,663 & .050 & 4,757 & .680 & 7,611 & .11 & 10,465 \\
\hline \multicolumn{11}{|l|}{ Basement walls } \\
\hline Frame & 228 & 68 & .029 & 450 & $.05 \mathrm{C}$ & 775 & .680 & 1,240 & .11 & $1,505^{\mathrm{d}}$ \\
\hline Blcck above grade & 153 & 68 & .031 & 323 & .090 & 936 & .150 & 1,561 & 1.07 & $9,823^{d}$ \\
\hline Blcck below grade & 459 & 68 & .025 & 780 & .052 & 1,623 & .150 & 4,682 & .18 & $4,957^{d}$ \\
\hline Roof & $1,26 \overline{5}$ & 68 & .026 & 2,238 & .029 & 2,497 & .0150 & 4,304 & .09 & $7,748^{\mathrm{d}}$ \\
\hline \multicolumn{11}{|l|}{ Basement floor } \\
\hline At grade & 485 & 60 & --- & --- & $---^{e}$ & 2,080 & $---^{e}$ & 2,340 & $--^{e}$ & 3,120 \\
\hline Bellow grade & $48 \overline{5}$ & 60 & --- & --- & .026 & 749 & .026 & 749 & .026 & $749^{d}$ \\
\hline \multicolumn{11}{|l|}{ Thermal storage } \\
\hline Walls & $26:$ & 68 & .028 & 510 & & & & & & \\
\hline Floor & $11,05 \equiv$ & 68 & .020 & 1,439 & & . & & & & \\
\hline \multicolumn{11}{|l|}{ Basement } \\
\hline Wiridows & $2 \Xi$ & 68 & .56 & 876 & .630 & 985 & .630 & 985 & 1.13 & $1.559^{\mathrm{d}}$ \\
\hline Doors-glass & $9 \equiv$ & 68 & .56 & 3,732 & .630 & 4,198 & .630 & 4,198 & 1.13 & $6,644^{\mathrm{d}}$ \\
\hline Doors-other & $7 \geq$ & 68 & .10 & 490 & .330 & 1,616 & .330 & 1,616 & .63 & $2,722^{\mathrm{d}}$ \\
\hline \multicolumn{11}{|l|}{$\begin{array}{l}\text { First and second } \\
\text { levels }\end{array}$} \\
\hline Windows & $17 \equiv$ & 68 & .56 & 6,702 & .630 & 7,540 & .630 & 7,540 & .63 & 7,540 \\
\hline Doors-glass & 95 & 68 & .56 & 3,732 & .630 & 4,198 & .630 & 4,198 & 1.13 & 7,530 \\
\hline Doors-other & 25 & 68 & .10 & 136 & .330 & 449 & .330 & 449 & .63 & 857 \\
\hline Subtotal & & & & $\overline{24,071}$ & & $\overline{32,383}$ & & $\overline{41,473}$ & & $\overline{65,219}$ \\
\hline $\begin{array}{l}\text { Infiltration and } \\
\text { ventilation }\end{array}$ & & ' & $.5 \mathrm{ACH}$ & 14,100 & $.75 \mathrm{ACH}$ & 21,150 & $.75 \mathrm{ACH}$ & $\underline{21,150}$ & $1.0 \mathrm{ACH}$ & $\underline{28,200}$ \\
\hline Totai heat loss. & & & & 38,171 & & 53,533 & & 62,623 & & 93,419 \\
\hline $\mathrm{NHR}^{\mathrm{f}}$ & & & & 561 & & 787 & & 921 & & 1,374 \\
\hline
\end{tabular}

NOTES: (a) The comparison houses have ar. identical plan, same floor area, same elevation, and same glazing area as

Brownell LER House, and have fiber glass batt insulation. A conventional basemeat is assumed for the comparison houses (no thermal storage bed), with edge inscllation as customarily provided in each ho'sse type. (b) Btu/hour-ft ${ }^{2}-{ }^{\circ} \mathrm{F}$.

(c) Btu/hour. (d) $60 \circ F \Delta T$ assumed Eor the typical inventory house basement. (e) Calculated on basis of edge loss.

(f) Normalized heating requirement, $B=u / h o u r-{ }^{\circ} \mathrm{F}$. 


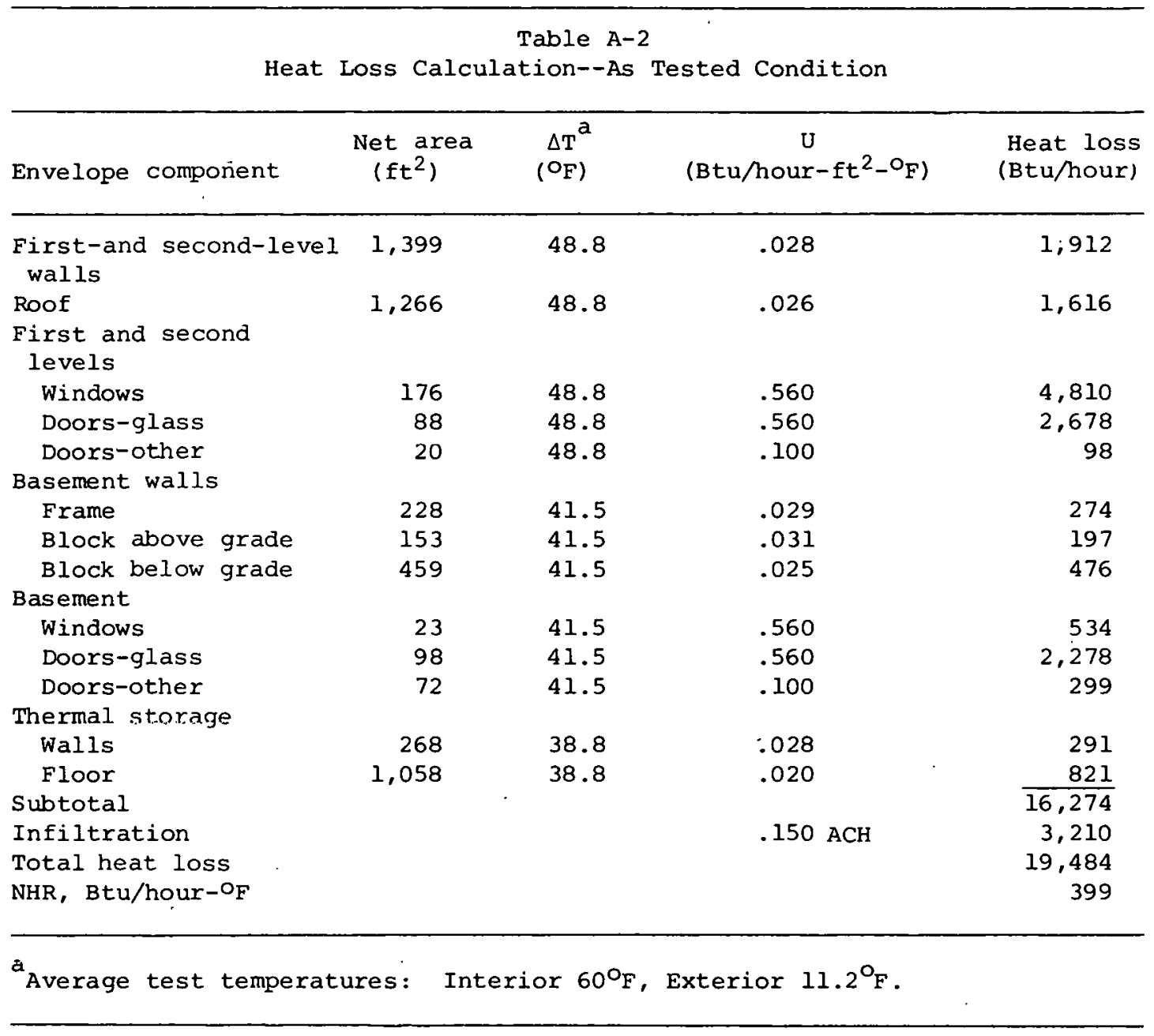


Table A-3

Internal Heat Sources

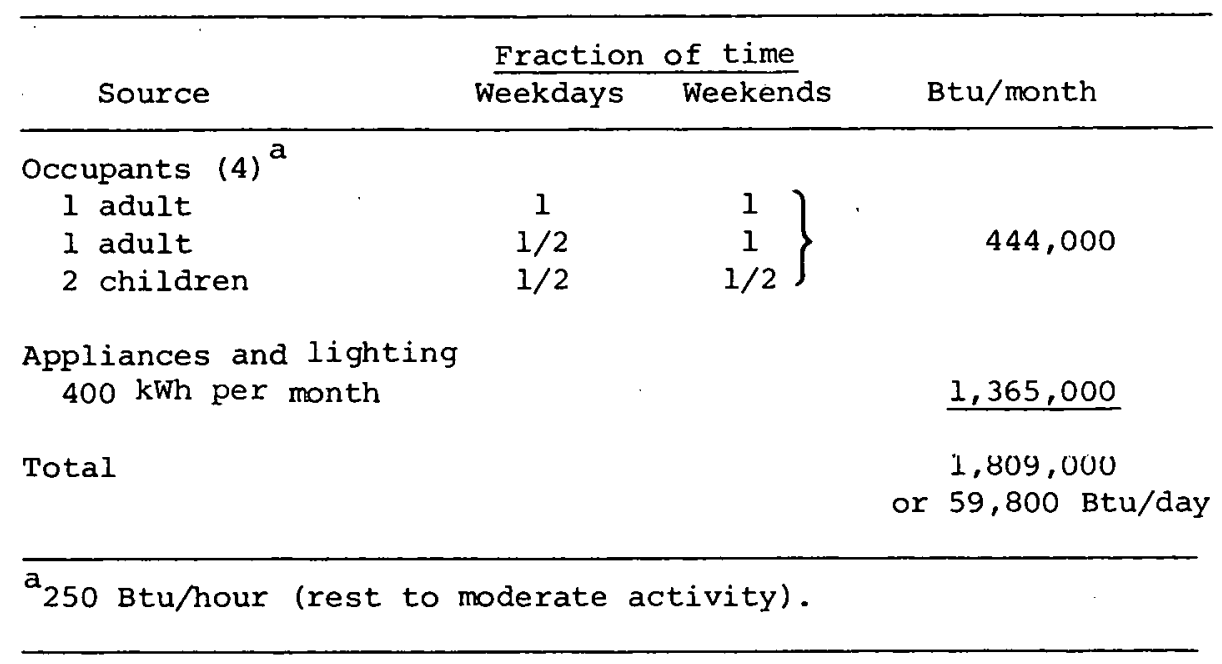

\begin{tabular}{|c|c|c|c|c|}
\hline \multicolumn{5}{|c|}{$\begin{array}{l}\text { Table A-4 } \\
\text { es of Const }\end{array}$} \\
\hline Malel Lal & $\begin{array}{c}\bar{W} \\
1 \downarrow / \Gamma L^{?}\end{array}$ & $\stackrel{k}{\text { Deu,hour } f t^{2} o_{F}}$ & $\frac{C}{B+u, / l b-O_{F}}$ & ${ }_{f+t^{2}} \alpha^{a} / h n u r$ \\
\hline Concrete & 144 & 0.540 & 0.1560 & 0.0240 \\
\hline Wood & 26 & 0.065 & 0.6700 & 0.0037 \\
\hline Gypsum & 78 & 0.250 & 0.2590 & 0.0124 \\
\hline${ }_{\alpha}{ }_{\alpha}=\frac{k}{C W}$. & & & & \\
\hline
\end{tabular}

